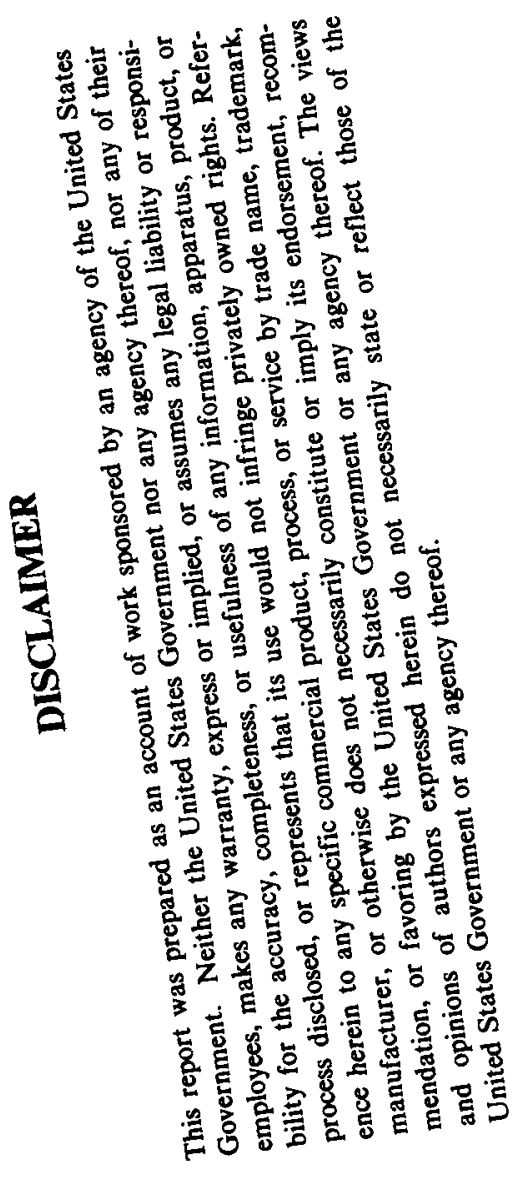

\title{
Testing and Analysis of Load-Side Immersed Heat Exchangers for Solar Domestic Hot Water Systems
}

\author{
R. B. Farrington \\ C. E. Bingham
}

October 1987

Prepared under Task No. 3073.41

FTP No. 624

Solar Energy Research Institute

A Division of Midwest Research Institute

1617 Cole Boulevard

Golden, Colorado 80401-3393

Prepared for the

U.S. Department of Energy

Contract No. DE-AC02-83CH10093

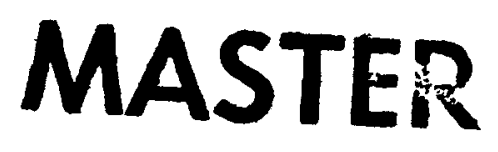




\section{NOTICE}

This report was prepared as an account of work sponsored by the United States Government. Neither the United States nor the United States Department of Energy, nor any of their employees, nor any of their contractors, subcontractors, or their employees, makes any warranty, expressed or implied, or assumes any legal liability or responsibility for the accuracy, completeness or usefulness of any information, apparatus. product or process disclosed, or represents that its use would not infringe privately owned rights.

\section{Printed in the United States of America \\ Available from: \\ National Technical Information Service \\ U.S. Department of Commerce \\ 5285 Port Royal Road \\ Springfield, VA 22161}
Price: Microfiche A01/
Printed Copy

Codes are used for pricing all publications. The code is determined by the number of pages in the publication. Information pertaining to the pricing codes can be found in the current issue of the following publications $\therefore$ - - - wich are:gerthral available in most libraries: Energy Research Abstracts, (ERA); Government Reports : Annfincthents sit Index (GRA and I): Scientific and Technical Abstract Reports (STAR); and publication, NTIS-PF 360 Evenlable from NTIS at the above address. 


\section{DISCLAIMER}

This report was prepared as an account of work sponsored by an agency of the United States Government. Neither the United States Government nor any agency Thereof, nor any of their employees, makes any warranty, express or implied, or assumes any legal liability or responsibility for the accuracy, completeness, or usefulness of any information, apparatus, product, or process disclosed, or represents that its use would not infringe privately owned rights. Reference herein to any specific commercial product, process, or service by trade name, trademark, manufacturer, or otherwise does not necessarily constitute or imply its endorsement, recommendation, or favoring by the United States Government or any agency thereof. The views and opinions of authors expressed herein do not necessarily state or reflect those of the United States Government or any agency thereof. 


\section{DISCLAIMER}

Portions of this document may be illegible in electronic image products. Images are produced from the best available original document. 
PREFACE

In keeping with the national energy policy goal of fostering an adequate supply of energy at a reasonable cost, the U.S. Department of Energy (DOE) supports a variety of programs to promote a balanced and mixed energy resource system. The mission of the DOE Solar Buildings Research and Development Program is to support this goal by providing for the development of solar technology alternatives for the buildings sector. It is the goal of the program to establish a proven technology base to allow industry to develop solar products and designs for buildings that are economically competitive and can contribute significantly to building energy supplies nationally. Toward this end, the program sponsors research activities related to increasing the efficiency, reducing the cost, and improving the long-term durability of passive and active solar systems for buildings water and space heating, cooling, and daylighting applications. These activities are conducted in four major areas: (1) Advanced Passive Solar Materials Research, (2) Collector Technology Research, (3) Cooling Systems Research, and (4) Systems Analysis and Applications Research.

Advanced Passive Solar Materials Research--This activity area includes work on new aperture materials for controlling solar heat gains and for enhancing the use of daylight for building interior lighting purposes. It also encompasses work on low-cost thermal storage materials that have high thermal storage capacity and can be integrated with conventional building elements, and work on materials and methods to transport thermal energy efficiently between any building exterior surface and the building interior by nonmechanical means.

Collector Technology Research--This activity area encompasses work on advanced low- to medium-temperature (up to $80^{\circ} \mathrm{C}\left[180^{\circ} \mathrm{F}\right]$ useful operating temperature) flat-plate collectors for water and space heating applications, and medium- to high-temperature (up to $204^{\circ} \mathrm{C}\left[400^{\circ} \mathrm{F}\right]$ useful operating temperature) evacuatedtube/concentrating collectors for space heating and cooling applications. The focus is on design innovations using new materials and fabrication techniques.

Cooling Systems Research--This activity area involves research on highperformance dehumidifiers and chillers that can operate efficiently with the variable thermal outputs and delivery temperatures associated with solar collectors. It also includes work on advanced passive cooling techniques.

Systems Analysis and Applications Research--This activity area encompasses experimental testing, analysis, and evaluation of solar heating, cooling, and daylighting systems for residential and nonresidential buildings. This involves system integration studies, the development of design and analysis tools, and the establishment of overall cost, performance, and durability targets for various technology or system options.

This report supports Systems Analysis and Applications Research by modeling and measuring the performance of four load-side, immersed heat exchangers that could be used in active solar domestic hot water systems. 
SEP

TR -3094

The authors gratefully acknowledge the assistance of Douglas Powell, who built the test loop and assisted with the experiments; Michael Connolly, who provide guidance with the computer modeling; and Charles Kutscher, who sized the heat exchanger and who initiated the interest in load-side heat exchangers at SERI. The encouragement and suggestions by Dr. Richard Bourne of Davis Energy Group were deeply appreciated. This report was reviewed at SERI by Ran Anderson, Mark Bohn, Meir Carasso, and Ed Hancock. The authors are gratefut to those reviewers and to W. Clark of Ramada Energy Systems Limited Sandra Go of Rockwell International Corp., and E. Kenneth May of Industrial Solar Technology, who provided many useful review comments.
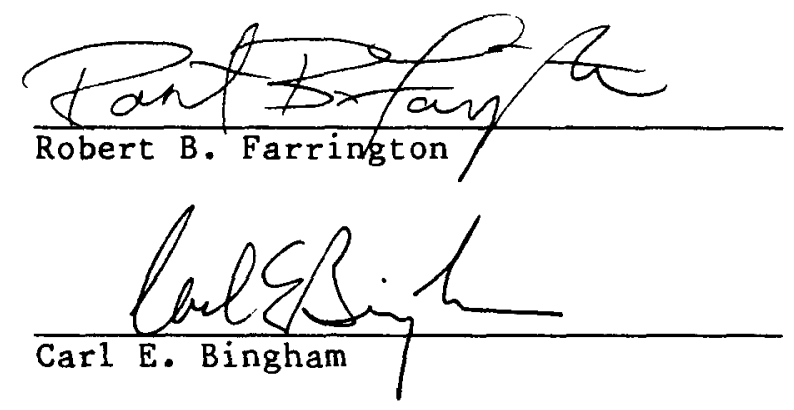

Approved for

SOLAR ENERGY RESEARCH INSTITUTE

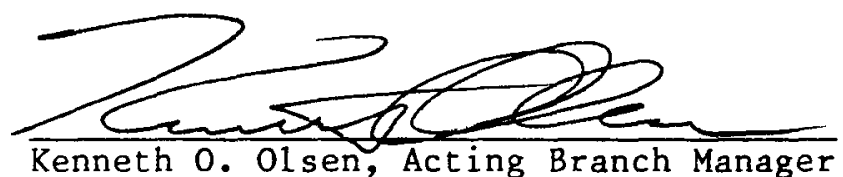

Buildings Research Branch

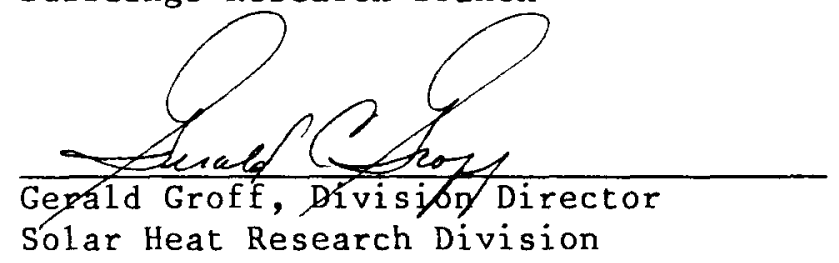

iv 


\section{SUMMARY}

\section{Objective}

The objective is to determine the performance of load-side heat exchangers that could be used in residential solar domestic hot water (SDHW) systems. The report is intended for those who test load-side heat exchangers and for designers who need an understanding of how these types of heat exchangers operate. Design guidelines and sizing techniques are not included.

\section{Discussion}

We measured the performance of four load-side heat exchangers: a smogth coil and a finned coil having overall heat transfer areas of $2.5 \mathrm{~m}^{2}\left(26 \mathrm{ft}^{2}\right)$ and a smooth coil and a finned coil having $1.7 \mathrm{~m}^{2}\left(19 \mathrm{ft}^{2}\right)$ of heat transfer area. A load-side heat exchanger is used to remove energy from a hot storage tank (usually unpressurized) by flowing water through the heat exchanger before going to the load. Water flows through the heat exchanger only on demand and is not continually circulated. A numerical model using MITAS, a general purpose thermal network program, was constructed, and the results were compared to the experimental results.

\section{Conclusions}

We measured heat exchanger U-values from $100 \mathrm{~W} / \mathrm{m}^{2}{ }^{\circ} \mathrm{C}\left(18 \mathrm{Btu} / \mathrm{h} \mathrm{f} \mathrm{t}^{2}{ }^{\circ} \mathrm{F}\right)$ at 1 ow cemperature differences to as high as $1200 \mathrm{~W} / \mathrm{m}^{2}{ }^{\circ} \mathrm{C}\left(212 \mathrm{Btu} / \mathrm{h} \mathrm{ft}{ }^{\circ}{ }^{\circ} \mathrm{F}\right)$ for very high temperature differences. The Nusselt numbers ranged from 1 (though were generally above 3) to about 35 for corresponding Rayleigh numbers of $6.3 \times 10^{4}$ to $7.9 \times 10^{6}$.

A significant result is that a smooth coil with only $70 \%$ of the surface area of a larger finned coil performed better than the finned coil. Therefore, we recommend that smooth coils be used for load-side as well as collector-side heat exchangers whenever storage space permits. The coil should be installed vertically throughout the storage tank to enhance tank stratification and improve system performance.

Also of significant interest is that load-side heat exchangers can maintain and enhance stratification in storage tanks. This permits the use of particular control strategies that take advantage of stratified storage tanks, which can increase system performance.

The analytical model developed agreed reasonably well with the experimental results. The model showed an increase in performance for stratified tanks over mixed tanks. We used the model to vary heat exchanger flow rate and area, as well as initial tank temperature, for both a smooth- and finned-coil heat exchanger. Increasing the heat exchanger flow rate and area results in higher heat transfer rates, but not necessarily optimal performance. Lower initial tank temperatures resulted in reduced stratification in the tank. We found the smooth heat exchanger to outperform the finned heat exchanger with the same outside surface area. A closed-form solution of heat exchanger performance should be developed to provide designers with a tool to size loadside heat exchangers. 
TABLE OF CONTENTS

$\underline{\text { Page }}$

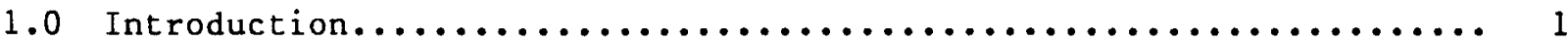

2.0 Development of Equations........................... 4

3.0 Experimental Setup and Test Plan........................ 10

4.0 Test Results...................................... 14

5.0 Numerical Model and Comparison with Experimental Results......... 31

5.1 Description of Model.............................. 31

5.2 Comparison of Stratified Tank with Mixed Tank.............. 35

5.3 Comparison of Experimental and Numerical Results........... 38

5.4 Results of Parametric Analysis....................... 42

6.0 Conclusions and Recommendations...................... 49

7.0 References.................................... 52

Appendix A Measurement Uncertainty Analysis.................... 53

Appendix B Typical Experimental Output, Original Finned

Heat Exchanger, $5 \mathrm{~L} / \mathrm{min} \ldots \ldots \ldots \ldots \ldots \ldots \ldots \ldots \ldots \ldots \ldots \ldots \ldots$

Selected Distribution List............................. 70 


\section{LIST OF FIGURES}

Page

1-1 Examples of Collector-Side and Load-Side Heat Exchanger Configurations....................................

2-1 Heat Exchanger Effectiveness versus $\Delta \mathrm{T} \ldots \ldots \ldots \ldots \ldots \ldots \ldots \ldots \ldots \ldots \ldots$

2-2 Family of Heat Exchanger Effectiveness Curves............... 7

3-1 Schematic of Test Loop............................... 10

3-2 Solar DHW System Performance as a Function of Load-Side Heat Exchanger Area for a Well-Mixed Storage Tank................. 11

4-1 Typical Temperature Profiles........................... 18

4-2 Heat Exchanger $U A$ and $U$ versus $\left(T_{S}\right.$, avg $-T_{H x, i}$ ) by Heat

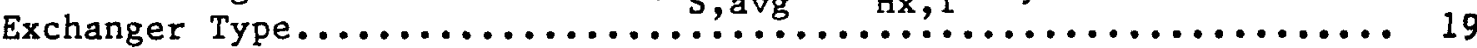

4-3 Heat Transfer Rate versus $\left(\mathrm{T}_{\mathrm{S}, \text { avg }}-\mathrm{T}_{\mathrm{Hx}, \mathrm{i}}\right)$ by Heat Exchanger Type...................................... 20

4-4 Heat Transfer Rate versus LMTD by Heat Exchanger Type.......... 22

4-5 Heat Transfer Rate versus LMTD for Three Heat Exchangers......... 23

4-6 Nusselt/Rayleigh Correlations by Heat Exchanger Type........... 24

4-7 Nusselt/Rayleigh Correlation for Three Heat Exchangers.......... 25

4-8 Heat Exchanger C-Factor versus LMTD by Heat Exchanger Type....... 26

4-9 Heat Exchanger C-Factor versus ( $\mathrm{T}_{\mathrm{S}, \text { avg }}-\mathrm{T}_{\mathrm{Hx}, \mathrm{i}}$ ) by Heat Exchanger Type................................... 28

4-10 Heat Exchanger Time Constants........................... 29

5-1 Nodal Schematic of MITAS Heat Exchanger Model.............. 32

5-2 Model versus Experimental Data: Smooth Heat Exchanger Variation of C-value............................... 34

5-3 Model versus Experimental Data: Finned Heat Exchanger Variation of C-value................................ 35

5-4 Heat Exchanger Effectiveness in a Mixed Tank as a Function of the Temperature Difference between the Tank and the Heat Exchanger Inlet................................. 36

5-5 Heat Exchanger Effectiveness in a Mixed Tank as a Function

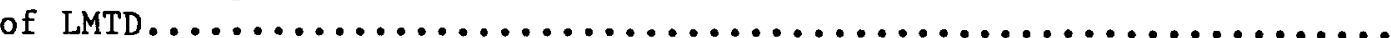




\section{LIST OF FIGURES (Continued)}

$\underline{\text { Page }}$

5-6 Heat Transfer Rate of a Smooth Heat Exchanger in a Mixed Tank

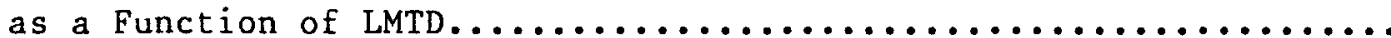

5-7 Comparison of Heat Transfer Rate of the Same Heat Exchanger in a Mixed and a Stratified Tank........................ 38

5-8 Stratified Tank Temperature Profile at Different Times during Simulation.......................................

5-9 Model versus Experimental Data: Smooth Heat Exchanger Outlet

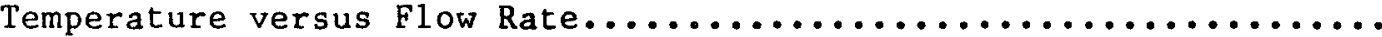

5-10 Model versus Experimental Data: Finned Heat Exchanger Outlet

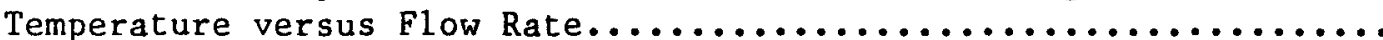

5-11 Model versus Experimental Data: Smooth Heat Exchanger Outlet Temperature with Lower Tank Temperature....................

5-12 Model versus Experimental Data: Finned Heat Exchanger Outlet Temperature with Lower Tank Temperature....................

5-13 Baseline Case: Outlet Temperature and Vertical Average Tank

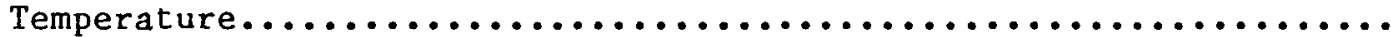

5-14 Baseline Case: Heat Transfer Rate versus LMTD............... 43

5-15 Smooth Coil Heat Exchanger Outlet Temperature versus Flow Rate.... 44

5-16 Smooth Coil Heat Exchanger Vertical Average Tank Temperature versus Flow Rate...................................

5-17 Heat Transfer Rate for Smooth Heat Exchanger versus Time for

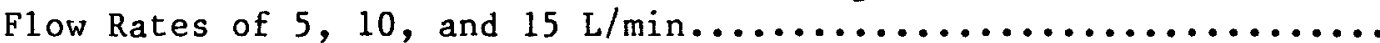

5-18 Heat Transfer Rate for Finned Heat Exchanger versus Time for

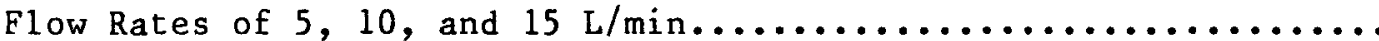

5-19 Comparison of Finned and Smooth Heat Exchangers: Heat Transfer Rates for Initial Tank Temperature of $40^{\circ} \mathrm{C}$ above Heat Exchanger

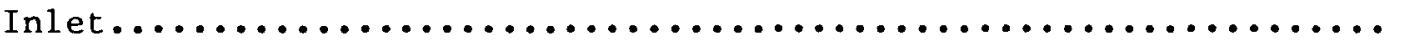

5-20 Comparison of Finned and Smooth Heat Exchangers: Heat Transfer Rates for Initial Tank Temperature of $10^{\circ} \mathrm{C}$ above Heat Exchanger

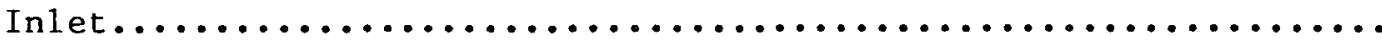

5-21 Effect of Smooth Heat Exchanger Surface Area on Heat Transfer

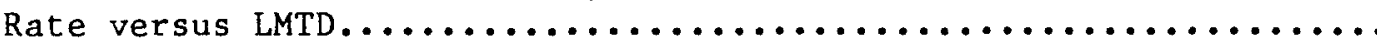

5-22 Effect of Finned Heat Exchanger Surface Area on Heat Transfer

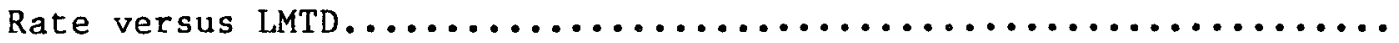




\section{LIST OF FIGURES (Concluded)}

$\underline{\text { Page }}$

A-1 Uncertainty of Effectiveness, Heat Transfer Rate, and UA for

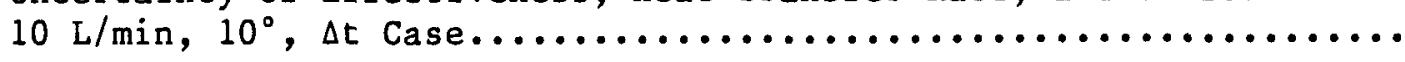

B-1 Heat Exchanger Effectiveness, $F n\left(T_{S}\right.$, avg $)$ versus

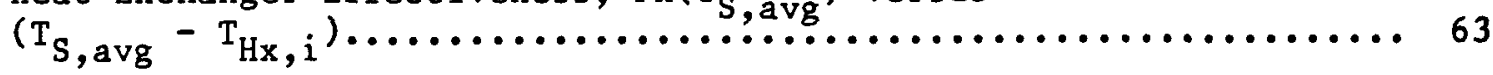

B-2 Heat Exchanger Effectiveness, $F n\left(T_{S, a v g}\right)$ versus LMTD........... 64

$B-3$ Heat Exchanger $U A$, Fn(LMTD) versus $\left(T_{s, a v g}-T_{H x}, i \ldots \ldots \ldots \ldots \ldots\right.$

B-4 Heat Exchanger UA, En(LMTD) versus LMTD.................. 65

B-5 Heat Exchanger Heat Transfer Rate versus $\left(T_{S, a v g}-T_{H x, i}\right) \ldots \ldots 65$

B-6 Heat Exchanger Heat Transfer Rate versus LMTD............... 66

B-7 Heat Exchanger $C$-factor versus $\left(T_{S, a v g}-T_{H x, i}\right) \ldots \ldots \ldots \ldots \ldots \ldots 6$

B-8 Heat Exchanger $\mathrm{C}$-factor versus LMTD.................... 67

B-9 Heat Exchanger Effectiveness, $\mathrm{Fn}\left(\mathrm{T}_{\mathrm{S}, \mathrm{t}}\right)$ versus

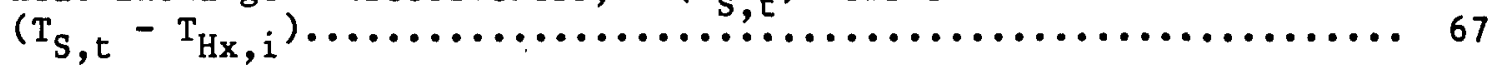

B-10 Heat Exchanger Effectiveness, $F n\left(T_{S}, a v g\right)$ versus

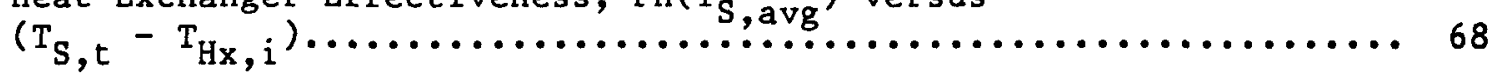

B-11 Heat Exchanger Effectiveness, $\operatorname{Fn}\left(\mathrm{T}_{\mathrm{S}, t}\right)$ versus

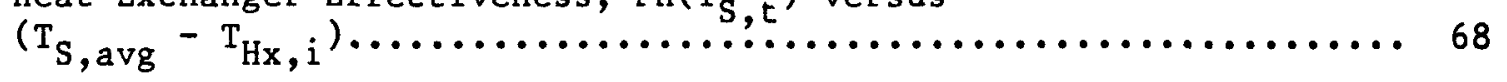

B-12 Heat Exchanger Effectiveness, $F n\left(T_{S, t}\right)$ versus LMTD........... 69

B-13 Heat Exchanger $\mathrm{UA}, \mathrm{Fn}\left(\mathrm{T}_{\mathrm{S}, \text { avg }}-\mathrm{T}_{\mathrm{Hx}, \mathrm{i}}\right)$ versus

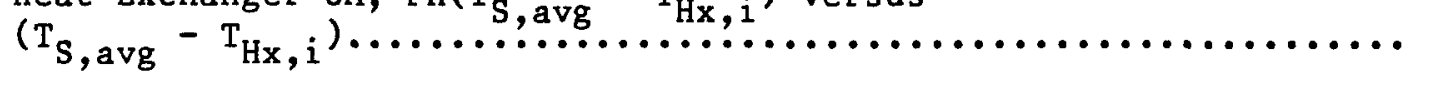




\section{LIST OF TABLES}

$\underline{\text { Page }}$

2-1 Performance Equations for Immersed Load-Side Heat Exchanger....... 5

3-1 Smooth- and Finned-Pipe Specifications.................... 12

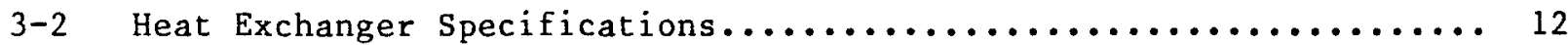

4-1 Heat Exchanger Test Conditions........................ 14

4-2 Graphs Plotted for Each Test.......................... 16

4-3 Heat Exchanger Time Constants $(\min ) \ldots \ldots \ldots \ldots \ldots \ldots \ldots \ldots \ldots$

4-4 Heat Exchanger Time Constant Coefficients................. 30

4-5 Residuals from Time Constant Curve Fits................. 30

5-1 Assumptions Used in Heat Exchanger Mode1.................. 33

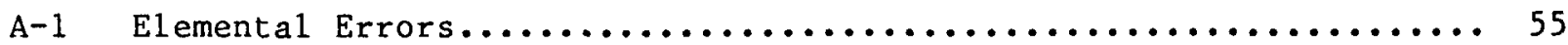

A-2 Total Sensor Measurement Uncertainty................... 56

A-3 Summary of Bias Limits and Random Errors................. 60

A-4 Measurement Uncertainty Summary...................... 61 


\section{NOMENCLATURE}

C empirically derived constant

$\mathrm{C}_{\mathrm{p}} \quad$ specific heat $\left(\mathrm{kJ} / \mathrm{kg} \mathrm{K}\left[\mathrm{Btu} / \mathrm{lb}{ }^{\circ} \mathrm{F}\right]\right)$

d outside diameter of heat exchanger tube, excluding fins ( $m[f t]$ )

$f \quad$ friction factor used in Petukhov-Popov correlation

g gravity $\left(9.807 \mathrm{~m} / \mathrm{s}^{2}\left[32.18 \mathrm{ft} / \mathrm{s}^{2}\right]\right)$

$\bar{h}_{i} \quad$ overall convective, heat transfer coefficient inside the heat exchanger tube $\left(\mathrm{W} / \mathrm{m}^{2}{ }^{\circ} \mathrm{C}\left[\mathrm{Btu} / \mathrm{h} \mathrm{ft}{ }^{2}{ }^{\circ} \mathrm{F}\right]\right)$

$h_{0} \quad$ local $h_{0}\left(W / m^{2} \mathrm{~K}\left[B t u / h \mathrm{ft}^{2}{ }^{\circ} \mathrm{F}\right]\right)$

$\bar{h}_{0} \quad$ overall convective heat transfer coefficient on the outside of the heat exchanger tube $\left(\mathrm{W} / \mathrm{m}^{2}{ }^{\circ} \mathrm{C}\left[\mathrm{Btu} / \mathrm{h} \mathrm{ft}^{2}{ }^{\circ} \mathrm{F}\right]\right)$

$k \quad$ thermal conductivity of storage medium ( $/ \mathrm{m} K\left[B t u / h\right.$ ft $\left.{ }^{\circ} \mathrm{F}\right]$ )

$\mathrm{K}_{1}, \mathrm{~K}_{2}$ coefficients in Petukhov-Popov correlation

LMTD logarithmic mean temperature difference $\left({ }^{\circ} \mathrm{C}\left[{ }^{\circ} \mathrm{F}\right]\right)$

$\mathrm{m}$ empirically derived constant

$\dot{\mathrm{m}}$ mass flow rate through the heat exchanger ( $\mathrm{kg} / \mathrm{s}[1 \mathrm{~b} / \mathrm{s}]$ )

$\mathrm{Nu}$ local Nusselt number for the outside of the tube

$\overline{\mathrm{Nu}} \quad$ overall Nusselt number for the outside of the tube, $\vec{h}_{\mathrm{o}} \mathrm{d} / \mathrm{k}$

$\overline{\mathrm{Nu}}_{i} \quad$ overall Nusselt number for the inside of the tube

Pr Prandtl number, $C_{p} \mu / k$

$q$ or $Q$ heat transfer rate (W $[B t u / h])$

Ra local Rayleigh number

$\overline{\mathrm{Ra}} \quad$ overall Rayleigh number, $\rho^{2} \mathrm{BC} \mathrm{p}_{\mathrm{pd}}{ }^{3} \mathrm{LMTD} / \mu \mathrm{K}$

Re Reynolds number [ $\left.4 \dot{\mathrm{m}} / 2 \pi \mu \mathrm{r}_{\mathrm{i}}\right]$

$r_{i} \quad$ inside radius of the tube ( $\left.m[f t]\right)$

$r_{0} \quad$ outside radius of the tube, excluding fins (m [ $\left.f t\right]$ )

$\mathrm{T}_{\mathrm{Hx}, \mathrm{i}}$ temperature of the fluid entering the heat exchanger $\left({ }^{\circ} \mathrm{C}\left[{ }^{\circ} \mathrm{F}\right]\right)$

$\mathrm{T}_{\mathrm{Hx}, \mathrm{O}}$ temperature of the fluid exiting the heat exchanger $\left({ }^{\circ} \mathrm{C}\left[{ }^{\circ} \mathrm{F}\right]\right)$

$\mathrm{T}_{\mathrm{S}} \quad$ storage tank temperature $\left({ }^{\circ} \mathrm{C}\left[{ }^{\circ} \mathrm{F}\right]\right)$

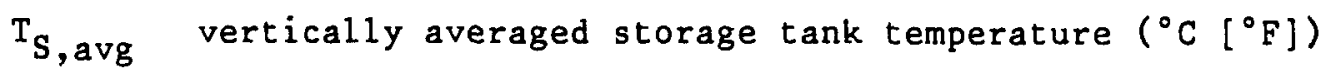

$\mathrm{T}_{\mathrm{S}, \mathrm{b}}$ storage tank bottom temperature $\left({ }^{\circ} \mathrm{C}\left[{ }^{\circ} \mathrm{F}\right]\right)$

$\mathrm{T}_{\mathrm{S}, \mathrm{t}} \quad$ storage tank top temperature $\left({ }^{\circ} \mathrm{C}\left[{ }^{\circ} \mathrm{F}\right]\right)$

$\mathrm{U}$ unit area heat transfer coefficient $\left(\mathrm{W} / \mathrm{m}^{2}{ }^{\circ} \mathrm{C}\left[\mathrm{Btu} / \mathrm{h} \mathrm{ft}^{2}{ }^{\circ} \mathrm{F}\right]\right)$

UA heat transfer area coefficient (W/K [Btu/h $\left.{ }^{\circ} \mathrm{F}\right]$ )

$v \quad$ fluid velocity $(\mathrm{m} / \mathrm{s}[\mathrm{ft} / \mathrm{s}])$ 
NOMENCLATURE (Concluded)

$\begin{array}{ll}\beta & \text { coefficient of thermal expansion }\left(1 /{ }^{\circ} \mathrm{C}\left[1 /{ }^{\circ} \mathrm{F}\right]\right) \\ \Delta \mathrm{T} & \mathrm{T}(\mathrm{x})-\mathrm{T}_{\mathrm{s}}\left({ }^{\circ} \mathrm{C}\left[{ }^{\circ} \mathrm{F}\right]\right) \\ \varepsilon & \text { heat exchanger effectiveness } \\ \mu & \text { absolute viscosity of storage medium }\left(\mathrm{Ns} / \mathrm{m}^{2}[1 \mathrm{~b} / \mathrm{ft} \mathrm{s}]\right) \\ \rho & \text { density of storage medium }\left(\mathrm{kg} / \mathrm{m}^{3}\left[1 \mathrm{~b} / \mathrm{ft}^{3}\right]\right) \\ \tau & \text { heat exchanger time constant }(\mathrm{min})\end{array}$




\subsection{INTRODUCTION}

Active solar energy systems are often designed and installed with heat exchangers so that potable water is separated from the fluid in the collector loop. The purpose for using a heat exchanger varies. Sometimes heat exchangers are used as part of a freeze protection scheme so that a freezetolerant fluid (such as a glycol solution) can be used in the collector loop. In other designs they may be used to avoid circulating "hard" water through the collectors, which could lead to scale accumulation in the collector passageways, causing low collector thermal performance and possibly system failure. In indirect drainback systems, where the water drains from the collector array into a small reservoir or large storage tank whenever the pump stops, the heat exchanger prevents the collector loop from being pressurized by the water supply.

Immersed heat exchangers* in residential solar energy systems generally can be classified as either "collector-side" or "load-side" heat exchangers. Collector-side (or supply-side) heat exchangers have the hot water (from either a collector array or a hot space-heating storage tank) flowing through the inside of the tubes (see Figure 1-1). The flow through the heat exchanger is continuous as long as the "supply" is sufficiently hotter than the load (usually a domestic hot water [DHW] tank). The temperature drop across this type of heat exchanger is typically less than $10^{\circ} \mathrm{C}\left(18^{\circ} \mathrm{F}\right)$, although it can be much higher in a space-heating system. For example, if a large space-heating storage tank is very hot and a user depletes the hot water in the DHW tank, then the temperature drop across the heat exchanger, as very hot water from the space-heating tank heats the DHW tank, can be quite high. Collector-side heat exchangers have been studied by Feiereisen (1982), Feiereisen et al. (1982), Klett et al. (1983), and Farrington and Bingham (1986), largely because of the discrepancy between predicted and measured performance.

The other type of heat exchanger is the load-side heat exchanger (see Figure 1-1). In this case, the water in the storage tank is heated directly by the collector $100 \mathrm{p}$, and the heat exchanger is used to remove energy from the tank. This type of heat exchanger has several advantages but also several limitations. One primary advantage of this type of heat exchanger is that it can be used with an unpressurized storage tank. Unpressurized storage tanks are often associated with low-cost systems (Kutscher et al. 1984) and permit the use of collectors that cannot be pressurized. An obvious design would be a drainback system, with the unpressurized storage tank also serving as the drainback tank (e.g., either of the load-side systems in Figure 1-1). A load-side heat exchanger allows the collector to directly heat the water in the storage tank. However, the penalty comes when energy is removed from the storage tank. The cold water flowing through the heat exchanger tube flows through the heat exchanger only once before going to the load. Hence, loadside heat exchangers are also called "once-through" or "instantaneous" heat exchangers. If the heat exchanger is poorly designed, the system will never perform well.

*External heat exchangers with forced flow on both sides are also common. However, they are relatively easy to characterize and therefore are not discussed in this report. 


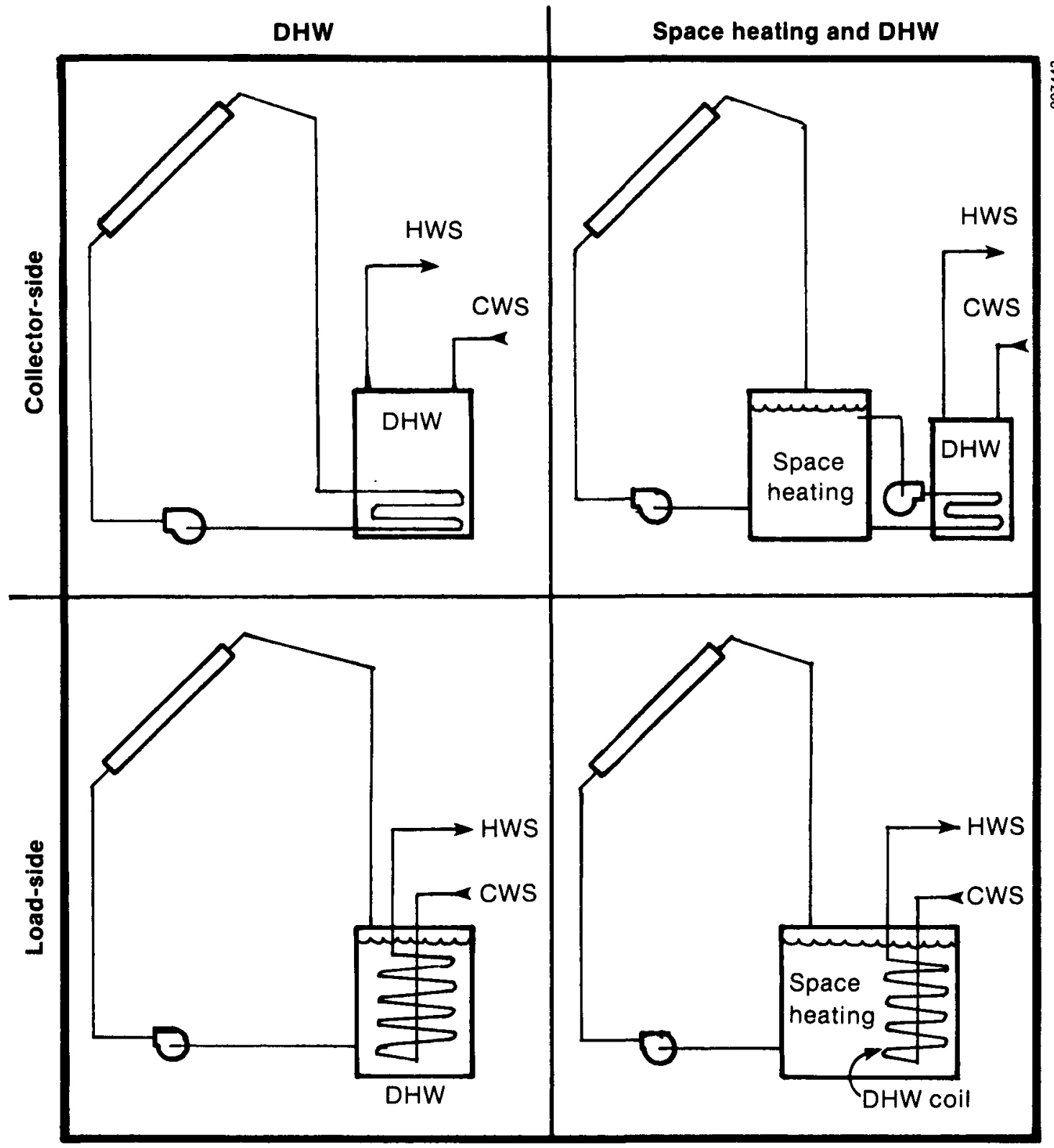

Figure 1-1. Examples of Collector-Side and Load-Side Heat Exchanger Configurations

One unique characteristic of a load-side heat exchanger is that it can enhance storage tank stratification. We will explain this in detail later, but for now consider either load-side system in Figure 1-1. The coldest water in the heat exchanger is at the bottom of the tank, cooling that part the most. As the water in the heat exchanger flows toward the top of the tank, it becomes warmer and removes less energy from the storage tank. Therefore, the bottom of the tank is the coldest and the top the warmest. Of course, this is only for a vertical heat exchanger as shown in Figure 1-1. Load-side heat exchangers could also be installed in other configurations, such as only at the top or only at the bottom of a storage tank. If the heat exchanger is installed only at the bottom of the tank, it can only remove energy from the bottom of the tank; this is clearly not a good design. If the heat exchanger 
is at the top of the storage tank, it will cool the top, causing the entire storage tank to mix. In some cases this may be the most efficient way to remove the energy from the storage tank. However, it reduces the hottest temperature in the storage tank and increases the bottom temperature (until all the energy is depleted).

For systems using collectors whose efficiency is dependent on the collector inlet temperature (such as flat-plate collectors), having a mixed tank will reduce collector performance. Maintaining stratification will lead to higher collector performance. Research performed jointly by the National Bureau of Standards and the University of Wisconsin (Fanney and Klein 1986) showed substantial improvement in performance for direct systems (those without heat exchangers) if the collector loop flow rate was significantly reduced, because of the low collector fluid inlet temperature that resulted from storage tank stratification. A system with a load-side heat exchanger that enhances storage tank stratification might be able to benefit from reduced collector flow rates as well. However, Ramada Energy Systems Limited has found scaling to be a problem with high heat flux systems that is characteristic of low flow systems (Clark 1987). Low flow systems would have to be properly engineered to avoid this.

Load-side heat exchangers have not been studied in much depth. A report on low-cost systems (Kutscher et al. 1984) numerically compared the performance of collector-side and load-side heat exchangers for a particular system. In 1985, SERI researchers measured the performance of a load-side heat exchanger inside a solar energy space-heating tank that was also used to preheat domestic water (Farrington 1986). The experiments these researchers performed showed that the load-side heat exchanger led to stratification in the $1.2-\mathrm{m}$ $(4-\mathrm{ft})$-high storage tank of up to $30^{\circ} \mathrm{C}\left(54^{\circ} \mathrm{F}\right)$. Attempts to present the results in an easily usable form (such as an effectiveness) were not successful; the reasons for this are discussed in section 2.0 .

SERI researchers investigated the performance of load-side heat exchangers in more depth because the performance of these heat exchangers was not welldocumented and they offer several advantages over collector-side heat exchangers, such as enhancing stratification and using low-cost systems.

Our discussion has been limited to active solar energy systems. However, thermosyphon systems have been designed with both collector-side and load-side heat exchangers. This report will be 1 imited to active systems although some of the principles developed here could be extrapolated to thermosyphon systems.

This report examines the inadequacies of using the effectiveness concept for an immersed heat exchanger in a stratified storage tank and then discusses the test loop, test procedure, performance measurements of two smooth and two finned load-side heat exchangers, and numerical modeling of a load-side heat exchanger, and compares the numerical model with experimental results. 


\subsection{DEVELOPMENT OF EQUATIONS}

An accurate mathematical model of unsteady natural convection (i.e., when the heat transfer rate changes with time) is very difficult. It involves simultaneously solving in three dimensions (or two dimensions if axisymmetry occurs) the equations for the conservation of mass (or continuity), conservation of momentum (or Navier-Stokes equations), and conservation of thermal energy.

Consider the following description. Assume a hot storage tank with no flow through the heat exchanger and no convection currents in the tank. Therefore, the water velocity inside the tank (ignoring heat loss from the side and top, which might otherwise cause small convection currents) is zero. When cold water begins to flow through the heat exchanger it causes the warm heat exchanger to cool rapidly.

As the heat exchanger cools, heat is transferred by conduction from the neighboring water molecules in the storage tank to the heat exchanger. As the water near the heat exchanger cools, the water density increases; the water begins to fall and warmer water underneath rises because of buoyancy. This is the beginning of the natural convection currents. The moving water sets up a velocity field in the storage tank that is dependent on the heat transfer rate to the heat exchanger. However, the heat transfer rate is dependent on the velocity of the fluid passing the surface of the heat exchanger. Therefore, the fluid velocity and heat transfer rate are mutually dependent on each other. Generally, this dependency is determined empirically and not numerically.

Designers want and need a simple approach to this complicated problem. A typical approach for analyzing the performance of a heat exchanger is to use the concept of effectiveness. The effectiveness of a heat exchanger is easy to understand and use. It is the ratio of the actual heat transfer to the theoretical maximum heat transfer. Knowing the effectiveness of a heat exchanger makes it possible to use various computer models to predict system performance.

For a heat exchanger removing energy from a hot tank (i.e., cooling the tank), the effectiveness is given by

Notice that

$$
\varepsilon=\frac{\left(\dot{\mathrm{m}} \mathrm{C}_{\mathrm{p}}\right)_{\mathrm{Hx}}\left(\mathrm{T}_{\mathrm{Hx}, \mathrm{O}}-\mathrm{T}_{\mathrm{Hx}, \mathrm{i}}\right)}{\left(\dot{\mathrm{m}} \mathrm{C}_{\mathrm{p}}\right)_{\min }\left(\mathrm{T}_{\mathrm{S}}-\mathrm{T}_{\mathrm{Hx}, \mathrm{i}}\right)} .
$$

$$
\mathrm{T}_{\mathrm{Hx}, \mathrm{O}}>\mathrm{T}_{\mathrm{Hx}, \mathrm{i}}
$$

since water is being heated as it flows through the heat exchanger.

The minimum flow-thermal capacitance $\left(\dot{m C}_{p}\right)_{\text {min }}$ is on the heat exchanger side. This is easy to visualize. Over a given time period, the temperature rise across the heat exchanger $\left(\mathrm{T}_{\mathrm{Hx}, \mathrm{O}}-\mathrm{T}_{\mathrm{Hx}}, \mathrm{i}\right)$ is much greater than the change in the storage tank temperature even though the energy lost by the tank (presuming it is well-insulated) is approximately the same as the energy gained by the heat exchanger. 
Therefore, the equation for the effectiveness for a load-side heat exchanger reduces to

$$
\varepsilon=\frac{T_{H x, o}-T_{H x, i}}{T_{S}-T_{H x, i}} .
$$

The remaining equations used to characterize the performance of the heat exchangers are given in Table 2-1 and can be found in most heat transfer texts (e.g., Kreith and Bohn 1986). However, the storage tank temperature $\mathrm{T}_{S}$ has not yet been defined.

Table 2-1. Performance Equations for Immersed Load-Side Heat Exchanger

Quantity

Equation ${ }^{\mathrm{a}}$

$\varepsilon=\frac{\mathrm{T}_{\mathrm{Hx}, 0}-\mathrm{T}_{\mathrm{Hx}, \mathrm{i}}}{\mathrm{T}_{\mathrm{S}}-\mathrm{T}_{\mathrm{Hx}, \mathrm{i}}}$

$q=\dot{m}_{p}\left(T_{H x, o}-T_{H x, i}\right)$

Heat transfer rate

Overall heat transfer area coefficient

Condenser logarithmic mean temperature difference

Parallel flow LMTD

$$
U A=q / L M T D
$$

$\operatorname{LMTD}_{c}=\frac{\left(T_{H x, o}-T_{H x, i}\right)}{\ln \left(\frac{T_{S}-T_{H x, i}}{T_{S}-T_{H x, o}}\right)}$

$$
\operatorname{LMTD}=\frac{\left(T_{S, b}-T_{H x, i}\right)-\left(T_{S, t}-T_{H x, o}\right)}{\ln \left(\frac{T_{S, b}-T_{H x, i}}{T_{S, t}-T_{H x, o}}\right)}
$$

$\mathrm{Nu}=\overline{\mathrm{h}}_{\mathrm{o}} \mathrm{d} / \mathrm{k}$

$\bar{h}_{0}=q /(A)$ (LMTD)

transfer coefficient

Overal1 Rayleigh number Number

Equation 
There are many definitions for a storage tank temperature that could be used in the effectiveness and logarithmic mean temperature difference (LMTD) calculations. Some are:

- Tank top temperature. This definition for storage tank temperature makes sense since the effectiveness is the ratio of the actual heat transfer rate to the theoretical maximum heat transfer rate. The theoretical maximum is proportional to the difference between the highest temperature (which is at the top of the tank) and the coldest temperature (which is at the inlet). Using the tank top temperature will always lead to a calculated effectiveness less than 1. However, it will result in unrealistic effectiveness values for the heat exchanger. For example, consider two similar heat exchangers that have the same inlet and outlet temperatures. One heat exchanger leaves $30 \mathrm{~cm}(1 \mathrm{ft})$ of hot water at a uniform temperature above it and the other leaves only $2 \mathrm{~cm}$ ( 1 in.) of hot water above it at the same temperature. Both heat exchangers will have the same effectiveness using the top tank temperature (which is unaffected by the heat exchanger) but one heat exchanger removes much more energy than the other. It is clear that one is in a better location than the other. Therefore, when analyzing this type of heat exchanger, one must look at the total energy removed from the tank as well as the heat transfer rate.

- The center of the tank. The problem with this definition is that the center doesn't reflect the bottom or top temperature. The center temperature may equal the heat exchanger inlet temperature, causing the calculated effectiveness to equal 0 while the heat exchanger is still removing energy from water above the center.

- Vertical average temperature calculated by taking the average of five sensors distributed vertically in the tank. This is a good idea, except that when the top is much hotter than the average, then the heat exchanger outlet temperature can exceed the average and cause the calculated effectiveness to be greater than 1 .

- Bulk tank temperature calculated from an energy balance. The weakness of this approach is that the temperature is not measured but calculated from a previously calculated tank temperature (except for the initial condition) and from a calculated heat loss. Errors in the calculated tank temperature are continually propagated. Since the new temperature is based on the old temperature, the errors will increase exponentially with each time step. This approach (if the heat-loss calculations were absolutely correct) would give the same result (within the propagated measurement uncertainty) as using a vertical average of a large number of temperature sensors in a tank that did not have a horizontal temperature gradient. This approach also has the same problems as the approach that calculates the vertical average temperature by taking the average of five sensors distributed vertically in the tank.

The effectiveness equation requires that the temperature distribution in the storage tank be represented by one temperature. Clearly, different degrees of stratification can have the same average temperature. Consider a well-mixed tank at some temperature. Decrease the bottom temperature while increasing the top temperature by the same amount. The average temperature remains the same. However, the heat transfer rate changes since natural convective heat transfer rates are not 1 inear functions of temperature differences. 
Consider the effectiveness equation (Eq. 2-3) with the storage tank temperature defined as the temperature at the top of the tank. In a stratified tank, the temperature in the top of the tank may not change much as energy is removed from the bottom of the tank, particularly if there is a layer of hot water above the top coil. However, as the bottom cools, the actual heat transfer rate drops, while the temperature at the top of the tank may remain relatively constant. This leads the numerator of Eq. 2-3 to decrease while the denominator remains relatively constant. This causes large changes in the effectiveness at small changes in the temperature difference at high temperature differences, as shown in Figure 2-1. That is, there are many values for the effectiveness at one temperature difference. Such a relationship is of little value to designers. Another problem with this approach is that the effectiveness is a function of the initial tank temperature. Representing the storage tank temperature by the top tank temperature leads to a family of curves as shown in Figure 2-2. For the effectiveness to be of use it must have only one value at one temperature difference. It must be a single-valued function of the temperature difference rather than a multivalued function. These results are shown and discussed in detail in Farrington (1986) for a load-side DHW heat exchanger in a space-heating storage tank.

For this report, methods other than heat exchanger effectiveness will be examined.

It is often useful to plot various parameters versus the LMTD rather than the difference between the storage tank and the heat exchanger inlet temperature. The LMTD accounts for the exponential temperature rise along the heat exchanger. If the tank is well-mixed, then

$$
\mathrm{T}_{\mathrm{S}, \mathrm{b}}=\mathrm{T}_{\mathrm{S}, \mathrm{t}}=\mathrm{T}_{\mathrm{S}}
$$

and Eq. 2-7 reduces to Eq. 2-6. Equation 2-6 is used with collector-side heat exchangers when the tank is well-mixed and is the equation used with constant temperature devices (such as condensers and evaporators).

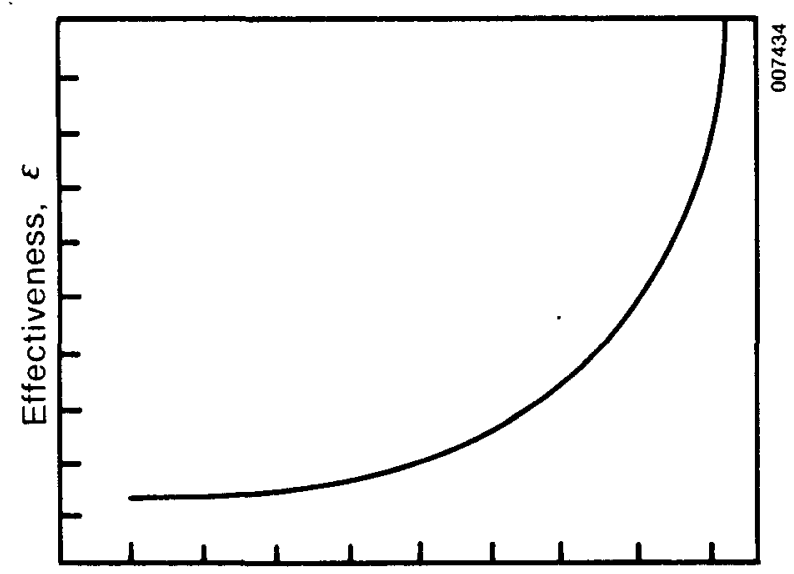

Temperature difference, $T_{S}-T_{H x, i}$ Effectiveness versus $\Delta T$

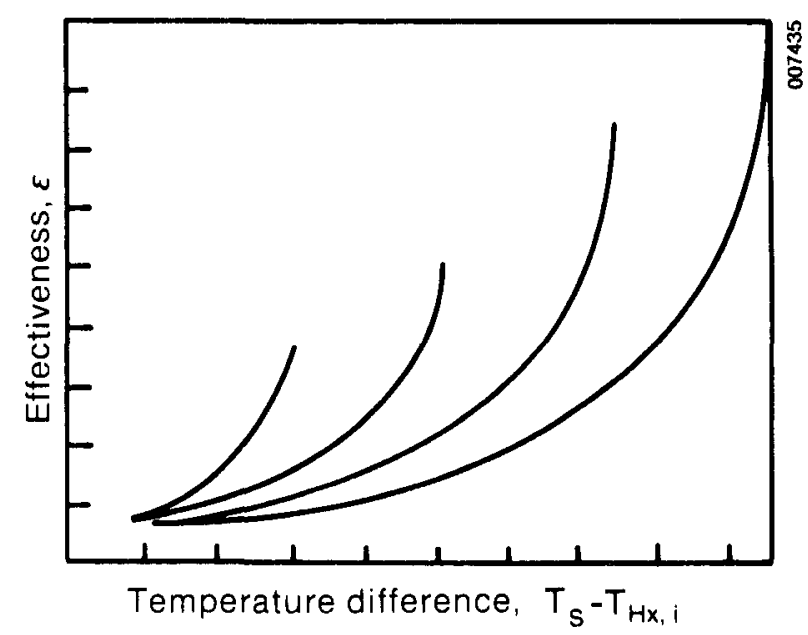

Figure 2-2. Family of Heat Exchanger Effectiveness Curves 
If the tank is stratified then Eq. 2-7 needs to be used. Equation 2-7 accounts not only for the exponential temperature rise along the heat exchanger, but also for the nonlinear temperature stratification in the storage tank. This is the same definition that would be used for parallel-flow and counterflow heat exchangers. Although there is little mixing inside a stratified tank, an analogy to a parallel-flow heat exchanger can be made. The tank and heat exchanger have the hot sides together (at the top) and the cold sides together (at the bottom). Equation 2-7 is used throughout this report to define the LMTD.

Equation 2-7 also has limitations since the temperature distribution along the heat exchanger may not be truly exponential. For example, consider a very high, but thin, cylindrical storage tank. Eventually, all of the energy is removed from the bottom part of the storage tank, resulting in no temperature gradient along that part of the heat exchanger. Likewise, at the very top, the heat exchanger temperature has approached the tank temperature and there is little temperature change along the heat exchanger. Therefore, in some circumstances (for example, very low flow rates, tall storage tanks, or low temperature differences), the temperature distribution along the heat exchanger may be $f l a t$ at both ends and exponential somewhere between the ends.

As mentioned at the beginning of this section, natural convective heat transfer occurs in a conjugate or paired manner. The natural convective heat transfer coefficient $\vec{h}_{0}$ is influenced by the velocity of the water flowing around the outside of the heat exchanger tube. The velocity is a function of the local temperature difference between the outside tube wall and the water. The temperature difference, however, is a function of the natural convective heat transfer coefficient. This relationship is often expressed by a correlation of two dimensionless numbers: the Nusselt number, $\mathrm{Nu}$, which is a measure of the outside convective heat transfer coefficient, and the Rayleigh number, Ra, which is a measure of the buoyancy force or momentum of the fluid.

The Nusselt number is the ratio of the convective heat transfer rate to the conductive heat transfer rate through the fluid. Dropping the temperature differences (which are equal), the Nusselt number is written as

$$
\mathrm{Nu}=\frac{\mathrm{h}_{\mathrm{o}} \mathrm{d}}{\mathrm{k}},
$$

where $d$ is the characteristic length and taken to be equal to the outside diameter of the pipe, excluding any fins. At a Nusselt number of 1 the convective heat transfer rate is equal to the conductive heat transfer rate through the fluid. For natural convective heat transfer in water to be significant the Nusselt number must be greater than 1 .

The Rayleigh number can be considered as the ratio of the buoyancy force to the change in momentum flux (Arpaci and Larsen 1984), and can be written as

$$
R a=\frac{g \rho \beta \Delta T}{\left(\mu v / d^{2}\right)}=\frac{\rho^{2} B C_{p} g d^{3} \Delta T}{\mu k}
$$


for a reference fluid velocity $k / \rho C_{p} d$. The Rayleigh number for natural convective heat transfer is quite high since the buoyancy force caused by the temperature difference is much greater than the change in momentum flux of the fluid passing by the outside of the heat exchanger. In our calculations, we used the LMTD for the $\Delta \mathrm{T}$ to account for the stratification in the storage tank.

The $\mathrm{Nu} / \mathrm{Ra}$ correlation is expressed as

$$
\mathrm{Nu}=\mathrm{CRa}^{\mathrm{m}} \text {, }
$$

where $\mathrm{C}$ and $\mathrm{m}$ are empirically derived constants. The constant $\mathrm{m}$ is generally given to be 0.25 for laminar natural convective heat transfer (McAdams 1954) while $C$ is a function of the heat exchanger geometry and test conditions (flow rate and temperature difference).

In Section 4.0 we discuss various correlations from the experimental results and their meaning. 


\subsection{EXPERIMENTAL SETUP AND TEST PLAN}

The test loop is shown in Figure 3-1. It included a 409-I (108-gal) clear acrylic tank with an inside diameter of $58 \mathrm{~cm}(23 \mathrm{in.})$ and an interior height of $152 \mathrm{~cm}$ ( $60 \mathrm{in.})$. The tank was constructed with removable end caps and was insulated during testing with $15 \mathrm{~cm}$ ( $6 \mathrm{in.})$ of fiberglass insulation on the sides, $5 \mathrm{~cm}$ ( 2 in.) of foam insulation on the bottom, and $8 \mathrm{~cm}$ ( 3 in.) of foam insulation on the top. The tank had a measured heat loss rate of $1.6 \mathrm{~W} /{ }^{\circ} \mathrm{C}$ $\left(3.0 \mathrm{Btu} / \mathrm{h}{ }^{\circ} \mathrm{F}\right)$. The top end cap of the acrylic tank had small holes to eliminate air during filling.

A 1552-L (410-gal) tank was used to provide a uniform source of hot water to initially fill the acrylic tank. Cold water was supplied from the building water mains. Cold water was diverted around the heat exchanger and dumped to a floor drain prior to the test to prevent cold water in the lines from warming to room temperature.

The heat exchanger was sized to provide $95 \%$ of the maximum system performance (i.e., without a heat exchanger) using the computer program SOLIPH (Kutscher et al. 1982). The relationship between heat exchanger area and system performance is shown in Figure 3-2. The model assumed a well-mixed storage tank, and was based on a collector-to-storage tank ratio of $41 \mathrm{~L} / \mathrm{m}^{2}\left(1.5 \mathrm{gal} / \mathrm{ft}^{2}\right)$, a tank volume of $380 \mathrm{~L}$ (100 gal), a cold water inlet temperature of $10^{\circ} \mathrm{C}\left(50^{\circ} \mathrm{F}\right)$, and tank insulation of $1.9^{\circ}\left(\mathrm{m}^{2}{ }^{\circ} \mathrm{C}\right) / \mathrm{W}\left(\mathrm{R}-11\left[\mathrm{~h} \mathrm{ft}^{2}{ }^{\circ} \mathrm{F}\right] / \mathrm{Btu}\right)$. A heat exchanger area of $2.45 \mathrm{~m}^{2}\left(26.4 \mathrm{ft}^{2}\right)$ resulted in a $5 \%$ performance penalty for a continuously well-mixed tank. For a stratified tank the performance penalty should be less since the inlet water to the collector is cooler than with a mixed tank.

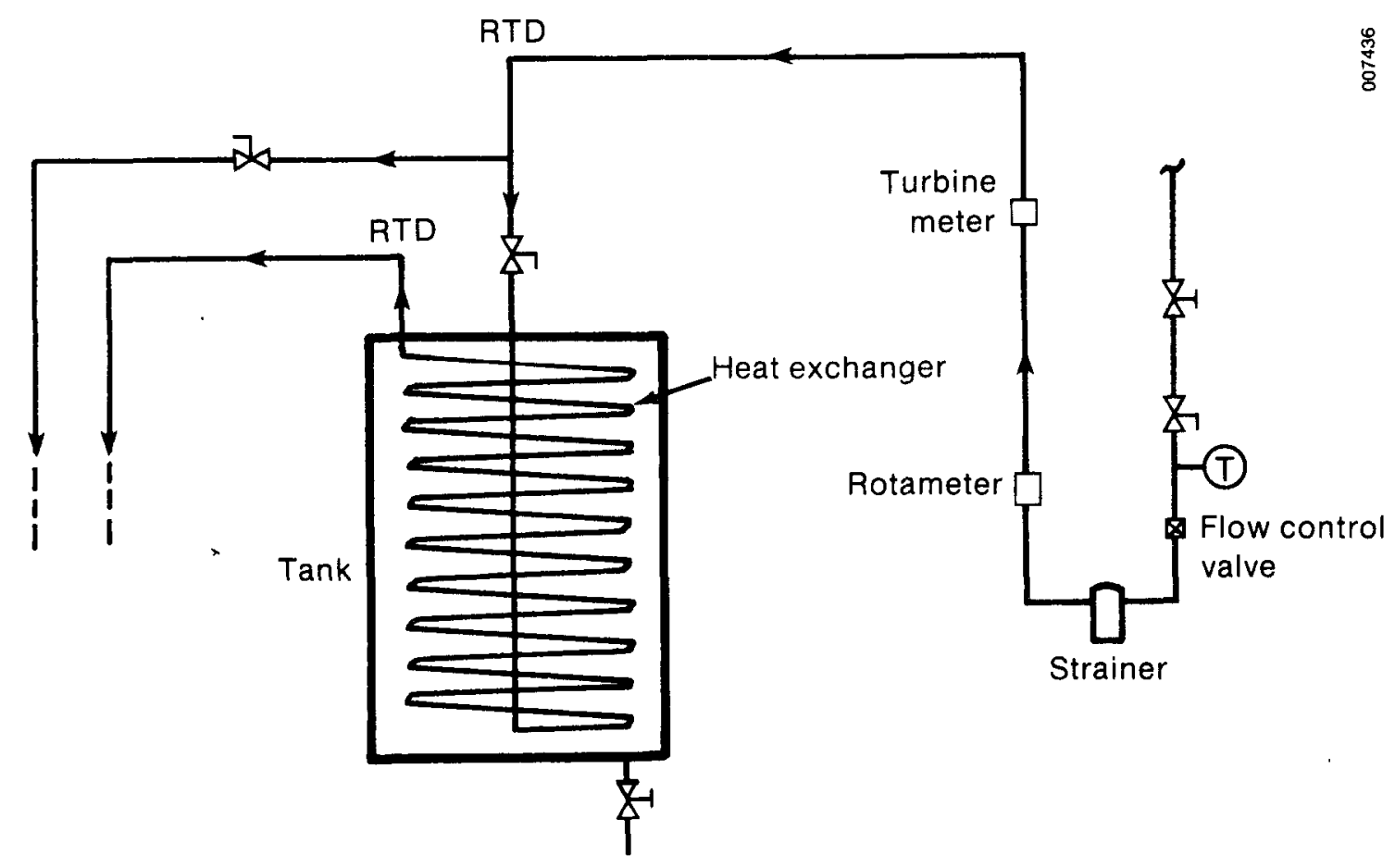

Figure 3-1. Schematic of Test Loop 


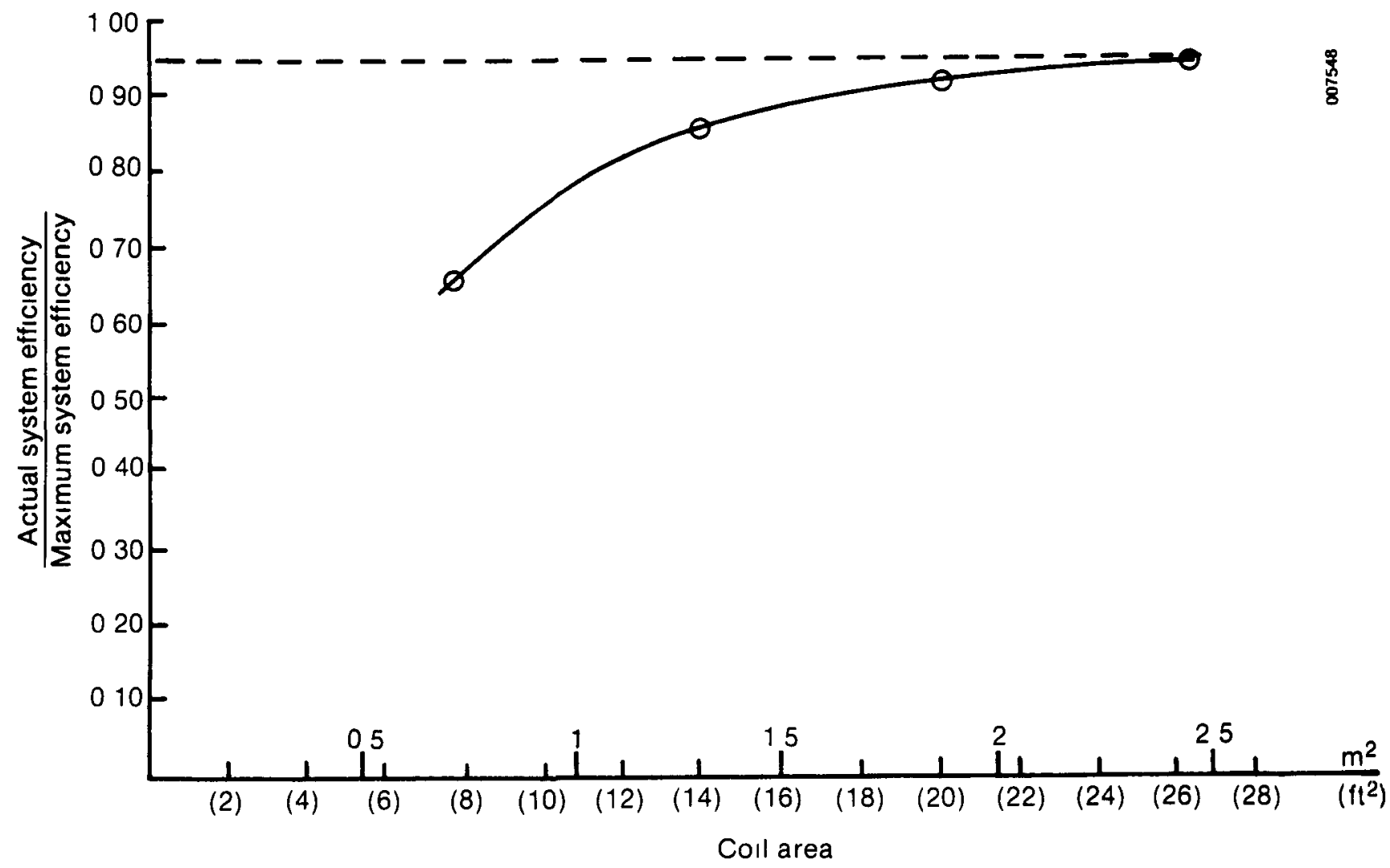

Figure 3-2. Solar DHW System Performance as a Function of Load-Side Heat Exchanger Area for a Well-Mixed Storage Tank

The heat exchangers tested were constructed from either smooth copper coils or finned copper coils. The specifications for the pipe used for the heat exchangers are given in Table 3-1; the dimensions of the four heat exchangers tested are presented in Table 3-2. Each heat exchanger spanned the height of the tank, spiraling with equal diameters, from the bottom of the tank to the top. The distances between each successive coil were equal for the smooth coil and also for the finned coil. The coils were located so that there were equal volumes of water on each side of the coil, between the coil and the side wall, and between the coil and the center of the tank. This resulted in a coil diameter of about $43 \mathrm{~cm}$ (17 in.). The finned coils had a $1.5-\mathrm{m}(5-\mathrm{ft})$ section of smooth pipe from the top of the tank to the bottom (see Figure 3-1). Following the practice of Trident Energy Systems (Farrington 1986) we used smooth pipe to minimize the disturbance of the stratification by this leg of pipe. Ideally, the heat exchanger inlet would come through the bottom of the tank. However, that is not practical with many unpressurized tanks, particularly those that are membrane-lined. Additional lengths of smooth pipe were used to exit the storage tank.

The finned tubing had a smaller inside diameter than the smooth tubing, which led to a $50 \%$ increase in the velocity for a given flow rate and about a $23 \%$ increase in the Reynolds number. In all cases the flow regime remained transitional. Therefore, the higher velocity should not significantly affect (i.e., < $10 \%$ ) the inside tube heat transfer coefficient. 
Table 3-1. Smooth- and Finned-Pipe Specifications

\begin{tabular}{ccccc}
\hline Tubing & $\begin{array}{c}\text { ID } \\
(\mathrm{mm}[\mathrm{in.}])\end{array}$ & $\begin{array}{c}\text { OD } \\
(\mathrm{mm}[\mathrm{in.}])\end{array}$ & $\begin{array}{c}\text { Fin Height } \\
(\mathrm{mm}[\mathrm{in} \cdot])\end{array}$ & $\begin{array}{c}\text { Fins/cm } \\
(\mathrm{fins} / \mathrm{in} .)\end{array}$ \\
\hline Smooth coil & 12.7 & 15.9 & 0 & 0 \\
Finned coil & $(0.53)$ & $(0.63)$ & 0 & 0 \\
& 10.9 & 12.4 & 3.2 & 4 \\
& $(0.43)$ & $(0.49)^{\mathrm{a}}$ & $(0.13)$ & $(11)$ \\
\hline
\end{tabular}

a Excluding fins.

The temperature profile inside the tank was measured with seven thermistors immersed $10 \mathrm{~cm}$ ( 4 in.) from the center of the tank and equally spaced between the top and bottom of the tank, with one sensor near the top of the tank and one near the bottom of the tank. The thermistors, suspended by their leads, were specified with an accuracy of $\pm 0.5^{\circ} \mathrm{C}\left( \pm 0.9^{\circ} \mathrm{F}\right)$ and a response time of $18 \mathrm{~ms}$ in a cold-water splash test. These thermistors read within $\pm 0.1^{\circ} \mathrm{C}$ $\left( \pm 0.2^{\circ} \mathrm{F}\right)$ of each other when the tank was well-mixed. The measured lead resistance of these $20-K \Omega$ sensors was accounted for in our data acquisition computer program.

The temperatures of the heat exchanger inlet and outlet were measured with four-wire, nominal $100-\Omega$, platinum-wound resistance temperature detectors (RTDs) calibrated in the SERI Metrology Laboratory. We performed an end-toend check of the RTDs after their installation using a stirred ice bath monitored with two digital quartz thermometers. The heat exchanger inlet RTD read $0.023^{\circ} \mathrm{C}\left(0.041^{\circ} \mathrm{F}\right)$ below, and the heat exchanger outlet RTD read within $0.001^{\circ} \mathrm{C}$ $\left(0.002^{\circ} \mathrm{F}\right)$ of the digital quartz thermometers. The RTDs, which had stainless steel sheaths, were mounted in the center of the flow; the entire sheath was parallel to the flow. The RTD mounting heads were well-insulated.

The flow rate was monitored visually with a rotameter and measured with a turbine meter $1.2 \mathrm{~cm}(0.5 \mathrm{in.})$ in diameter that had flow straighteners and 40 pipe diameters of unobstructed flow upstream and also downstream of the

Table 3-2. Heat Exchanger Specifications

\begin{tabular}{|c|c|c|c|c|c|}
\hline $\begin{array}{c}\text { Heat } \\
\text { Exchanger }\end{array}$ & $\begin{array}{l}\text { Smooth } \\
\text { Length } \\
(m[f t])\end{array}$ & $\begin{array}{c}\text { Smooth } \\
\left(\mathrm{m}^{2}\left[\mathrm{ft}^{2}\right]\right)\end{array}$ & $\begin{array}{l}\text { Finned } \\
\text { Length } \\
(\mathrm{m}[\mathrm{ft}])\end{array}$ & $\begin{array}{c}\text { Finned } \\
\left(\mathrm{m}^{2}\left[\mathrm{ft}^{2}\right]\right)\end{array}$ & $\begin{array}{c}\text { Total } \\
\text { Area } \\
\left(m^{2}\left[f t^{2}\right]\right)\end{array}$ \\
\hline $\begin{array}{l}\text { Original smooth } \\
\text { coil }\end{array}$ & $\begin{array}{c}48.31 \\
(158.5)\end{array}$ & $\begin{array}{c}2.41 \\
(25.9)\end{array}$ & $\begin{array}{c}0 \\
(0)\end{array}$ & $\begin{array}{c}0 \\
(0)\end{array}$ & $\begin{array}{c}2.41 \\
(25.9)\end{array}$ \\
\hline $\begin{array}{l}\text { Reduced smooth } \\
\text { coil }\end{array}$ & $\begin{array}{c}33.83 \\
(111.0)\end{array}$ & $\begin{array}{c}1.69 \\
(18.2)\end{array}$ & $\begin{array}{c}0 \\
(0)\end{array}$ & $\begin{array}{c}0 \\
(0)\end{array}$ & $\begin{array}{c}1.69 \\
(18.2)\end{array}$ \\
\hline $\begin{array}{l}\text { Original finned } \\
\text { coil }\end{array}$ & $\begin{array}{c}2.03 \\
(6.67)\end{array}$ & $\begin{array}{c}0.08 \\
(0.9)\end{array}$ & $\begin{array}{c}13.44 \\
(44.08)\end{array}$ & $\begin{array}{c}2.38 \\
(25.6)\end{array}$ & $\begin{array}{c}2.46 \\
(26.5)\end{array}$ \\
\hline $\begin{array}{l}\text { Reduced finned } \\
\text { coil }\end{array}$ & $\begin{array}{c}1.88 \\
(6.17)\end{array}$ & $\begin{array}{l}0.07 \\
(0.8)\end{array}$ & $\begin{array}{c}9.40 \\
(30.83)\end{array}$ & $\begin{array}{l}1.66 \\
(17.9)\end{array}$ & $\begin{array}{l}1.74 \\
(18.7)\end{array}$ \\
\hline
\end{tabular}


turbine meter. We used the factory calibration for the turbine meter and corrected the viscosity for temperature effects.

We calculated the random uncertainty of each sensor (thermistors, RTDs, and turbine meter) by calculating the standard deviation of 100 readings at steady state. The random fluctuations were always significantly less than $1 \%$ of the mean. Thermistor and RTD resistances were measured with a Hewlett-Packard (HP) HP3456A digital voltmeter that was calibrated by HP at the start of the test period. Scanning and frequency measurements were accomplished using an HP3497A scanner and an HP3498 extender box. An uncertainty analysis of our measurements is presented in Appendix A.

The acquisition of data was controlled by an HP9816S computer that collected data every $30 \mathrm{~s}$, calculated necessary results, and printed both tabular and graphic results. Both raw data and reduced data were stored on magnetic disks for easy retrieval and manipulation. The data acquisition system, with the exception of the computer, was left on continuously to avoid waiting during warm-up periods.

The following test procedure was used:

- With the storage tank empty, set the flow rate through the heat exchanger.

- Divert the cold water around the heat exchanger and storage tank.

- Fill the storage tank with hot water at the appropriate temperature.

- After filling the storage tank, let it set for at least $30 \mathrm{~min}$ to reach quasiequilibrium.

- When ready to start the test, begin the data collection program.

- Start flow through the heat exchanger.

- Observe the flow rate and adjust if necessary.

- Stop the test when the temperature rise across the heat exchanger is less than $1^{\circ} \mathrm{C}$.

There were some exceptions to the procedure. With the original smooth-coil heat exchanger, we did not realize the value of bypassing the cold, water around the heat exchanger during the 30-min waiting period. Hence, when the test began, the water temperature had warmed and became cooler as the test progressed. Therefore, the initial temperature differences were sometimes less than anticipated. The cold water generally reached a steady temperature within $3 \mathrm{~min}$ at $20 \mathrm{~L} / \mathrm{min}(5.3 \mathrm{gal} / \mathrm{min})$ and within $10 \mathrm{~min}$ at $5 \mathrm{~L} / \mathrm{min}$ ( $1.3 \mathrm{gal} / \mathrm{min})$. The increased temperature of the cold water was generally less than $1^{\circ} \mathrm{C}\left(2^{\circ} \mathrm{F}\right)$.

When the tank was filled with very hot water, on the order of $80^{\circ} \mathrm{C}\left(175^{\circ} \mathrm{F}\right)$, the level sometimes dropped on the order of a few millimeters during the 30-min waiting period. This was probably due to warming of the plastic tank and its subsequent expansion. We would then "top off" the tank with water close to the tank temperature without restarting the 30 -min period. It generally took about $10 \mathrm{~min}$ to initially fill the tank. At times the waiting period exceeded $30 \mathrm{~min}$, but that would not have affected the test results. 


\subsection{TEST RESULTS}

The potential for data analysis increases greatly with the availability of microcomputers. We took advantage of the computing power of our machine to plot as many variables as we could think of at the time. The conditions for each test are shown in Table 4-1. The finned coils had a corrugated interior that was a by-product of manufacturing a finned coil that could be bent. This caused a sufficiently high pressure drop that limited our test flow rate to $15 \mathrm{~L} / \mathrm{min}(4.0 \mathrm{gal} / \mathrm{min})$. The graphs that were plotted for each test - four heat exchangers, three or four flow rates, and three or four initial temperature differences - are shown in Table 4-2.

Table 4-1. Heat Exchanger Test Conditions

\begin{tabular}{|c|c|c|c|c|c|c|}
\hline $\begin{array}{l}\text { Heat Exchanger } \\
\text { Type }\end{array}$ & $\begin{array}{c}\text { Flow Rate } \\
(\mathrm{L} / \mathrm{min})\end{array}$ & $\begin{array}{c}\text { Nominal Temp. } \\
\text { Difference }\end{array}$ & $\begin{array}{l}\mathrm{T}_{\mathrm{S}}(0) \\
\left({ }^{\circ} \mathrm{C}\right)\end{array}$ & $\begin{array}{c}\mathrm{T}_{\mathrm{Hx}, \mathrm{i}}(0) \\
\left({ }^{\circ} \mathrm{C}\right)\end{array}$ & $\begin{array}{c}\Delta \mathrm{T} \\
\left({ }^{\circ} \mathrm{C}\right)\end{array}$ & $\begin{array}{l}\text { Test Length } \\
\text { (min) }\end{array}$ \\
\hline \multirow[t]{4}{*}{ Original smooth coil } & $\begin{array}{l}5 \\
5 \\
5\end{array}$ & $\begin{array}{l}\text { low } \\
\text { medium } \\
\text { high }\end{array}$ & $\begin{array}{l}30.0 \\
45.0 \\
61.0\end{array}$ & $\begin{array}{l}16.0 \\
15.8 \\
15.5\end{array}$ & $\begin{array}{l}14.0 \\
29.2 \\
45.5\end{array}$ & $\begin{array}{l}180 \\
240 \\
240\end{array}$ \\
\hline & $\begin{array}{l}10 \\
10 \\
10 \\
10\end{array}$ & $\begin{array}{l}\text { low } \\
\text { medium } \\
\text { high } \\
\text { very high }\end{array}$ & $\begin{array}{l}30.4 \\
45.2 \\
58.0 \\
75.0\end{array}$ & $\begin{array}{l}16.1 \\
16.4 \\
16.3 \\
16.3\end{array}$ & $\begin{array}{l}14.3 \\
28.8 \\
41.7 \\
58.7\end{array}$ & $\begin{array}{l}120 \\
240 \\
240 \\
360\end{array}$ \\
\hline & $\begin{array}{l}15 \\
15 \\
15\end{array}$ & $\begin{array}{l}\text { low } \\
\text { medium } \\
\text { high }\end{array}$ & $\begin{array}{l}31.0 \\
44.2 \\
57.5\end{array}$ & $\begin{array}{l}15.7 \\
15.8 \\
15.0\end{array}$ & $\begin{array}{l}15.3 \\
28.4 \\
42.5\end{array}$ & $\begin{array}{r}90 \\
360 \\
120\end{array}$ \\
\hline & $\begin{array}{l}20 \\
20 \\
20 \\
20\end{array}$ & $\begin{array}{l}\text { low } \\
\text { medium } \\
\text { high } \\
\text { very high }\end{array}$ & $\begin{array}{l}29.8 \\
41.7 \\
59.0 \\
77.3\end{array}$ & $\begin{array}{l}17.3 \\
16.7 \\
16.6 \\
17.1\end{array}$ & $\begin{array}{l}12.5 \\
25.0 \\
42.4 \\
60.2\end{array}$ & $\begin{array}{l}120 \\
120 \\
120 \\
120\end{array}$ \\
\hline \multirow[t]{4}{*}{ Reduced smooth coil } & $\begin{array}{l}5 \\
5 \\
5 \\
5\end{array}$ & $\begin{array}{l}\text { low } \\
\text { medium } \\
\text { high } \\
\text { very high }\end{array}$ & $\begin{array}{l}30.4 \\
44.7 \\
54.2 \\
74.2\end{array}$ & $\begin{array}{l}15.0 \\
14.6 \\
14.7 \\
14.0\end{array}$ & $\begin{array}{l}15.4 \\
30.1 \\
39.5 \\
60.2\end{array}$ & $\begin{array}{l}180 \\
210 \\
240 \\
300\end{array}$ \\
\hline & $\begin{array}{l}10 \\
10 \\
10 \\
10\end{array}$ & $\begin{array}{l}\text { low } \\
\text { medium } \\
\text { high } \\
\text { very high }\end{array}$ & $\begin{array}{l}30.7 \\
44.6 \\
55.4 \\
76.5\end{array}$ & $\begin{array}{l}14.8 \\
15.0 \\
15.5 \\
15.8\end{array}$ & $\begin{array}{l}15.9 \\
29.6 \\
39.9 \\
60.7\end{array}$ & $\begin{array}{l}180 \\
210 \\
220 \\
240\end{array}$ \\
\hline & $\begin{array}{l}15 \\
15 \\
15 \\
15\end{array}$ & $\begin{array}{l}\text { low } \\
\text { medium } \\
\text { high } \\
\text { very high }\end{array}$ & $\begin{array}{l}28.7 \\
44.7 \\
54.1 \\
73.4\end{array}$ & $\begin{array}{l}13.4 \\
14.3 \\
14.1 \\
13.8\end{array}$ & $\begin{array}{l}15.3 \\
30.4 \\
40.0 \\
59.6\end{array}$ & $\begin{array}{l}180 \\
180 \\
180 \\
165\end{array}$ \\
\hline & $\begin{array}{l}20 \\
20 \\
20 \\
20\end{array}$ & $\begin{array}{l}\text { low } \\
\text { medium } \\
\text { high } \\
\text { very high }\end{array}$ & $\begin{array}{l}29.1 \\
44.0 \\
54.1 \\
73.5\end{array}$ & $\begin{array}{l}13.4 \\
13.4 \\
13.7 \\
13.8\end{array}$ & $\begin{array}{l}15.7 \\
30.6 \\
40.4 \\
59.7\end{array}$ & $\begin{array}{l}120 \\
150 \\
150 \\
180\end{array}$ \\
\hline
\end{tabular}


Table 4-1. Heat Exchanger Test Conditions (Concluded)

\begin{tabular}{|c|c|c|c|c|c|c|}
\hline $\begin{array}{c}\text { Heat Exchanger } \\
\text { Type }\end{array}$ & $\begin{array}{c}\text { Flow Rate } \\
\text { (L/min) }\end{array}$ & $\begin{array}{c}\text { Nominal Temp. } \\
\text { Difference }\end{array}$ & $\begin{array}{l}\mathrm{T}_{\mathrm{S}}(0) \\
\left({ }^{\circ} \mathrm{C}\right)\end{array}$ & $\begin{array}{c}\mathrm{T}_{\mathrm{Hx}, \mathrm{i}}(0) \\
\left({ }^{\circ} \mathrm{C}\right)\end{array}$ & $\left(\begin{array}{l}\Delta \mathrm{T} \\
\left({ }^{\circ} \mathrm{C}\right)\end{array}\right.$ & $\begin{array}{c}\text { Test Leng } \\
\text { (min) }\end{array}$ \\
\hline \multirow[t]{3}{*}{ Original finned coil } & $\begin{array}{l}5 \\
5 \\
5 \\
5\end{array}$ & $\begin{array}{l}\text { low } \\
\text { medium } \\
\text { high } \\
\text { very high }\end{array}$ & $\begin{array}{l}31.2 \\
40.9 \\
59.8 \\
77.0\end{array}$ & $\begin{array}{l}21.8 \\
21.7 \\
21.9 \\
21.9\end{array}$ & $\begin{array}{r}9.4 \\
19.2 \\
37.9 \\
55.1\end{array}$ & $\begin{array}{l}180 \\
240 \\
300 \\
480\end{array}$ \\
\hline & $\begin{array}{l}10 \\
10 \\
10 \\
10\end{array}$ & $\begin{array}{l}\text { low } \\
\text { medium } \\
\text { high } \\
\text { very high }\end{array}$ & $\begin{array}{l}30.6 \\
39.9 \\
57.8 \\
73.9\end{array}$ & $\begin{array}{l}21.8 \\
22.1 \\
18.9 \\
21.7\end{array}$ & $\begin{array}{r}8.8 \\
17.8 \\
38.9 \\
52.2\end{array}$ & $\begin{array}{l}180 \\
180 \\
180 \\
240\end{array}$ \\
\hline & $\begin{array}{l}15 \\
15 \\
15 \\
15\end{array}$ & $\begin{array}{l}\text { low } \\
\text { medium } \\
\text { high } \\
\text { very high }\end{array}$ & $\begin{array}{l}30.6 \\
39.6 \\
61.0 \\
77.0\end{array}$ & $\begin{array}{l}21.8 \\
21.9 \\
21.8 \\
21.9\end{array}$ & $\begin{array}{r}8.8 \\
17.7 \\
39.2 \\
55.1\end{array}$ & $\begin{array}{l}120 \\
150 \\
180 \\
180\end{array}$ \\
\hline \multirow[t]{3}{*}{ Reduced finned coil } & $\begin{array}{l}5 \\
5 \\
5 \\
5\end{array}$ & $\begin{array}{l}\text { low } \\
\text { medium } \\
\text { high } \\
\text { very high }\end{array}$ & $\begin{array}{l}27.0 \\
37.4 \\
57.0 \\
76.4\end{array}$ & $\begin{array}{l}16.7 \\
17.1 \\
17.1 \\
17.3\end{array}$ & $\begin{array}{l}10.3 \\
20.3 \\
39.9 \\
59.1\end{array}$ & $\begin{array}{l}240 \\
300 \\
360 \\
360\end{array}$ \\
\hline & $\begin{array}{l}10 \\
10 \\
10 \\
10\end{array}$ & $\begin{array}{l}\text { low } \\
\text { medium } \\
\text { high } \\
\text { very high }\end{array}$ & $\begin{array}{l}30.0 \\
37.8 \\
58.4 \\
76.4\end{array}$ & $\begin{array}{l}17.5 \\
17.7 \\
18.3 \\
17.6\end{array}$ & $\begin{array}{l}12.5 \\
20.1 \\
40.1 \\
58.8\end{array}$ & $\begin{array}{l}240 \\
240 \\
300 \\
420\end{array}$ \\
\hline & $\begin{array}{l}15 \\
15 \\
15 \\
15\end{array}$ & $\begin{array}{l}\text { low } \\
\text { medium } \\
\text { high } \\
\text { very high }\end{array}$ & $\begin{array}{l}27.1 \\
37.6 \\
57.0 \\
76.5\end{array}$ & $\begin{array}{l}17.1 \\
17.2 \\
17.3 \\
17.2\end{array}$ & $\begin{array}{l}10.0 \\
20.4 \\
39.7 \\
59.3\end{array}$ & $\begin{array}{l}150 \\
180 \\
180 \\
240\end{array}$ \\
\hline
\end{tabular}

What is needed is one correlation per heat exchanger based on some type of measurable operating parameter (such as temperature difference or LMTD). The correlation must be independent of how the physical operating condition was reached. For example, if the temperature difference is used, a particular temperature difference can be achieved by starting with a well-mixed tank or by reaching that condition with a stratified tank. Ideally, there would be a correlation that would not change with flow rate or temperature difference (although the values would be a function of flow rate and temperature difference). Such a correlation does exist and will be discussed later in this section.

A brief review of the graphs shown in Table 4-2 is useful. The first nine graphs plot various parameters versus time. These plots give insight into the test conditions and permit quick review for any anomalies. Comparing the heat exchanger outlet temperature (as well as the heat exchanger temperature profile) to the tank temperature profile shows how closely the heat exchanger temperature approached the tank temperature. 
Table 4-2. Graphs Plotted for Each Test

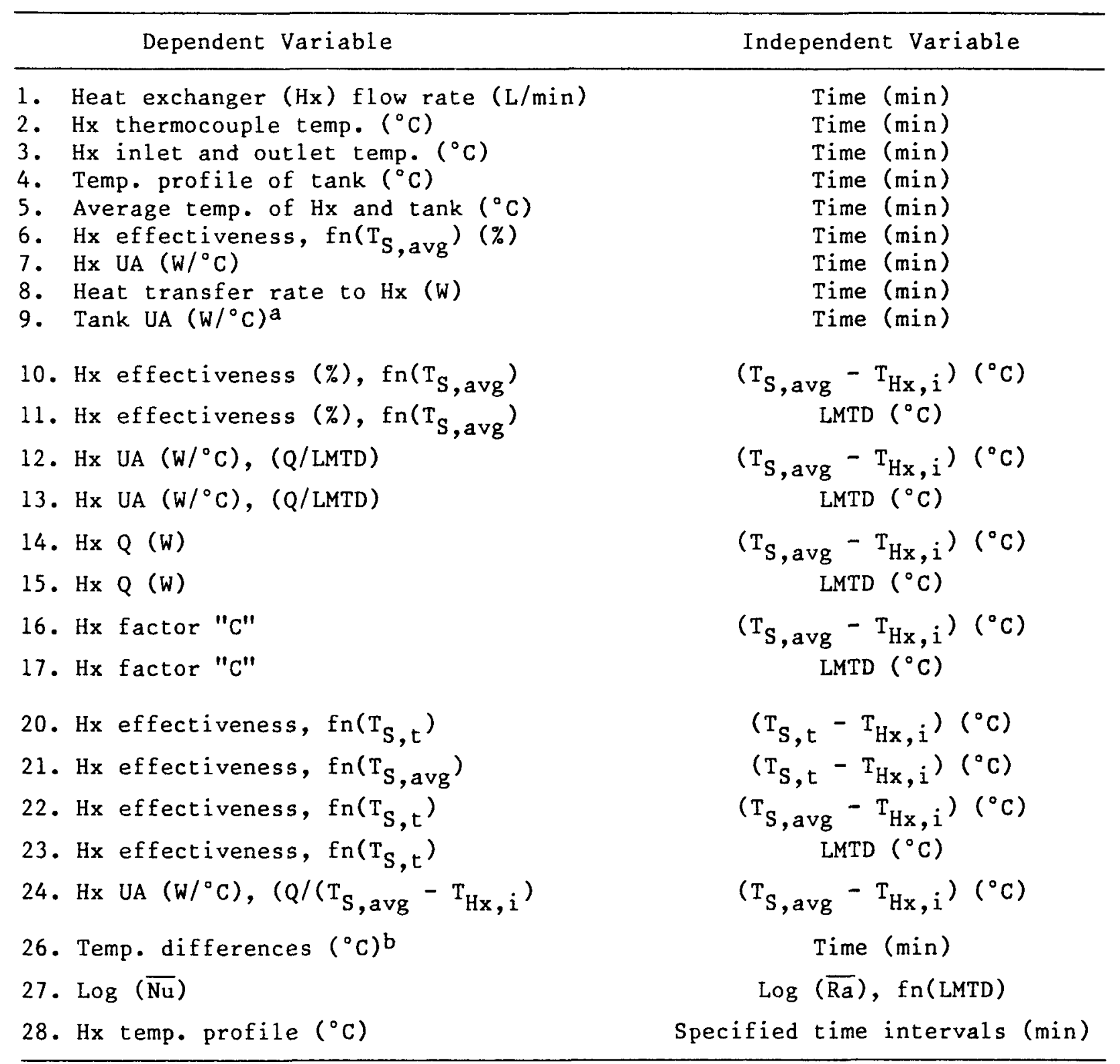

a Used only for tank cool-down tests.

b $\left(\mathrm{T}_{\mathrm{S}, \mathrm{t}}-\mathrm{T}_{\mathrm{Hx}, \mathrm{i}}\right),\left(\mathrm{T}_{\mathrm{S}, \text { avg }}-\mathrm{T}_{\mathrm{Hx}, \mathrm{i}}\right)$ and LMTD.

In general, the lower flow rates had greater variations in the results, as did the larger heat exchanger areas. The lower flow rates and larger heat exchanger areas accentuated the nonlinearity of the heat transfer process. At higher flow rates and smaller heat exchanger areas, there were lower temperature differences between the heat exchanger inlet and outlet and more even heating of the heat exchanger. At lower flow rates (and larger heat exchanger areas) there was greater tank stratification.

The storage tank stratified very well, particularly at low flow rates. Typical temperature profiles of the original, finned heat exchanger (graph 28 in 
Table 4-2) and the storage tank at a flow rate of $5 \mathrm{~L} / \mathrm{min}(1.3 \mathrm{gal} / \mathrm{min})$ are given in Figure 4-1. Each 1 ine represents an elapsed time of 30 min from the previous line. The thermocouples were placed at the top and bottom of the tank and at equal intervals in between. The tank temperature profile, shown in Figure 4-la, shows stratification of $37^{\circ} \mathrm{C}\left(67^{\circ} \mathrm{F}\right)$ after $30 \mathrm{~min}$ and $30^{\circ} \mathrm{C}$ $\left(54^{\circ} \mathrm{F}\right)$ after $1 \mathrm{~h}$ of continuous draw of $5 \mathrm{~L} / \mathrm{min}(1.3 \mathrm{gal} / \mathrm{min})$ through the heat exchanger. Clearly, removing energy from the storage tank in this way results in stratifying the storage tank. The heat exchanger thermocouples in Figure 4-1b were spaced evenly apart, the distance between them being equal to one-tenth of the length of the heat exchanger. The first thermocouple (TC1) was located at the inlet to the heat exchanger and hence was at the top of the storage tank. TC2 was located at the bottom of the tank. The tank was initially well-mixed at about $78^{\circ} \mathrm{C}\left(172^{\circ} \mathrm{F}\right)$. TCl is cooler because of conduction losses through the heat exchanger to the ambient temperature. The heat exchanger outlet temperature TCll, also at the top of the tank, is slightly cooler due to losses from the tank top. TC2 represents the cooler water at the bottom of the storage tank. The temperature rise along the heat exchanger is nonlinear as expected. This nonlinearity causes the difficulty in the analysis and in easily presenting the performance of such a heat exchanger.

Initially, plotting the heat exchanger UA (based on LMTD) versus ( $\mathrm{T}_{\mathbf{S}}$, avg $\mathrm{T}_{\mathrm{Hx}, \mathrm{i}}$ ) (graph 12) looked promising. However, as Figure 4-2 shows, there'was a tions.) The heat exchanger UA should vary with flow rate, but the individual flow rates cannot be distinguished in the results. The U-values of the heat exchangers are determined by dividing the heat exchanger UA by the heat exchanger area given in Table 3-2. The results are shown on the right side of Figure 4-2. One result is that the original finned heat exchanger generally had a higher UA value (and U-value) than the original smooth heat exchanger at temperature differences less than $30^{\circ} \mathrm{C}\left(54^{\circ} \mathrm{F}\right)$. However, at the lower heat exchanger areas, the smooth coil had a higher U-value. In fact, the reduced smooth heat exchanger had the highest U-values of the heat exchangers tested. It could be that the larger smooth heat exchanger was oversized and the extra area did not contribute significantly to the overall heat transfer but did effectively reduce the $U$-value, which has a unit-area basis. The finned coil was significantly shorter, and causes larger spaces between coils and possibly larger convection cells. However, the fins also tend to restrict flow between the fins, reducing the heat transfer coefficient.

The two larger heat exchangers had larger UAs because of the larger heat exchanger surface area. However, the U-values were comparable.

The heat transfer rate is 1 inearly proportional to the temperature rise across the heat exchanger inlet and outlet. It is also related to the temperature in the storage tank. Figure 4-3 shows a plot of the heat transfer rate versus $\left(\mathrm{T}_{\mathrm{S} \text {, avg }}-\mathrm{T}_{\mathrm{Hx}, \mathrm{i}}\right)$. It shows that the heat transfer rate was generally independent of how the temperature difference was reached but was a strong function of the flow rate. The initial temperature differences are determined by the right end of each curve. These curves are quite useful for the heat exchangers tested because the results are not strongly dependent on how the temperature difference was achieved. 


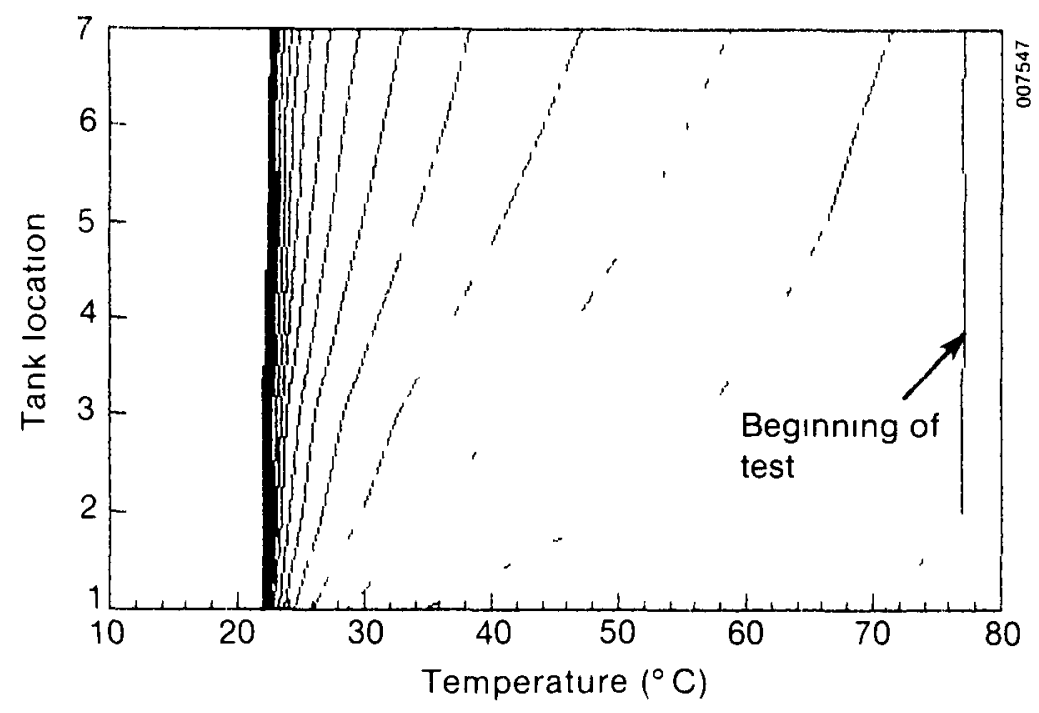

(a) Tank temperature profile for original finned coil, $5 \mathrm{~L} / \mathrm{min}$, at start of test and every $30 \mathrm{~min}$

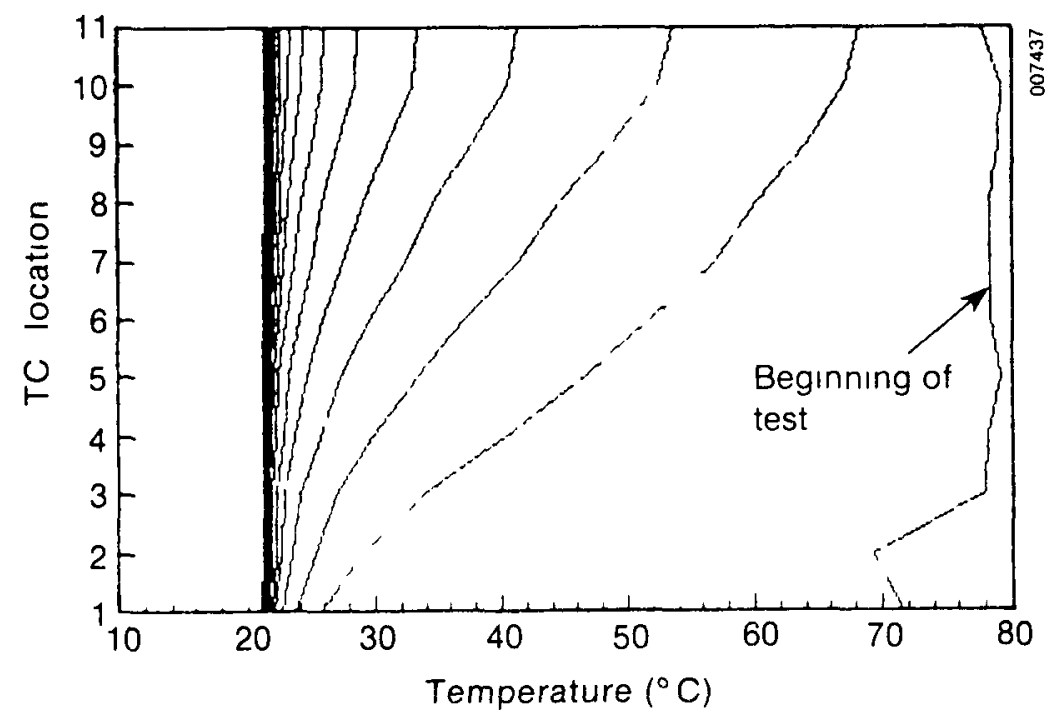

(b) Heat exchanger temperature profile for original finned coil, $5 \mathrm{~L} / \mathrm{min}$, at start of test and every $30 \mathrm{~min}$

Figure 4-1. Typical Temperature Profiles 


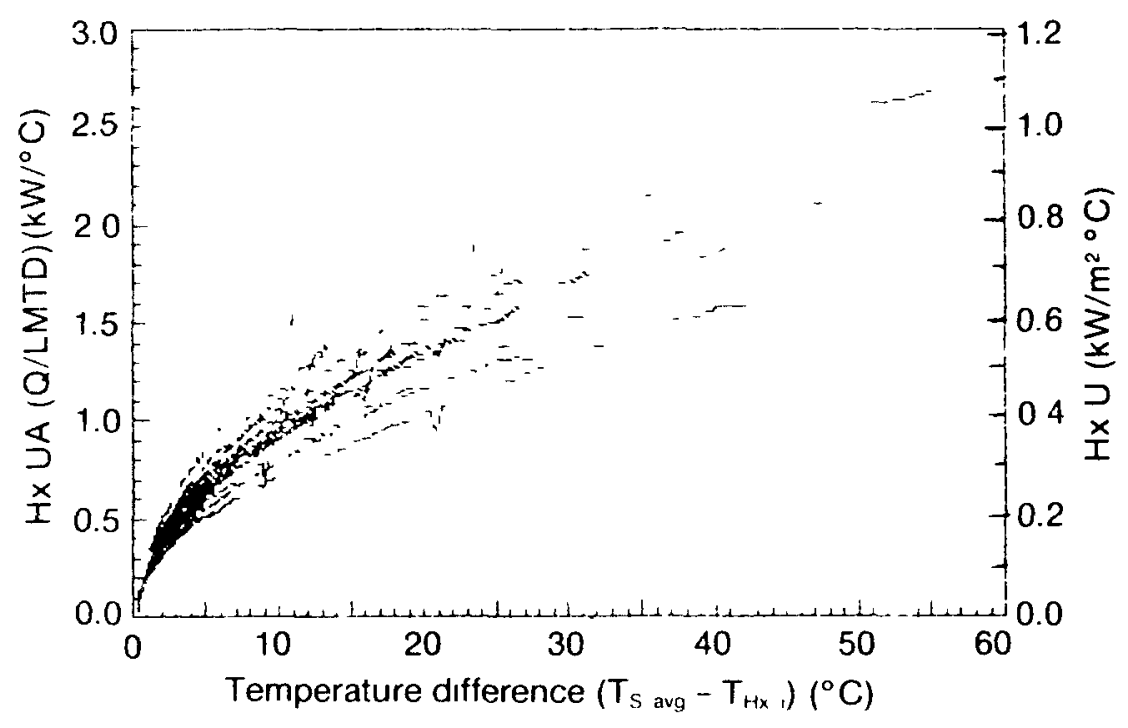

(a) Original smooth heat exchanger

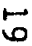

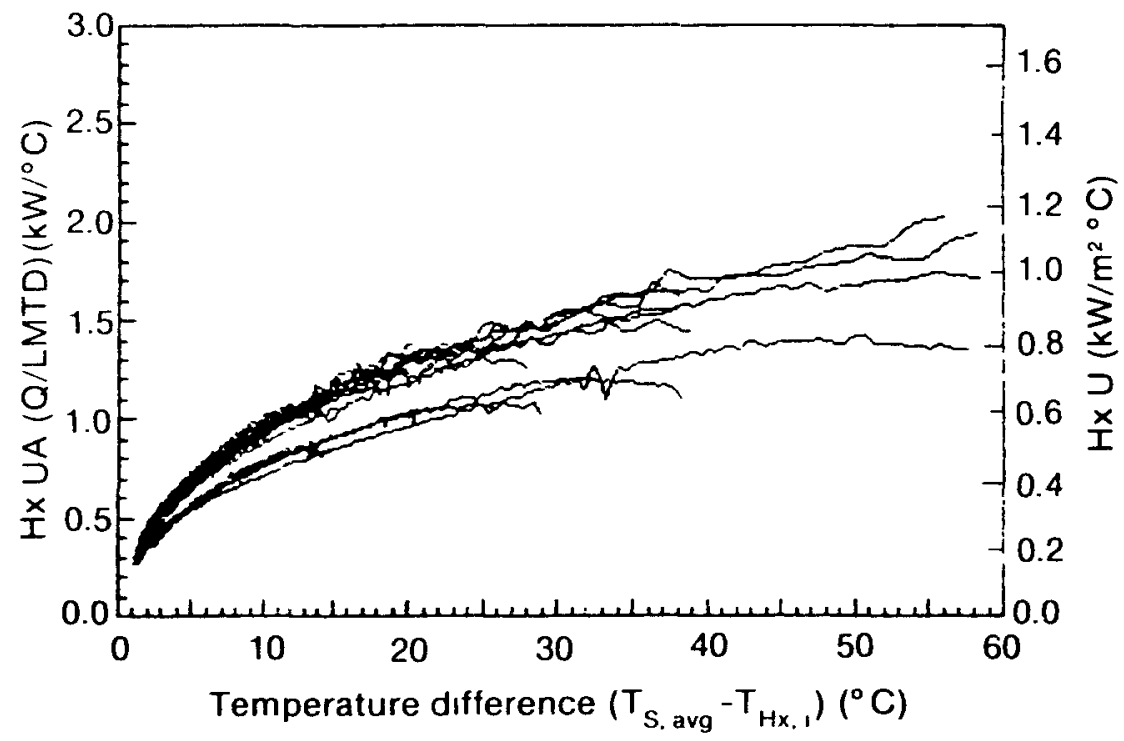

(c) Reduced smooth heat exchanger

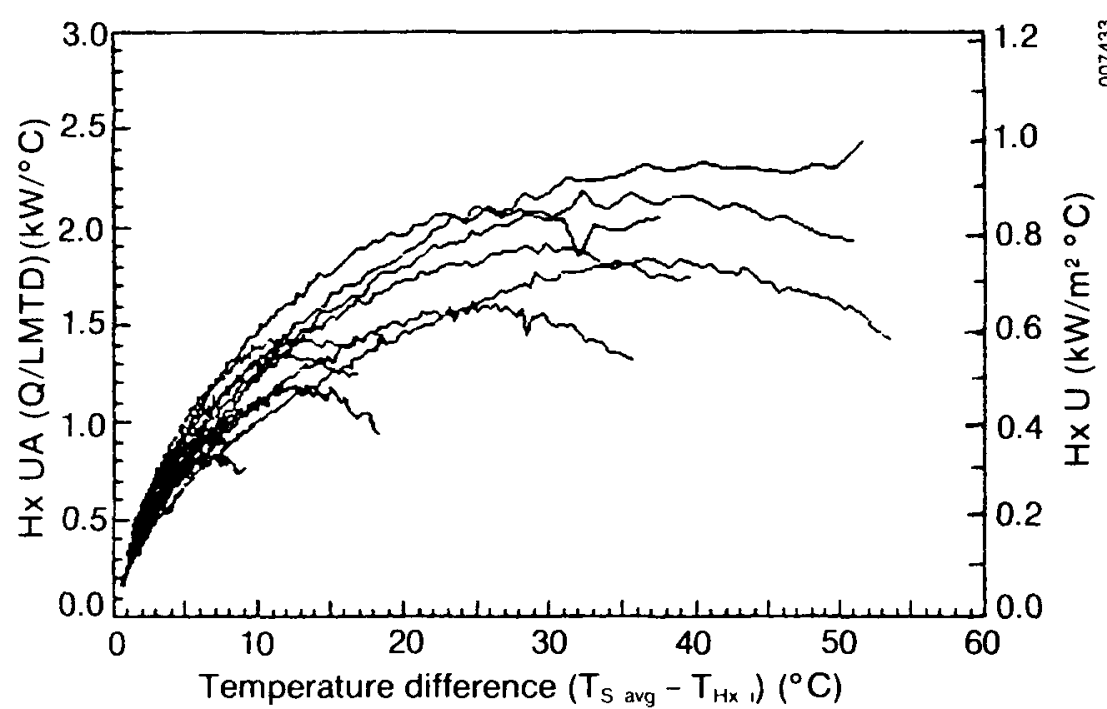

(b) Original finned heat exchanger

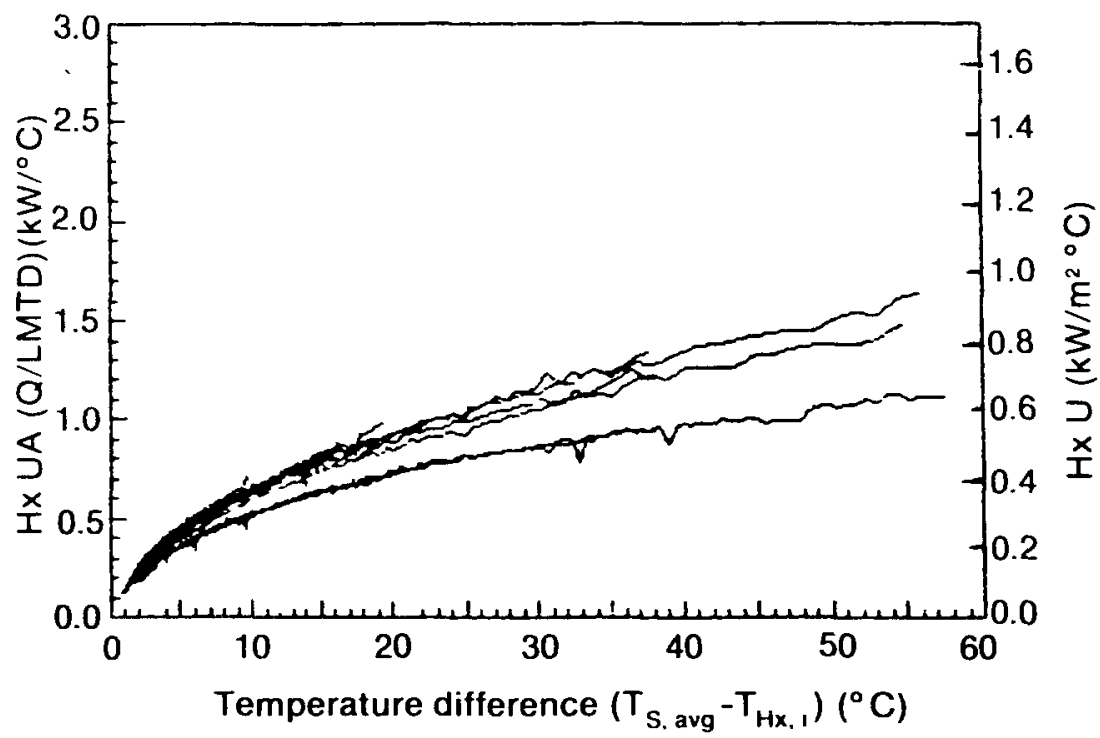

(d) Reduced finned heat exchanger

Figure 4-2. Heat Exchanger $U A$ and $U$ versus $\left(T_{S, a v g}-T_{H x, i}\right)$ by Heat Bxchanger Type 


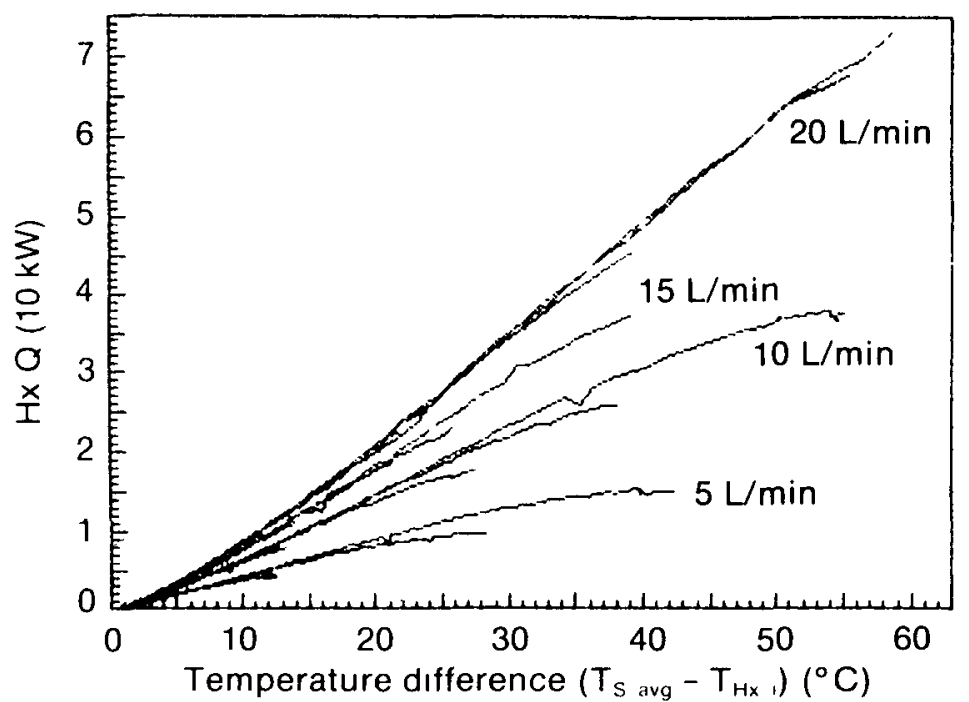

(a) Original smooth heat exchanger

(c) Reduced smooth heat exchanger

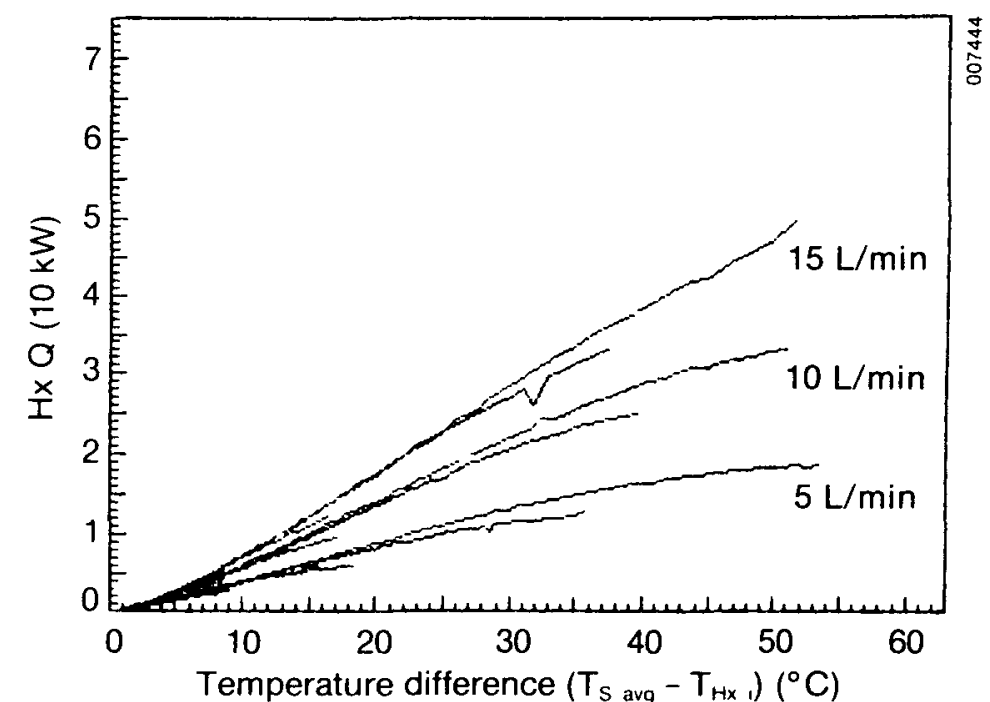

(b) Original finned heat exchanger

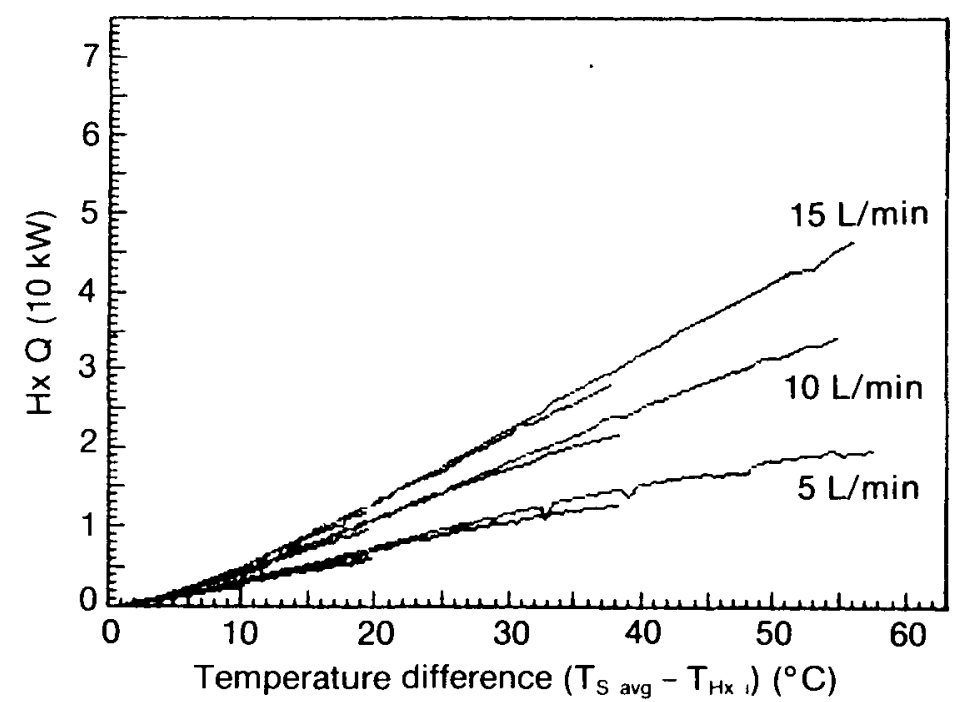

(d) Reduced finned heat exchanger

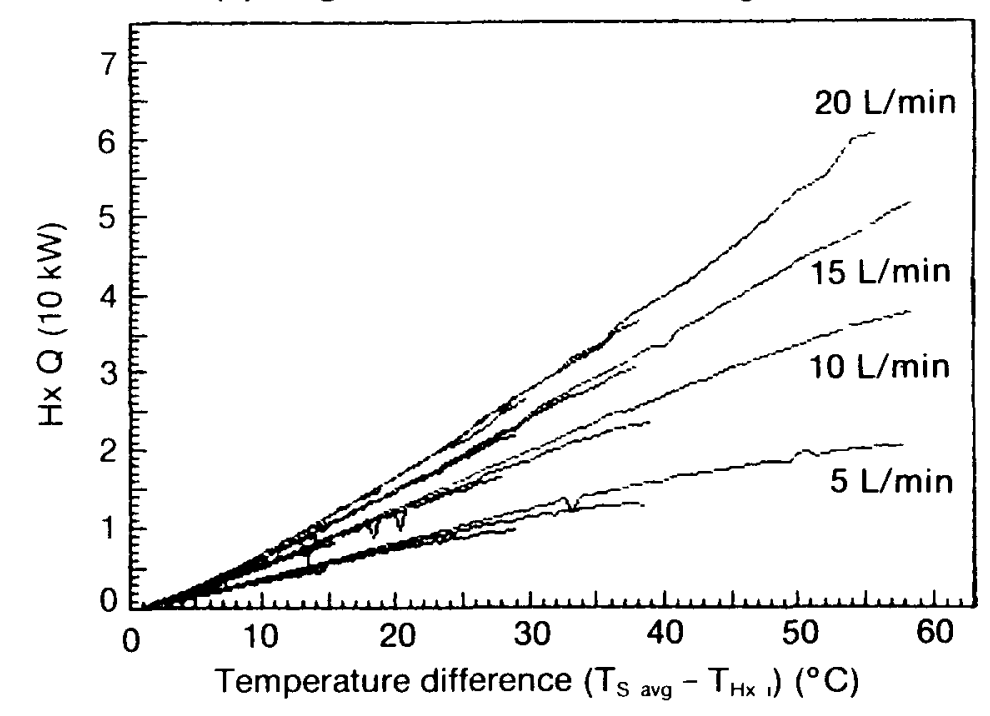

Figure 4-3. Heat Transfer Rate versus $\left(T_{S, \text { avg }}-T_{H x}, i\right)$ by Heat Exchanger Type 
One can observe from Figure 4-3 that the heat transfer rate is higher for the stratified tank than for the mixed tank. For example, consider the original finned heat exchanger (Figure 4-3b). The tanks were essentially isothermal at the start of a test. The tests at highest temperature differences, for all three flow rates, began at about $53^{\circ} \mathrm{C}\left(95^{\circ} \mathrm{F}\right)$. The tests at next lowest temperature differences began at $36^{\circ}-39^{\circ} \mathrm{C}\left(65^{\circ}-70^{\circ} \mathrm{F}\right)$. The initial heat transfer rates of the tests at the lower initial temperature differences were lower than the heat transfer rates of the tests at the higher initial temperature difference tests near the same temperature differences of about $35^{\circ}-39^{\circ} \mathrm{C}$ $\left(63^{\circ}-70^{\circ} \mathrm{F}\right)$. For the tests at the lower of the two initial sets of temperature differences, the tank was at a uniform temperature (since the test was just beginning), while the tank at the higher initial temperature differences was stratified by the time it reached $36^{\circ}-39^{\circ} \mathrm{C}\left(65^{\circ}-70^{\circ} \mathrm{F}\right)$. When stratified, the top of the tank is hotter than the average, leading to a higher heat exchanger outlet temperature. This pattern was also true of the other two lower initial temperature differences of about $8^{\circ}$ and $17^{\circ} \mathrm{C}\left(14^{\circ}\right.$ and $\left.31^{\circ} \mathrm{F}\right)$. However, as the temperature difference decreased from its initial condition, the tank stratified and the differences caused by the initial condition disappeared. This result was common to all four heat exchangers tested.

It would be possible to extrapolate the results for flow rates other than those tested. However, the change in flow rate does not cause a linear change in heat transfer rate based on the temperature difference in Figure 4-3. An examination of Figure $4-3 c$ shows that the difference in flow rates is not 1 inearly proportional to the difference in the heat transfer rate. For example, at a temperature difference of $25^{\circ} \mathrm{C}\left(45^{\circ} \mathrm{F}\right)$, changing the flow rate from 5 to $10 \mathrm{~L} / \mathrm{min}(1.3$ to $2.6 \mathrm{gal} / \mathrm{min}$ ) has a much more significant effect than changing it from 15 to $20 \mathrm{~L} / \mathrm{min}(4.0$ to $5.2 \mathrm{gal} / \mathrm{min})$.

The effect of flow rate can be determined from Figure 4-3. As expected, heat transfer rates increased with higher flow rates.

The flow rate dependency is removed from the curves by plotting the heat transfer rate against the LMTD as in Figure 4-4. The LMTD contains the heat exchanger outlet temperature and is therefore related to the flow rate. Plotting the data in this manner also removes the effect of the initially wellmixed tank, for the two reduced-area heat exchangers. The relative performance of the heat exchangers can be determined by comparing the heat transfer rate versus LMTD as shown in Figure 4-5. The original smooth heat exchanger is not included due to failure of some of the thermocouples on the heat exchanger which were needed to calculate the LMTD. The original fin had a higher heat transfer rate because of the larger heat transfer area. The reduced-area smooth-coil heat exchanger transferred heat much more effectively than did the finned exchanger that had the same heat transfer area.

The best correlation is perhaps also the most difficult to use. It is the correlation between the Nusselt and Rayleigh numbers, shown in Figure 4-6 by heat exchanger type. The original smooth-coil heat exchanger is not shown because of instrumentation problems with the thermocouples on the heat exchanger. The correlations include all the flow rates tested at all the initial temperature differences. The correlations for a given heat exchanger are remarkably close. The heat exchangers are compared to each other in Figure 4-7. What was surprising was that the reduced-area smooth-coil heat exchanger had higher Nusselt numbers than the larger, original finned-coil 

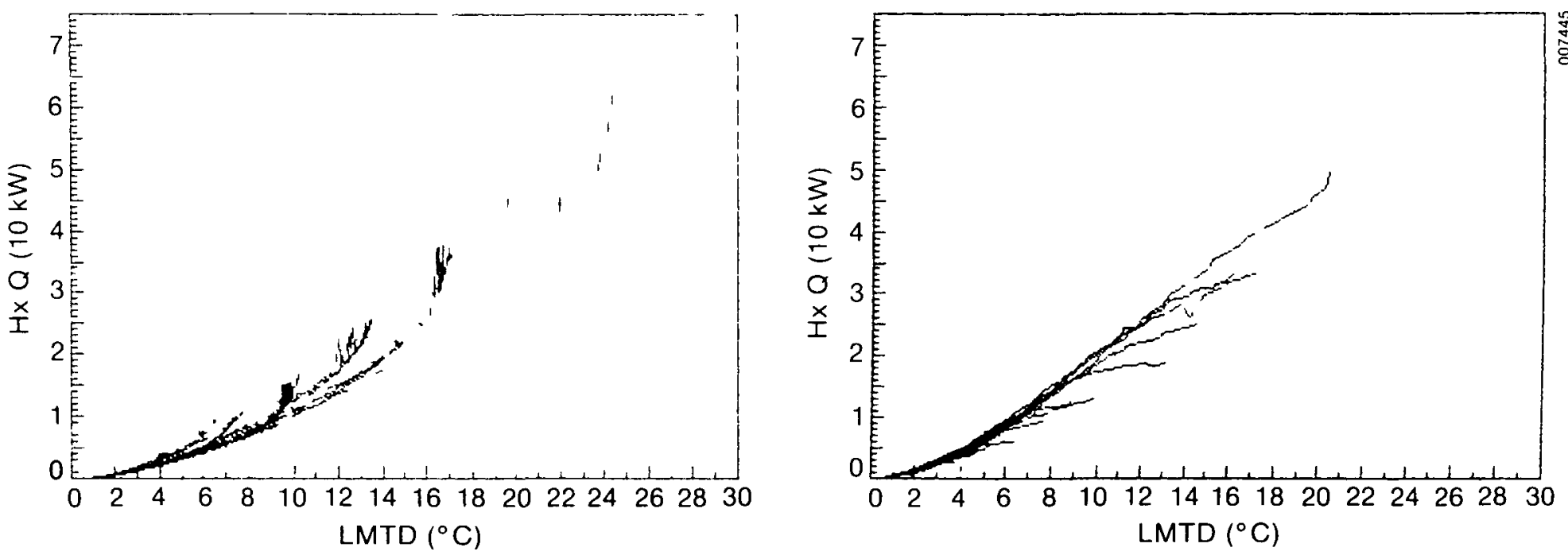

(a) Original smooth heat exchanger

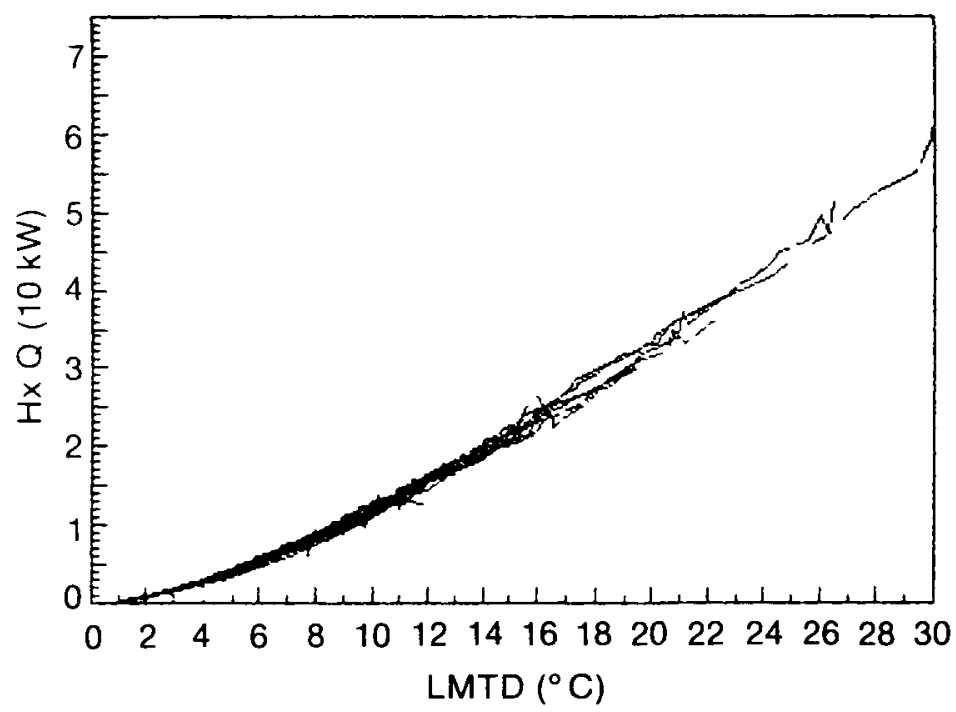

(c) Reduced smooth heat exchanger

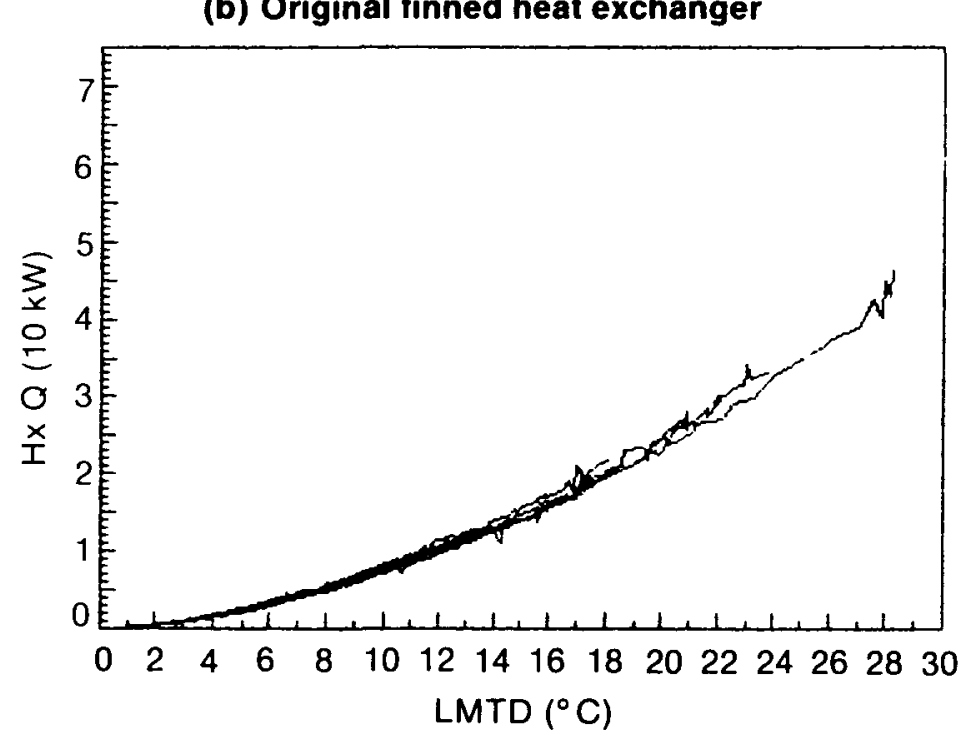

(d) Reduced finned heat exchanger

Figure 4-4. Heat Transfer Rate versus L.MTD by Heat Exchanger Type 


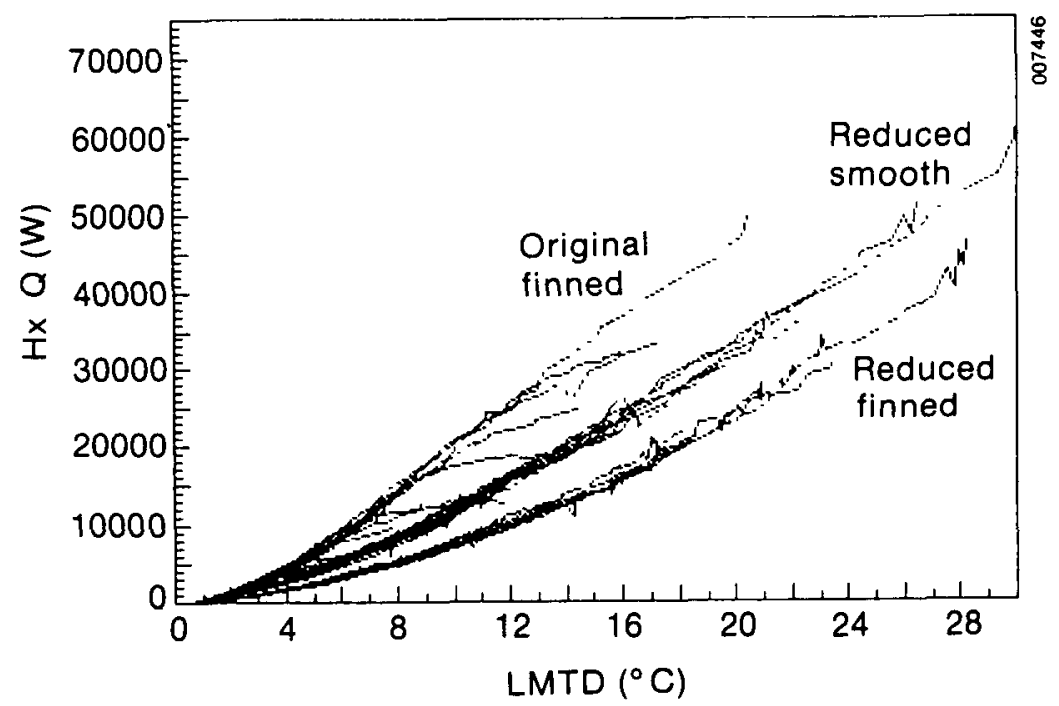

Figure 4-5. Heat Transfer Rate vergus LMTD for Three Heat Exchangers heat exchanger over the range of Rayleigh numbers tested. Since the results are plotted on a logarithmic scale (base 10), the differences are even greater than they may seem in the graph. The smooth coil performed about $25 \%$ better. However, the actual overall convective heat transfer coefficient, ho (see eq. 2-8, Table 2-1), was about the same for these two heat exchangers since there was about a $25 \%$ difference in the pipe diameters.

Comparing results on this graph may not seem easy at first. The Rayleigh number may be considered as a type of potential. It is a measure of the buoyancy force created by the temperature difference between the coil and the tank and causes the natural convection flow. The Nusselt number is a measure of the convective heat transfer from the tank to the coil. Generally, as the Rayleigh number increases, the velocity past the outside of the tube increases and the natural convective heat transfer coefficient increases. The heat exchangers may be compared at a particular operating point (such as a Rayleigh number) by examining the corresponding Nusselt number, which represents the heat transfer.

The magnitude of the Nusselt number is an indication of the ratio of the convective heat transfer rate to the conductive heat transfer rate through the fluid. A Nusselt number of 1 indicates that the convection is occurring at the same rate as conduction. In forced convection flows the Nusselt number is very high (on the order of several hundred). In a case of pure conduction, the Nusselt number is equal to 1 . These test results showed that the convective heat transfer coefficient was strongly dependent on the operating conditions and varied from about 50 to more than $1300 \mathrm{~W} / \mathrm{m}^{2}{ }^{\circ} \mathrm{C}$ $\left(9-230 \mathrm{Btu} / \mathrm{h} \mathrm{ft}{ }^{2}{ }^{\circ} \mathrm{F}\right)$. The conductivity of water changed less than $15 \%$ over the temperature ranges during the tests. The analysis accounted for the temperature dependence of all the required water properties.

The Nusselt number in our tests ranged from 1 to about 35 for corresponding Rayleigh numbers of $6.3 \times 10^{4}$ to $7.9 \times 10^{6}$. Generally, the Nusselt number did not fall below 3 or 4 near the end of a test. The data at the lower left end of Figure 4-7 are from an extended 8-h test. Near the end of a test, where the low Nusselt numbers occurred, the temperature rise across the heat exchanger was about $1^{\circ} \mathrm{C}\left(2^{\circ} \mathrm{F}\right)$ and the heat transfer rate was on the order of 300-400 $\mathrm{W}(1000-1360 \mathrm{Btu} / \mathrm{h})$. Even at these very low heat transfer rates, some convection heat transfer occurs. 


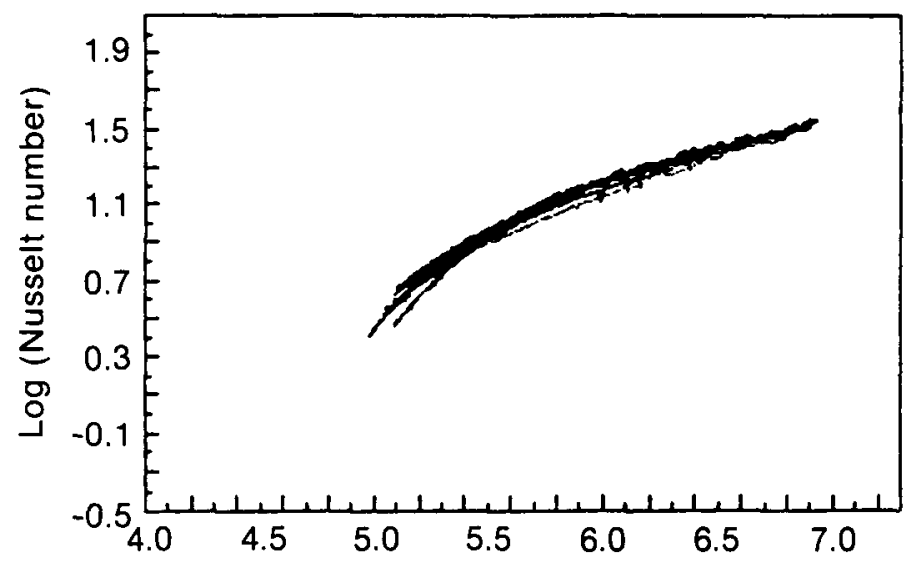

(a) Reduced smooth heat exchanger

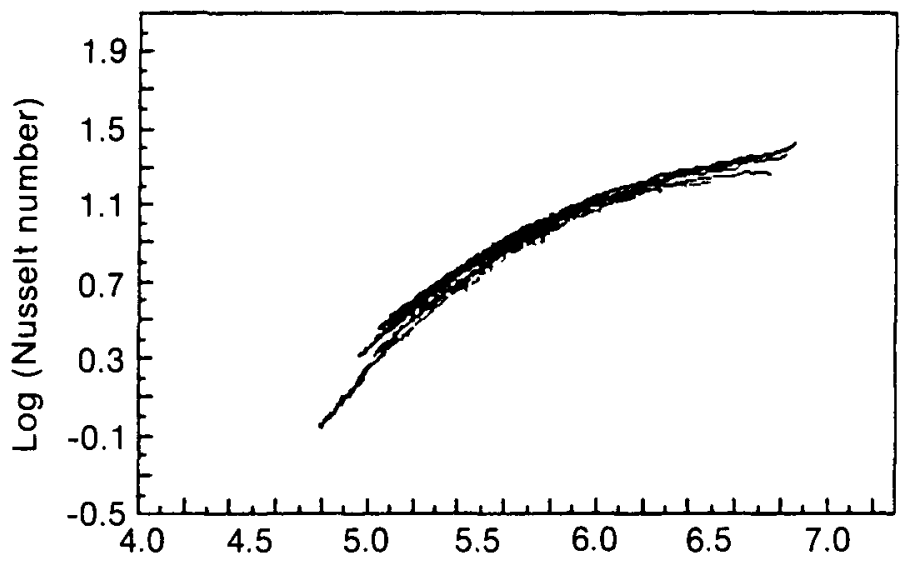

(b) Original finned heat exchanger

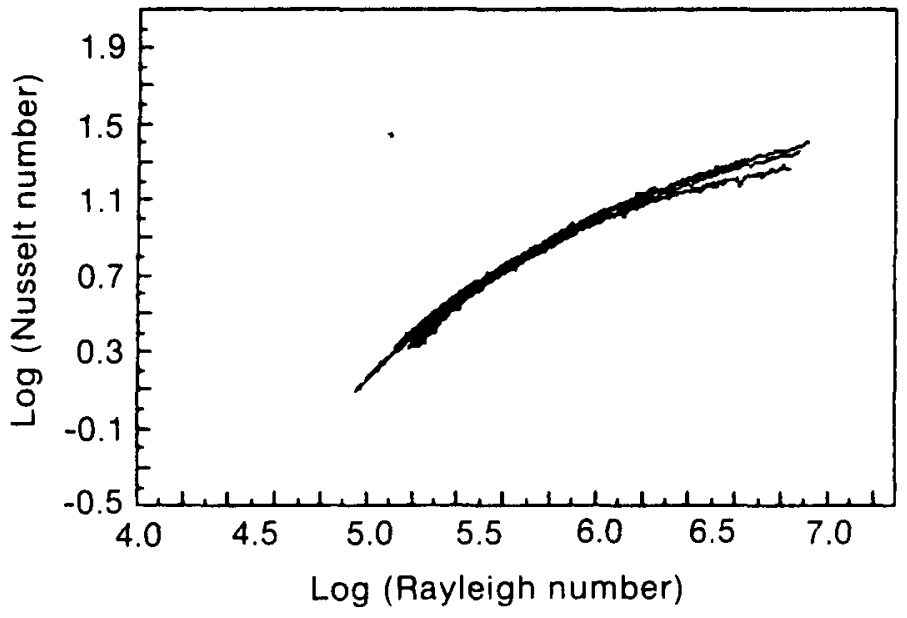

(c) Reduced finned heat exchanger

Figure 4-6. Nusselt/Rayleigh Correlations by Heat Exchanger Type 


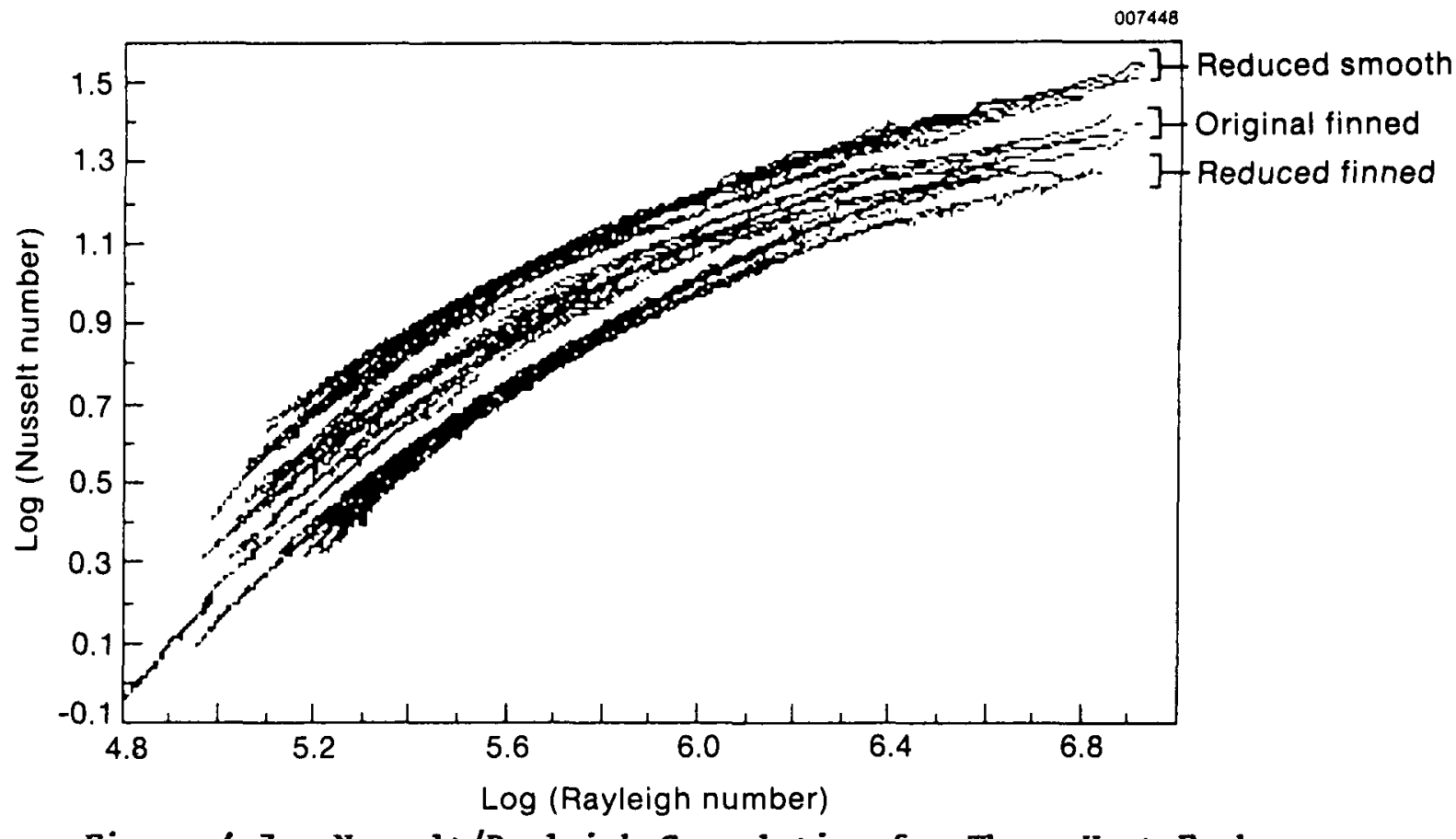

Figure 4-7. Nusselt/Rayleigh Correlation for Three Heat Exchangers

The Nusselt and Rayleigh numbers are related by an empirical factor " $C$ " (see Eq. 4-1). This factor should differ among various heat exchanger geometries. Figure 4-8 shows the factor $C$ for three of the heat exchangers we tested for all the flow rates and initial temperature differences. The factor $C$ is not a strong function of heat exchanger flow rate or initial temperature difference. However, the factor $C$ does vary with the LMTD, which makes it difficult to choose the proper C-value. It is easy to observe from Figure 4-8 that the relationship between the logarithms of the $\overline{\mathrm{Nu}}$ and $\overline{\mathrm{Ra}}$ numbers is not linear and therefore the simple equation

$$
\overline{\mathrm{Nu}}=\mathrm{C} \overline{\mathrm{Ra}^{\mathrm{m}}}
$$

is inadequate to properly fit the data. Taking the logarithm of each side of eq. 2-13 leads to

$$
\log _{10} \mathrm{Nu}=\operatorname{mog}_{10} \mathrm{Ra}+\mathrm{C},
$$

where $m$ is the slope of the curve in Figure 4-7 and $C$ is the intercept of the ordinate. One can see from this figure that the slope $m$ is not constant, which is one of the reasons the calculated value of $C$ varies for a specific curves heat exchanger in these tests. For a heat exchanger in a mixed tank, the curves would be nearly linear and parallel (Farrington and Bingham 1986). The change in $C$ would shift the entire curve up or down but not change its slope. To adequately account for the tank stratification, the factor $m$ needs to be modified.

If the heat transfer in a given system will generally occur above about $6^{\circ} \mathrm{C}$ $\left(11^{\circ} \mathrm{F}\right)$, then an average $\mathrm{C}$ value may be chosen. At the lower LMTDs the C-value is strongly dependent on the LMTD. Only a small portion of the overall heat transfer occurs at the very low LMTDs. The C-values are plotted as a function 


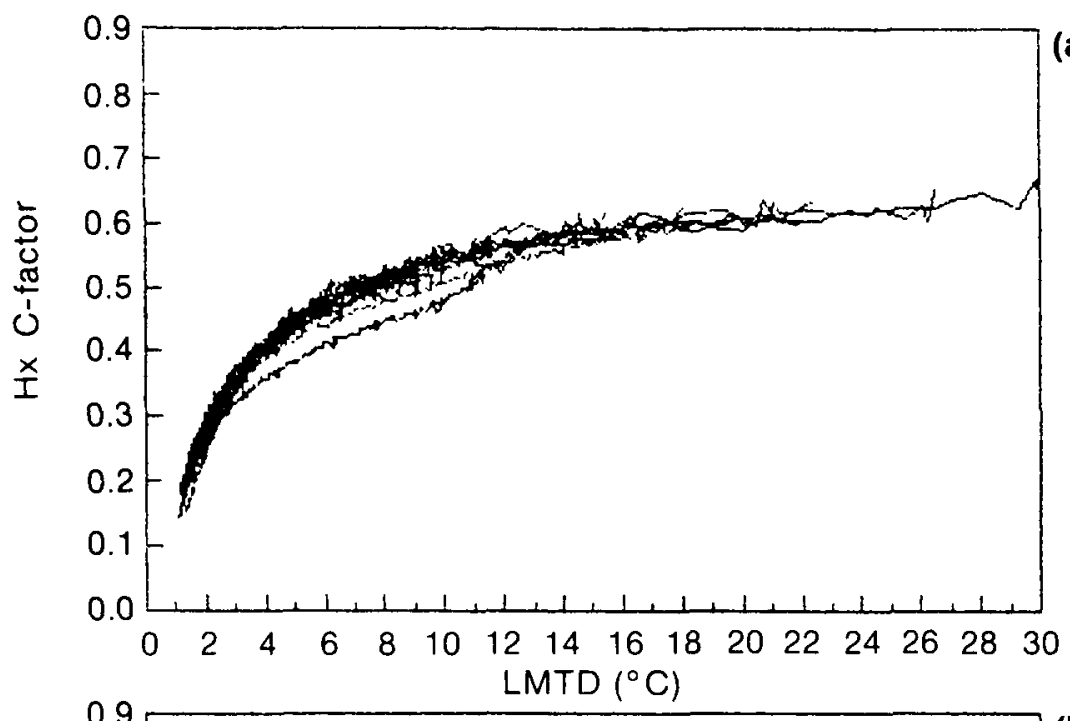

(a) Reduced smooth heat exchanger

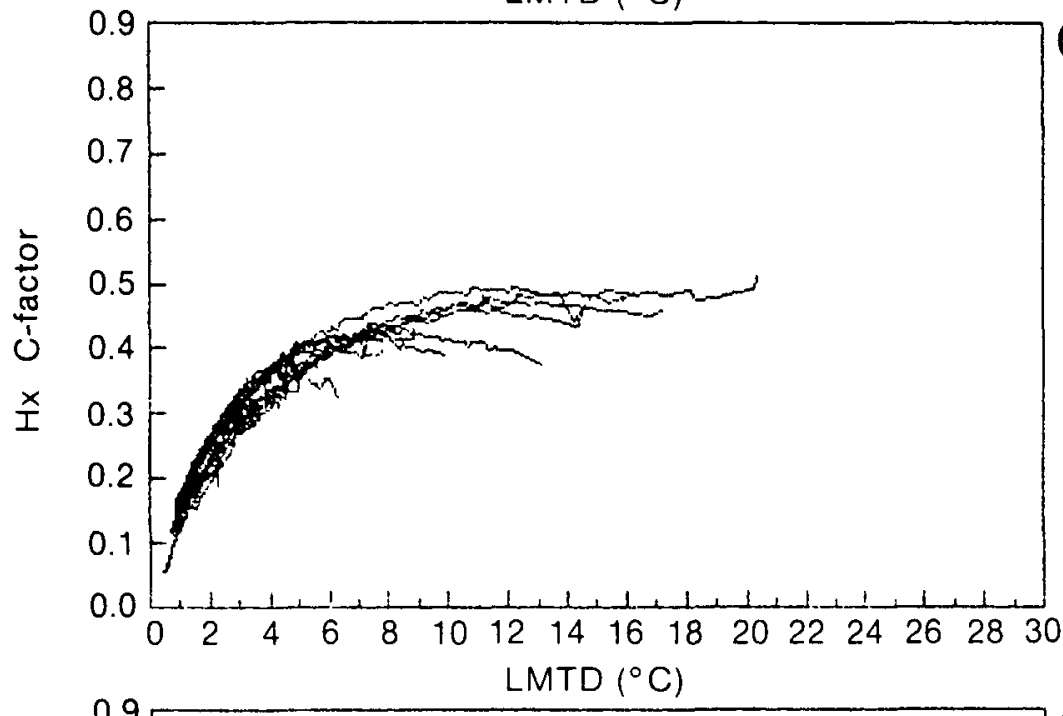

(b) Original finned heat exchanger

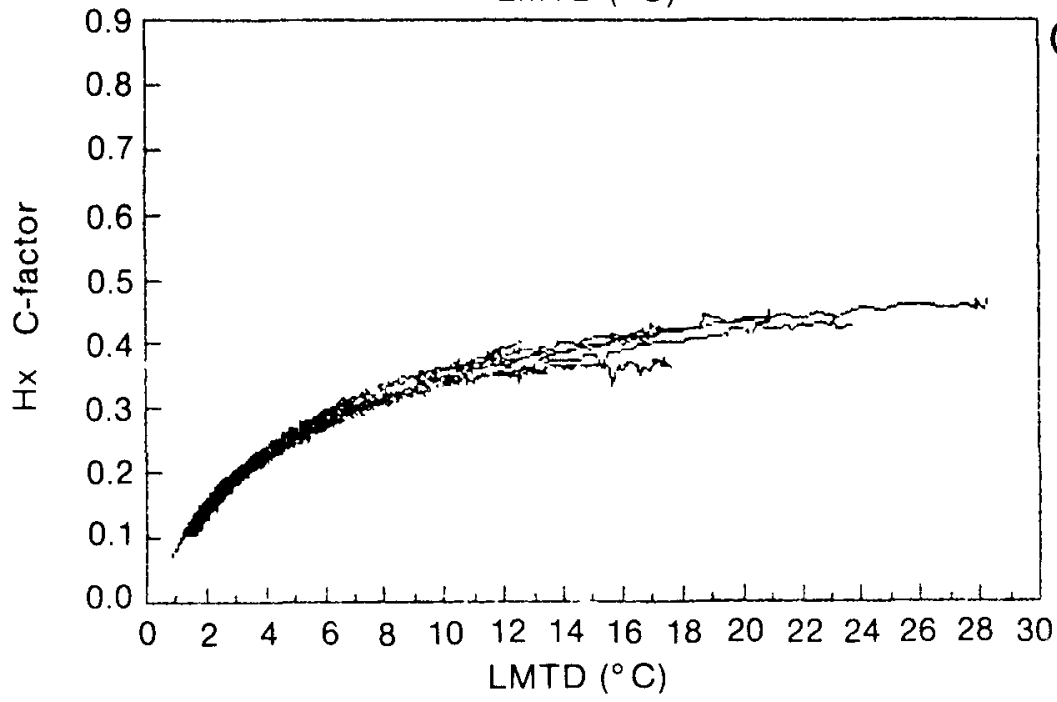

(c) Reduced finned heat exchanger

Figure 4-8. Heat Exchanger C-Factor versus LMTD by Heat Exchanger Type 
of $\left(\mathrm{T}_{\mathrm{S}, \text { avg }}-\mathrm{T}_{\mathrm{Hx}, \mathrm{i}}\right)$ in Figure $4-9$ and, although they have more spread than the $C$ versus IMTD curves, are easier to use since the average tank temperature can be calculated from an energy balance and the heat exchanger inlet temperature is generally known.

The Nusselt-Rayleigh correlations depend on the LMTD since the Rayleigh number was calculated using the LMTD. The LMTD was used because it accounts for the nonlinear temperature distributions in the storage tank and along the heat exchanger. Hence, although Figures $4-6$ and 4-7 show good correlations, they are not particularly useful to designers because if the designers know the LMTD then they have more than enough information already to calculate the heat transfer rate.

Since modeling is complicated by the temperature stratification in the storage tank, we also considered using time constants to characterize the performance of a load-side heat exchanger. We defined the time constant to be the time it took the heat transfer rate to drop to $63.2 \%$ of its initial value. The results are shown in Table 4-3.

A plot of the time constants versus flow rate is given in Figure 4-10. The best-fit curves were power curves of the form

$$
\tau=\mathrm{AV}^{-\mathrm{b}} \text {, }
$$

where the coefficients are given in Table 4-4. The residuals for the curve are given in Table 4-5. The residuals are for the average time constant which, as seen in Table 4-3, can have variations of several minutes from the time constants for particular test runs. The difficulty in calculating the time constant accurately comes from variations in the flow rate, time response of the sensors, and data collection rate. Changing the selection of the initial heat transfer rate by $1 \mathrm{~min}$ can result in a change in the time constant of 5 min or more.

This approach, although simple, may not be particularly accurate. The better heat exchanger should result in the lowest time constant since it would remove energy the quickest. There is no consistency in the order of the time constants. Our tests were not developed to measure this parameter. The time constant approach could be a useful tool if data collection rates were quicker. A further discussion of how to use an effectiveness with this approach is given by Farrington (1986) and includes data from a solar spaceheating system. 


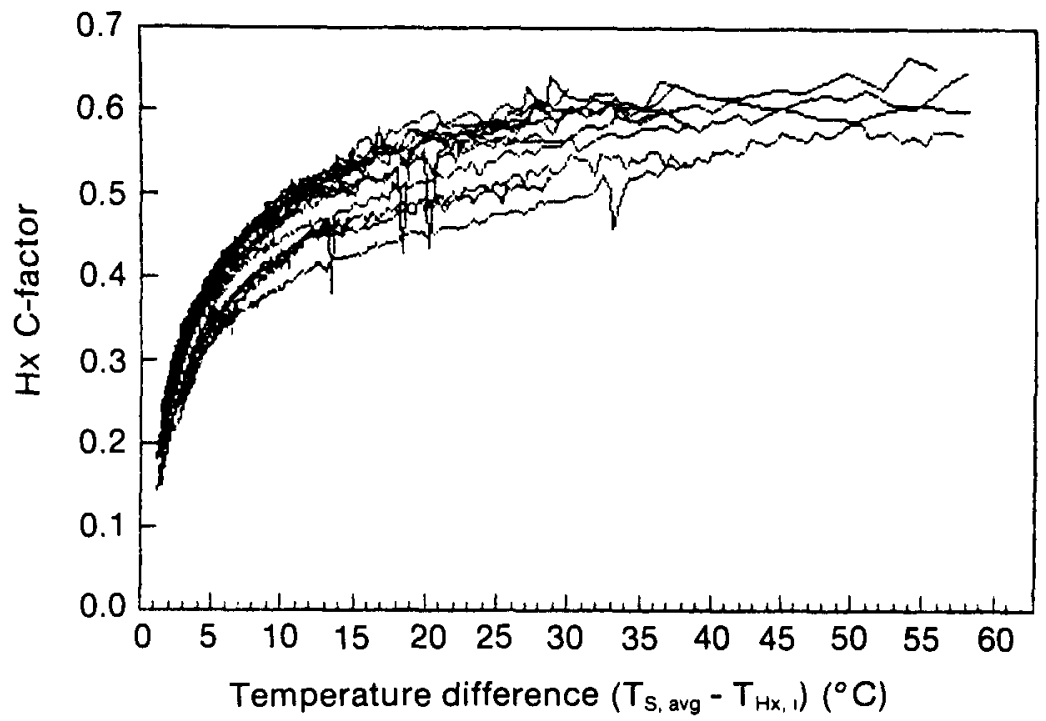

(a) Reduced smooth heat exchanger $\frac{0}{8}$

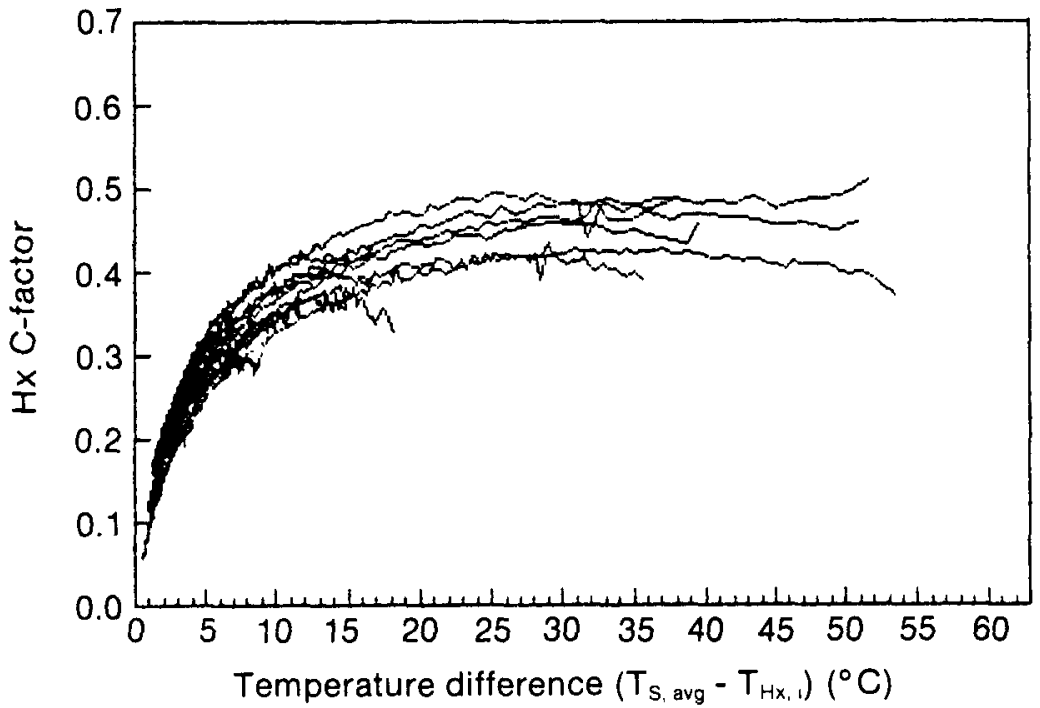

(b) Reduced finned heat exchanger

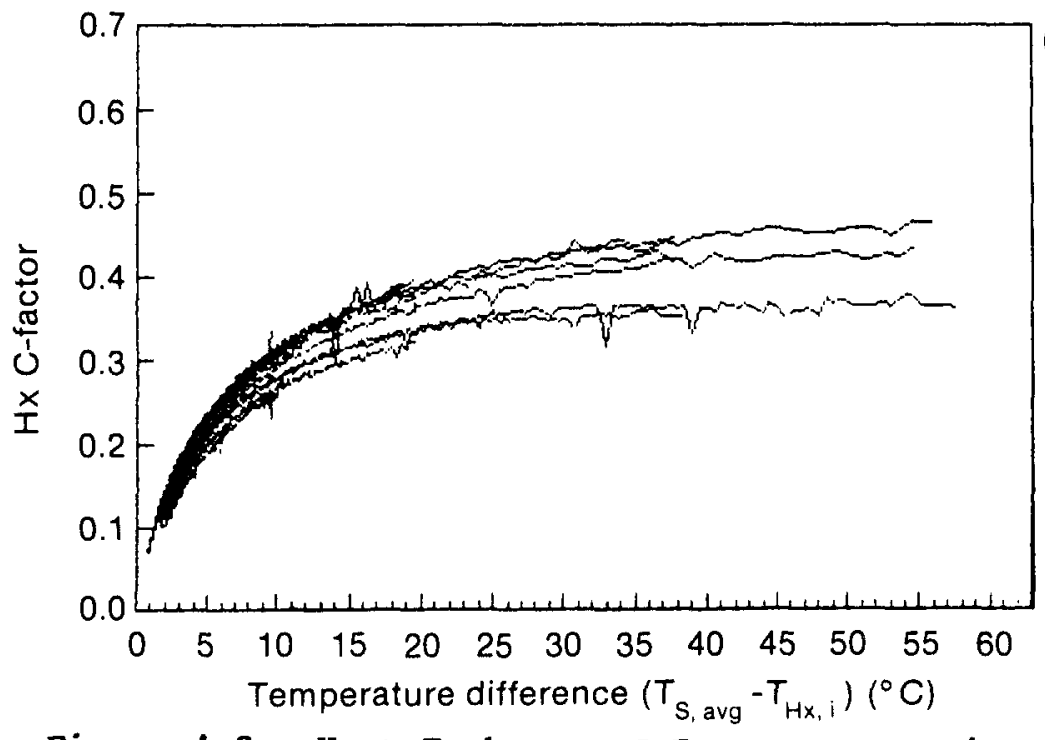

(c) Original finned heat exchanger

Figure 4-9. Heat Exchanger C-Factor versus $\left(\mathrm{T}_{\mathrm{S}, \text { avg }}-\mathrm{T}_{\mathrm{Hx}, \mathrm{i}}\right)$ by Heat
Exchanger Type 
Table 4-3. Heat Exchanger Time Constants (min)

\begin{tabular}{|c|c|c|c|c|c|}
\hline \multirow{2}{*}{$\begin{array}{c}\text { Heat } \\
\text { Exchanger }\end{array}$} & \multirow{2}{*}{$\begin{array}{c}\text { Initial } \\
\text { Temperature } \\
\text { Difference }\end{array}$} & \multicolumn{4}{|c|}{ Flow Rate (L/min) } \\
\hline & & 5 & 10 & 15 & 20 \\
\hline \multirow[t]{2}{*}{ Original smooth } & $\begin{array}{l}\text { low } \\
\text { medium } \\
\text { high } \\
\text { very high }\end{array}$ & $\begin{array}{l}57.2 \\
52.6 \\
52.9 \\
-- \\
\end{array}$ & $\begin{array}{l}21.9 \\
23.9 \\
21.1 \\
21.8 \\
\end{array}$ & $\begin{array}{l}17.2 \\
15.1 \\
14.6 \\
-- \\
\end{array}$ & $\begin{array}{l}13.8 \\
12.4 \\
10.7 \\
11.0 \\
\end{array}$ \\
\hline & average & 54.2 & 22.2 & 15.6 & 12.0 \\
\hline \multirow[t]{2}{*}{ Reduced smooth } & $\begin{array}{l}\text { low } \\
\text { medium } \\
\text { high } \\
\text { very high }\end{array}$ & $\begin{array}{l}44.2 \\
44.5 \\
45.9 \\
-- \\
\end{array}$ & $\begin{array}{l}22.6 \\
21.7 \\
22.0 \\
22.1 \\
\end{array}$ & $\begin{array}{l}17.3 \\
16.2 \\
14.3 \\
-- \\
\end{array}$ & $\begin{array}{r}16.9 \\
12.3 \\
11.7 \\
9.6 \\
\end{array}$ \\
\hline & average & 44.9 & 22.1 & 15.9 & 12.6 \\
\hline \multirow[t]{2}{*}{ Original finned } & $\begin{array}{l}\text { low } \\
\text { medium } \\
\text { high } \\
\text { very high }\end{array}$ & $\begin{array}{l}46.3 \\
46.0 \\
46.5 \\
48.9 \\
\end{array}$ & $\begin{array}{l}23.8 \\
23.8 \\
22.8 \\
23.2 \\
\end{array}$ & $\begin{array}{l}17.6 \\
15.1 \\
14.1 \\
13.5 \\
\end{array}$ & $\begin{array}{l}-- \\
-- \\
-- \\
-- \\
\end{array}$ \\
\hline & average & 46.9 & 23.2 & 15.1 & -- \\
\hline \multirow[t]{2}{*}{ Reduced finned } & $\begin{array}{l}\text { low } \\
\text { medium } \\
\text { high } \\
\text { very high }\end{array}$ & $\begin{array}{l}39.0 \\
41.9 \\
44.9 \\
46.3 \\
\end{array}$ & $\begin{array}{l}28.2 \\
24.5 \\
22.9 \\
22.0 \\
\end{array}$ & $\begin{array}{l}20.1 \\
17.0 \\
15.6 \\
14.5 \\
\end{array}$ & $\begin{array}{l}-- \\
-- \\
-- \\
-- \\
\end{array}$ \\
\hline & average & 43.0 & 24.4 & 16.8 & -- \\
\hline
\end{tabular}

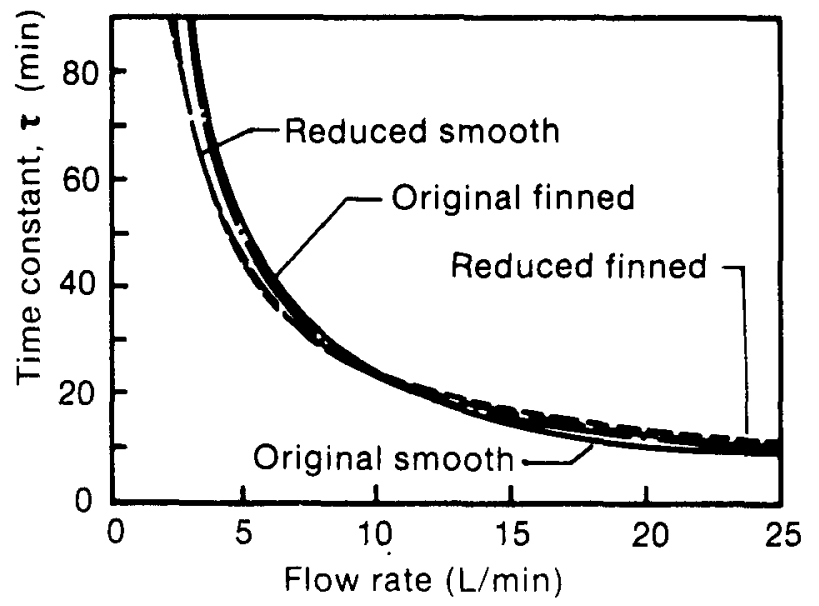

Figure 4-10. Heat Exchanger Time Constants 
Table 4-4. Heat Exchanger Time Constant Coefficients

\begin{tabular}{lccc}
\hline \multirow{2}{*}{ Heat Exchanger } & \multicolumn{2}{c}{ Coefficients } & \multirow{2}{*}{$\mathrm{R}^{2^{\mathrm{a}}}$} \\
\cline { 2 - 3 } & $\mathrm{A}$ & $\mathrm{b}$ & \\
\hline Original smooth coil & 298.491 & -1.089 & 0.990 \\
$70 \%$ smooth coil & 192.101 & -0.918 & 0.996 \\
Original finned coil & 246.707 & -1.030 & 1.000 \\
$70 \%$ finned coil & 170.334 & -0.851 & 0.999 \\
\hline
\end{tabular}

a $R^{2}$ is one measure of how well a particular curve is fitted to the data. Generally, the fit is better as $\mathrm{R}^{2}$ approaches 1 .

Table 4-5. Residuals from Time Constant Curve Fits

\begin{tabular}{|c|c|c|c|c|}
\hline $\begin{array}{c}\text { Heat } \\
\text { Exchanger }\end{array}$ & $\begin{array}{c}\text { Flow } \\
\text { Rate } \\
\text { (L/min) }\end{array}$ & $\begin{array}{c}\tau_{\text {actual }} \\
(\min )\end{array}$ & $\begin{array}{c}\tau^{\tau} \text { calculated } \\
(\min )\end{array}$ & $\begin{array}{l}\text { Residual } \\
\quad(\min )\end{array}$ \\
\hline Original smooth coil & $\begin{array}{r}5 \\
10 \\
15 \\
20\end{array}$ & $\begin{array}{l}54.2 \\
22.2 \\
15.6 \\
12.0\end{array}$ & $\begin{array}{l}51.8 \\
24.3 \\
15.6 \\
11.4\end{array}$ & $\begin{array}{r}2.4 \\
-2.1 \\
0.0 \\
0.6\end{array}$ \\
\hline $70 \%$ smooth coil & $\begin{array}{r}5 \\
10 \\
15 \\
20\end{array}$ & $\begin{array}{l}44.9 \\
22.1 \\
15.9 \\
12.6\end{array}$ & $\begin{array}{l}43.8 \\
23.2 \\
16.0 \\
12.3\end{array}$ & $\begin{array}{r}1.1 \\
-1.1 \\
-0.1 \\
0.3\end{array}$ \\
\hline Original finned coil & $\begin{array}{r}5 \\
10 \\
15\end{array}$ & $\begin{array}{l}46.9 \\
23.2 \\
15.1\end{array}$ & $\begin{array}{l}47.0 \\
23.0 \\
15.2\end{array}$ & $\begin{array}{r}-0.1 \\
0.2 \\
-0.1\end{array}$ \\
\hline $70 \%$ finned coil & $\begin{array}{r}5 \\
10 \\
15\end{array}$ & $\begin{array}{l}43.0 \\
24.4 \\
16.8\end{array}$ & $\begin{array}{l}43.3 \\
24.0 \\
17.0\end{array}$ & $\begin{array}{r}-0.3 \\
0.4 \\
-0.2\end{array}$ \\
\hline
\end{tabular}




\subsection{NUMERICAL MODEL AND COMPARISON WITH EXPERIMENTAL RESULTS}

\subsection{Description of Model}

Experimental data from a limited number of configurations are inadequate to describe the performance of all load-side immersed-coil heat exchangers.

We developed a numerical model and validated it with our experimental results to analyze other configurations or conditions not able to be tested in the laboratory. Our objective was to build a simple model that would enable us to predict general trends of overall heat exchanger performance. No attempt was made to characterize in detail all heat transfer mechanisms present. For this analysis we developed a finite difference numerical model of the heat exchangers tested in the laboratory. The model used the MITAS (Conner et al. 1971) thermal analyzer program.

MITAS is a general-purpose program designed primarily to solve lumped parameter (i.e., resistor-capacitor $[R-C]$ ), network representations of thermal systems. It has the capability to solve large thermal networks (up to 8,200 nodes and 12,000 unique conductors). Users can interact with the network solution by providing their own logic to direct the program execution. This is done through a user input language very similar to FORTRAN but allows the user access to all the program variables during execution.

The model developed had 22 nodes to represent the tank fluid, heat exchanger tube, and tube fluid. Boundary conditions were the inlet fluid temperature and heat exchanger flow rate. The immersed coil-in-tank heat exchanger was modeled as seven vertically stacked, horizontal tube/fluid nodes surrounded by tank fluid volume nodes.

Many assumptions used in the model are apparent from the nodal schematic (Figure 5-1). There were no conductors from the tank to the ambient room air. This assumption of no tank losses was justified for several reasons. First, the measured heat loss from the tank was quite low, with a UA of $1.6 \mathrm{~W} /{ }^{\circ} \mathrm{C}\left(3.0 \mathrm{Btu} / \mathrm{h}{ }^{\circ} \mathrm{F}\right)$. Second, the time period of the test, up to $4 \mathrm{~h}$, was a short enough period that the heat loss from the tank did not play a major part, particularly as the driving temperature difference was relatively low during most of the test period.

We also did not include the conduction across the heat exchanger tube wall itself. The temperature drop across a $1.6-\mathrm{mm}$ copper tube wall was negligible when compared to the temperature drop on either side of the tube wall. We also assumed an axially adiabatic tube with no conduction down the length of the copper tube itself.

Finally, we assumed no mixing of the fluid in the tank itself. Test results showed a significant amount of stratification in the tank, indicating very little mixing of the tank fluid. We felt connecting the tank nodes with a simple conduction term would be sufficient for our purposes. The model allows only conduction from tank node to tank node. The fluid is not allowed to circulate. This is somewhat similar to the model of Jones et al. (1985). Parameters used in the model are 1 isted in Table 5-1. 


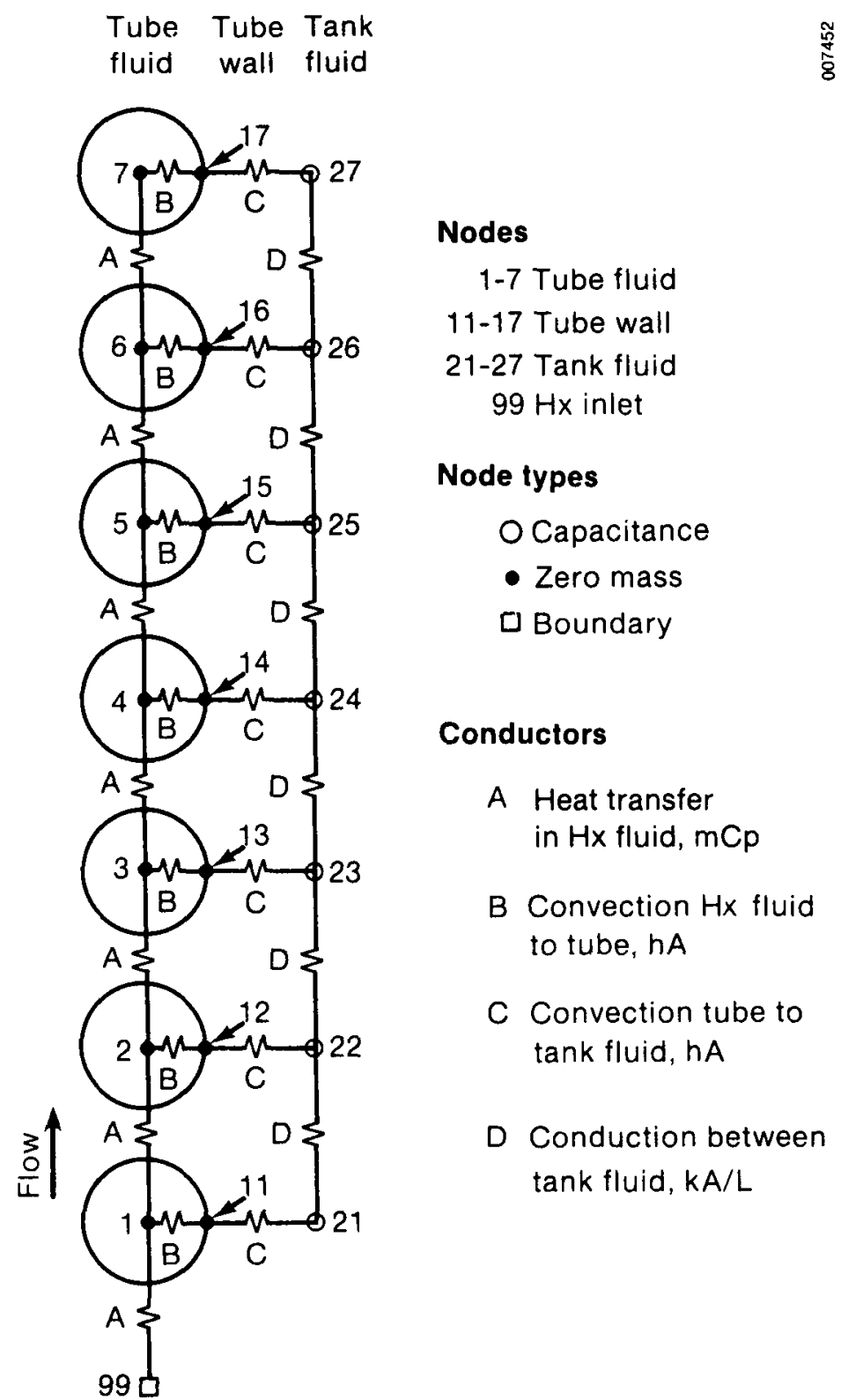

$\mathrm{Hx}$ inlet

Figure 5-1. Nodal Schematic of MITAS Heat Exchanger Model 
Table 5-1. Assumptions Used in Heat Exchanger Model

\begin{tabular}{|c|c|c|}
\hline Parameter & $\begin{array}{l}\text { Smooth Heat } \\
\text { Exchanger }\end{array}$ & $\begin{array}{c}\text { Finned Heat } \\
\text { Exchanger }\end{array}$ \\
\hline $\begin{array}{l}\text { Tank volume }\left(\mathrm{m}^{3}\right) \\
\text { Tank height }(\mathrm{m}) \\
\text { Tank radius }(\mathrm{m}) \\
\text { Heat exchanger flow } \\
\text { rate ( } \mathrm{L} / \mathrm{min}) \\
\text { Heat exchanger length }(\mathrm{m}) \\
\text { Heat exchanger outside } \\
\text { area }\left(\mathrm{m}^{2}\right) \\
\text { Heat exchanger inside } \\
\left.\text { area ( } \mathrm{m}^{2}\right) \\
\text { Fin efficiency } \\
\text { C-value } \\
\text { m-value } \\
\text { Tube inside diameter (mm) } \\
\text { Tube outside diameter }(\mathrm{mm}) \\
\text { (excluding fins) }\end{array}$ & $\begin{array}{c}5 \text { to } 15 \\
49.07 \\
2.45 \\
1.958 \\
1.0 \\
0.9 \\
0.25 \\
12.7\end{array}$ & $\begin{array}{c}0.409 \\
1.524 \\
0.292 \\
5 \text { to } 15 \\
13.90 \\
2.46 \\
0.476 \\
0.854 \\
0.6 \\
0.25 \\
10.9\end{array}$ \\
\hline
\end{tabular}

With these assumptions, the model calculated new conductors using new fluid properties (density, viscosity, specific heat, and thermal conductivity) each time step as a function of temperature. The "B" conductors (see Figure 5-1) from the fluid inside the tube to the inner tube wall were determined from an overall inside film coefficient, $\bar{h}_{i}$ :

$$
\bar{h}_{i}=\frac{k \overline{N u}_{i}}{2 r_{i}} \text {. }
$$

The overall inside Nusselt number $\overline{\mathrm{Nu}}_{\mathrm{i}}$ included the temperature drop across the inside boundary layer using the Petukhov-Popov correlation (Petukhov 1970),

where

$$
\overline{\mathrm{Nu}}_{\mathrm{i}}=\frac{(\mathrm{f} / 8) \operatorname{Re} \operatorname{Pr}}{\mathrm{K}_{1}+\mathrm{K}_{2}(\mathrm{f} / 8)^{1 / 2}\left(\operatorname{Pr}^{2 / 3}-1\right)}
$$

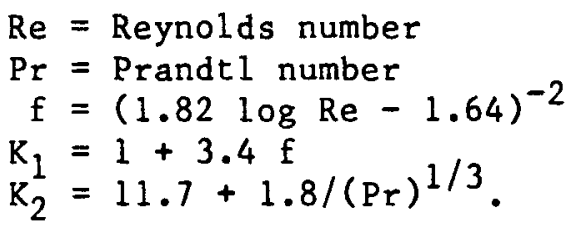

The convection conductors ("C" in Figure 5-1) from the outer tube wall to the tank fluid were determined from an outside film coefficient $\bar{h}_{0}=k \overline{N u} / 2 r_{0}$, where

$$
\overline{\mathrm{Nu}}=\mathrm{C} \overline{\mathrm{Ra}} \mathrm{m},
$$

where $\mathrm{m}=0.25$ and $\mathrm{C}$ is a constant determined by the experimental data. We ran cases with values of $C$ ranging from 0.1 to 0.9 and used the value that was most consistent with the experimental data. 
The experimental values of $\mathrm{C}$ (see Figures $\mathrm{B}-7$ and $\mathrm{B}-8$ in Appendix $\mathrm{B}$ ) were not constant. The determination of $C$ for this model was quite difficult. We varied the constant values of $\mathrm{C}$ in the model until reasonable agreement with the experimental data was obtained. In Figure 5-2 we compare the experimental data with values of $C$ from 0.4 to 0.7 .

Increasing values of $C$ resulted in a higher heat exchanger outlet temperature for a given time. This shows that the heat transfer rate is proportional to the C-value, which is not unexpected, since the Nusselt number and resulting outside heat transfer coefficient $\bar{h}_{0}$ vary directly with the $\mathrm{C}$-value as seen in Eq. 5-3. However, the variation due to C-value was not great. The C-value used for the outside heat transfer coefficient for the smooth coil was 0.9 , which was the value that resulted in a model that most closely agreed with the experimental data.

In the case of the finned heat exchanger, we performed the same variation of the value of $\mathrm{C}$ and compared it with experimental data. The results are shown in Figure 5-3. The heat exchanger outlet temperature varied about $10 \%$ for C-values of 0.6 to 1.0. Also shown in this figure are the experimental data, which agree fairly well with C-values in this range. We used a C-value of 0.6 for all the finned heat exchanger simulations.

The heat transfer in the heat exchanger fluid as a result of the fluid flow inside the tube is represented by the $\mathrm{mC}_{p}$ conductor (" $\mathrm{A}$ " in Figure 5-1). The final group of conductors " $D$ " connect the tank fluid nodes by a simple kA/L conduction. Convection between tank nodes was not modeled.

SMOOTH HX OUTLET, C-VAL VARIATION

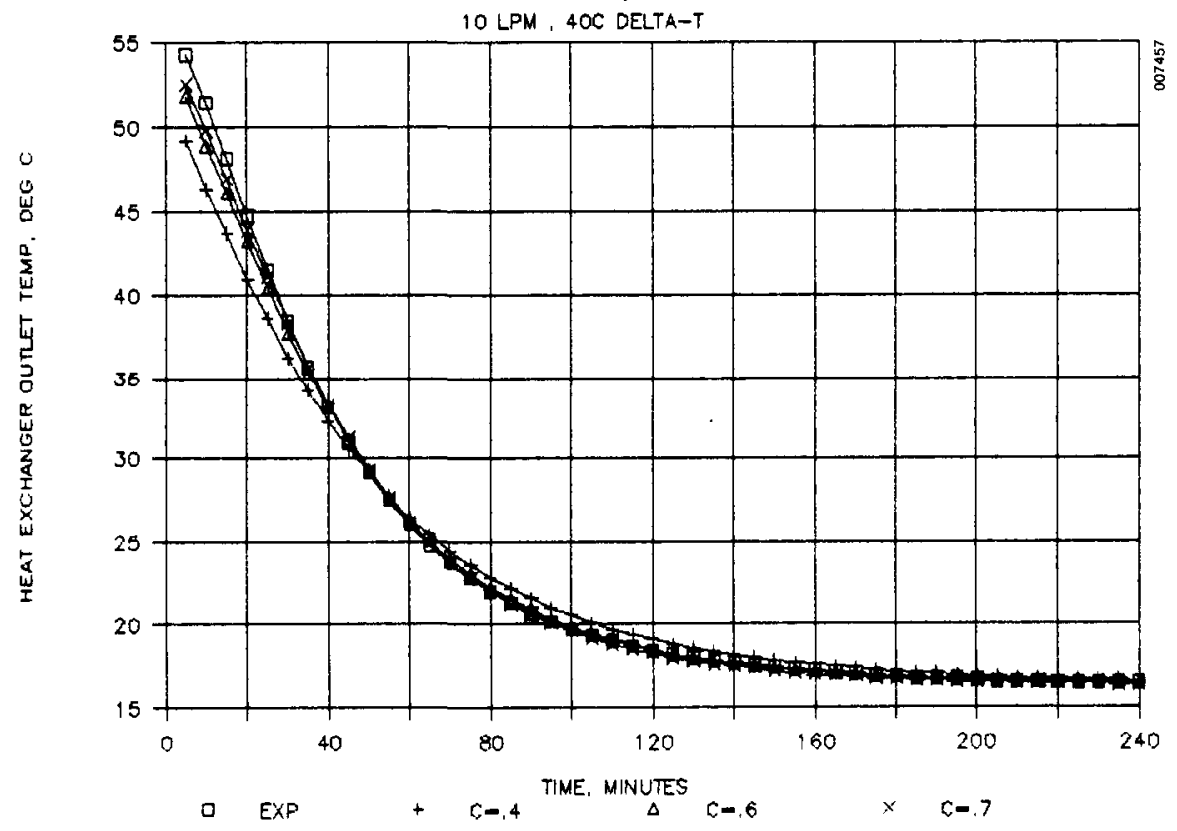

Figure 5-2. Model versus Experimental Data: Smooth Heat Exchanger Variation of C-value 


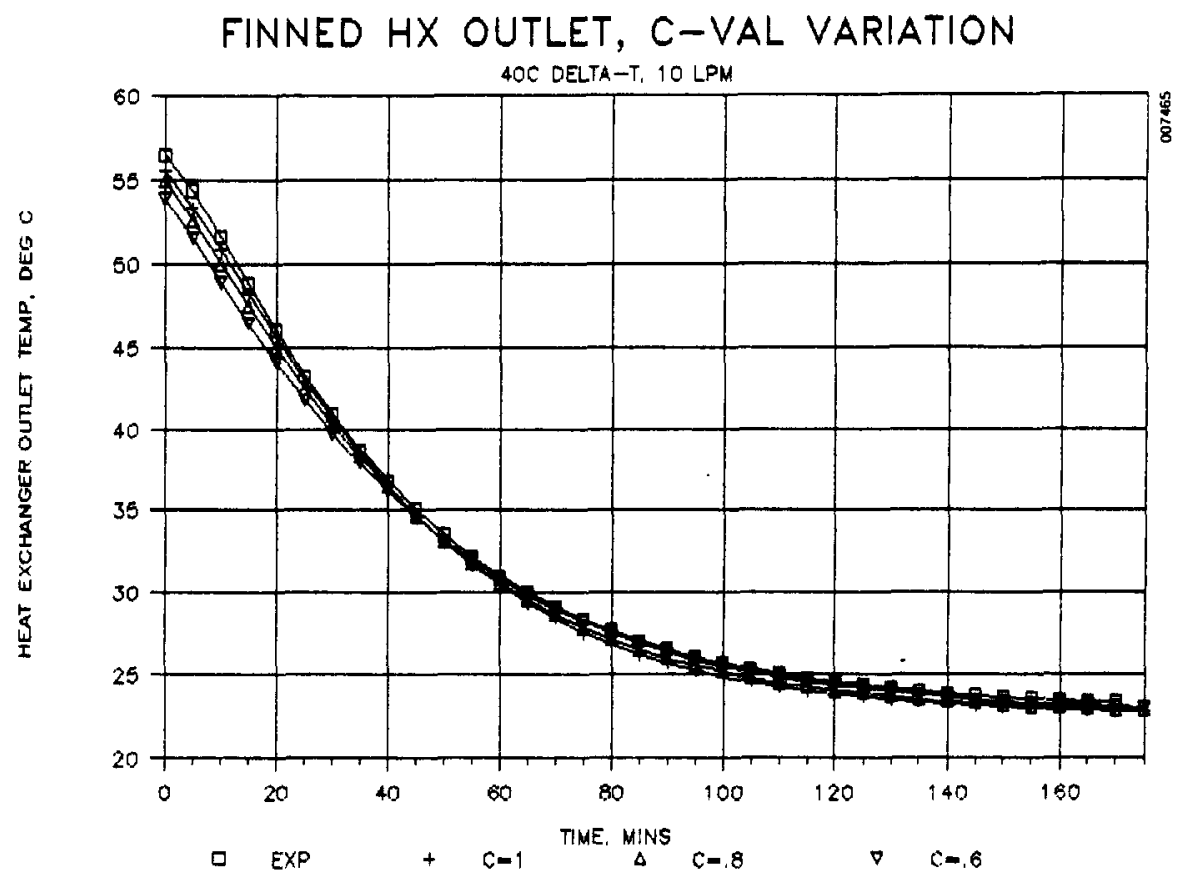

Figure 5-3. Model versus Experimental Data: Finned Heat Exchanger Variation of C-value

The time step used in the model is $10 \mathrm{~s}$, which results in an energy balance on each node to within $2 \%$. The overall system energy balance is within $1 \%$. Each iteration, the maximum temperature change for each node is $0.01^{\circ} \mathrm{C}$. This appeared to be a good compromise between accuracy and computational time.

Previous analytical work on immersed-coil heat exchangers (Farrington and Bingham 1986) identified several key parameters for heat exchanger performance. These parameters are (1) heat exchanger area, (2) heat exchanger flow rate, (3) temperature difference between the heat exchanger inlet and tank temperature, and (4) the $C$ factor relating the Rayleigh and Nusselt numbers in Eq. 5-3. In our model, we will vary each of these factors to determine its effect on heat exchanger performance.

\subsection{Comparison of Stratified Tank with Mixed Tank}

We compared the results of our stratified tank model with a mixed tank by increasing the value of the tank-to-tank conductors $D$ in Figure 5-1 to a large value. In the stratified tank, the value of the $D$ conductor was 3000 times smaller than the $\mathrm{C}$ conductor from the tank nodes to the heat exchanger tube nodes. In the mixed tank, the $D$ conductor is 150 times larger than the $C$ conductor. This reduced the stratification to less than $0.3^{\circ} \mathrm{C}$. This allowed us to determine the effect of stratification on the performance of a load-side heat exchanger. In addition, since a heat exchanger located in the top of the tank tends to reduce stratification, we can approximate the performance of this configuration. 
Because of the difficulty in defining the tank temperature in a stratified tank, it is very difficult to define heat exchanger effectiveness, as discussed in previous sections. In a well-mixed tank this heat exchanger effectiveness is easily defined. With Eq. 2-3, Figure 5-4 shows the effectiveness of a heat exchanger in a mixed tank plotted against the temperature difference between the average tank temperature and the heat exchanger inlet. Note the high effectiveness for this heat exchanger, which is the same heat exchanger used in the smooth heat exchanger testing discussed in the previous section. When we plot the effectiveness versus the LMTD as defined in Eq. 2-6, we again see high values of effectiveness for this heat exchanger (Fig. 5-5). This is largely due to the large $\left(2.45-\mathrm{m}^{2}\right)$ surface area.

The results shown in these figures should not be compared to effectiveness results elsewhere in this report, due not only to the difference in the definition of tank temperature, but also in LMTD. These results for heat exchanger effectiveness in the mixed tank are shown here to indicate the high effectiveness of the heat exchanger tested and modeled in a tank where effectiveness is a meaningful measurement.

The heat transfer rate of the smooth heat exchanger in a mixed tank is shown in Figure 5-6, as plotted against LMTD. At large values of LMTD, the heat transfer rate is over $20 \mathrm{~kW}$. Although we cannot accurately compare the effectiveness of a load-side heat exchanger between mixed and stratified tanks, we can compare the heat transfer rate of the same smooth heat exchangers. In Figure 5-7 we can compare the heat transfer rate versus time for the two tanks. At the beginning of the simulation, when both tanks are mixed, the

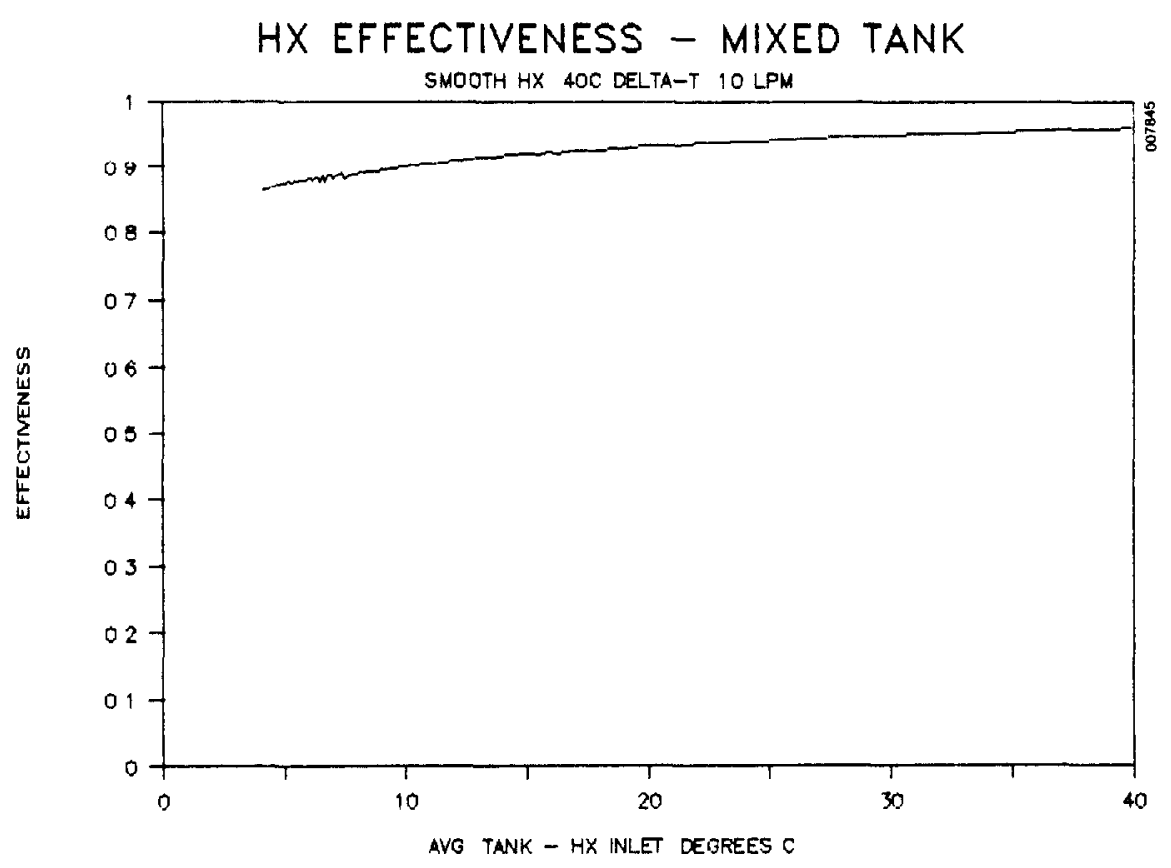

Figure 5-4. Heat Exchanger Effectiveness in a Mixed Tank as a Function of the Temperature Difference between the Tank and the Heat Exchanger Inlet 


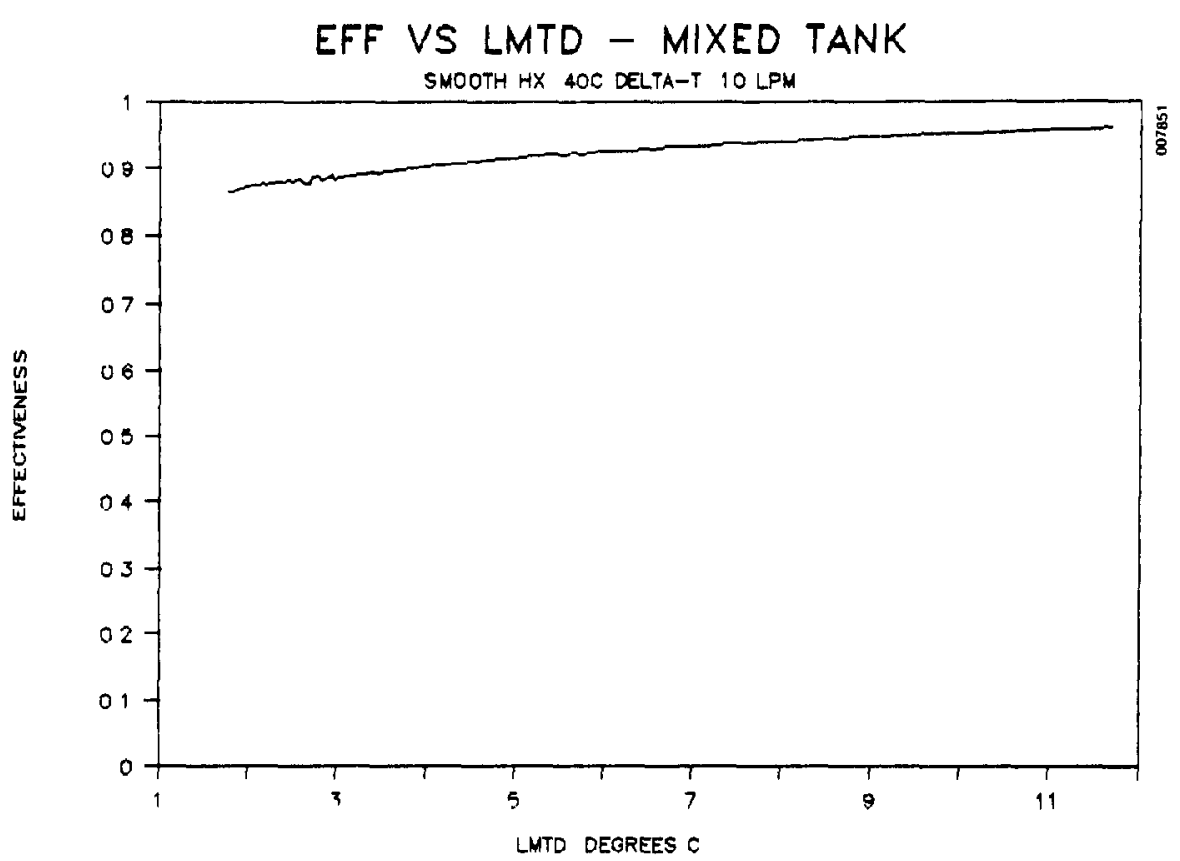

Figure 5-5. Heat Exchanger Effectiveness in a Mixed Tank as a Function of LMTD

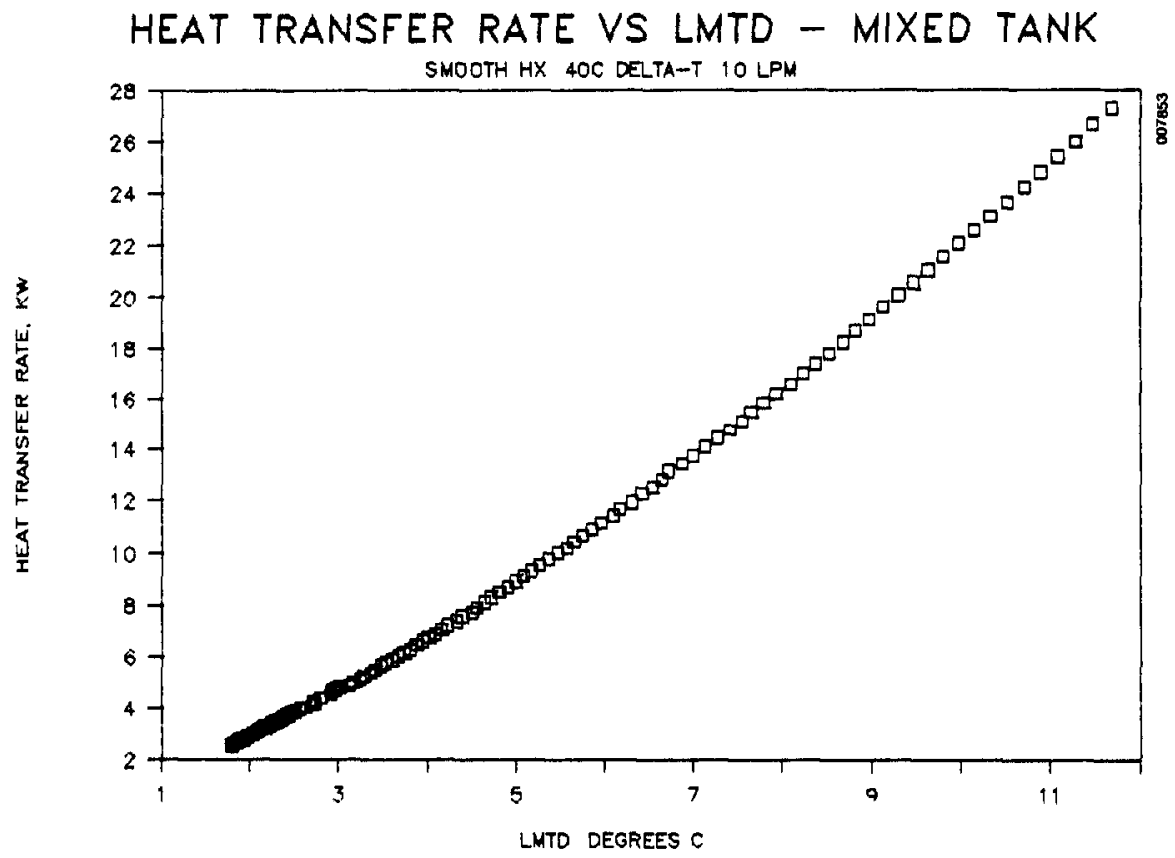

Figure 5-6. Heat Transfer Rate of a Smooth Heat Exchanger in a Mixed Tank as a Function of LMTD 


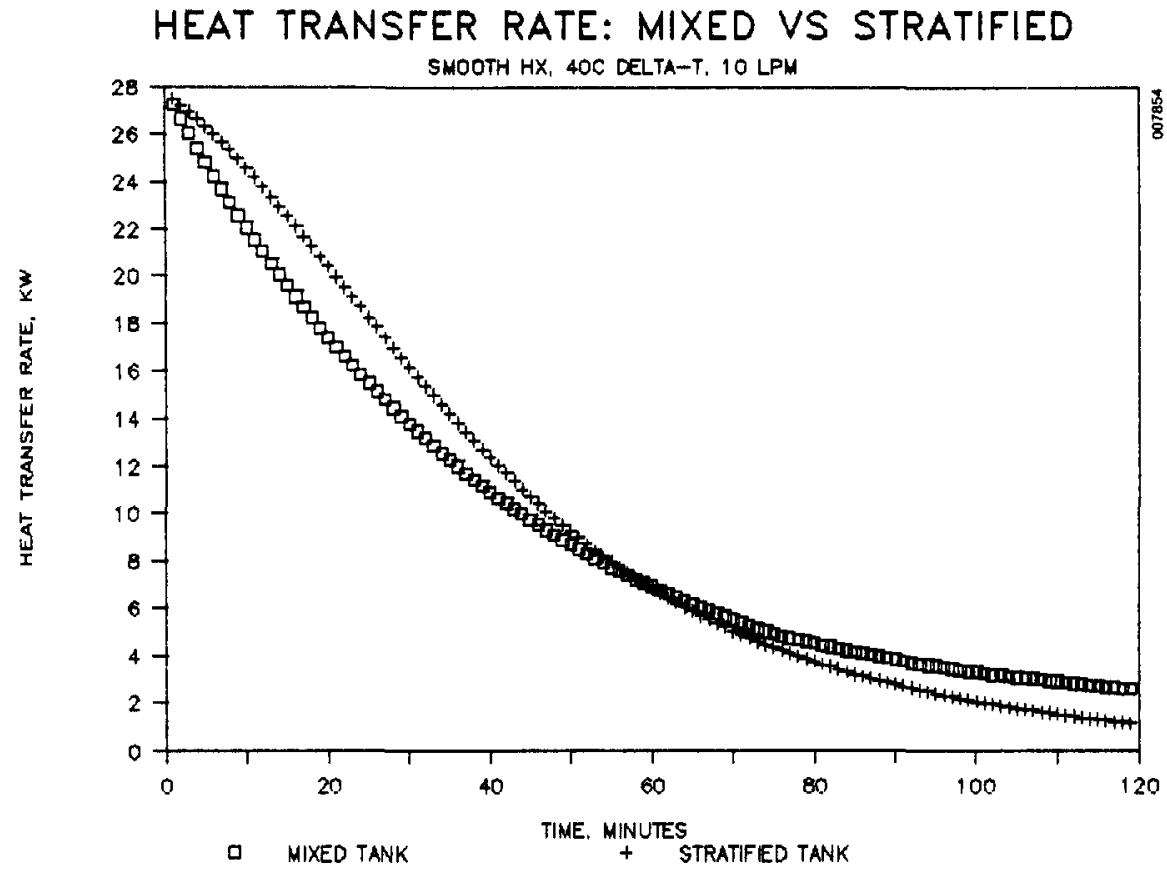

Figure 5-7. Comparison of Heat Transfer Rate of the Same Heat Exchanger in a Mixed and a Stratified Tank

heat transfer rate is the same. Within $10 \mathrm{~min}$, the stratified tank shows an improved heat transfer rate by $2 \mathrm{~kW}$. The heat transfer rate of the stratified tank is 2-3 kW higher from 10 to $30 \mathrm{~min}$ and is higher until 60 min into the test. Most draws from a storage tank in practice are less than $40 \mathrm{~min}$. This shows a significant improvement for stratified tanks over mixed tanks or tanks with load-side heat exchangers located at the top of the tank.

Figure 5-8 shows the tank node temperatures in the stratified tank during the simulation. The node height from the bottom of the tank is shown on the $x$ axis, and tank node temperature on the $y$ axis. At time $=0$, all nodes are at $57.6^{\circ} \mathrm{C}$. During the simulation, the stratification increases to a point, and as the energy is removed from the tank, the stratification decreases. This figure shows the large amount of stratification in the tank, especially at $25 \mathrm{~min}$, when there is a $22^{\circ} \mathrm{C}$ difference between the top and bottom tank nodes. The stratification in the tank in this base case (smooth coil, $10 \mathrm{~L} / \mathrm{min}$ draw, and $40^{\circ} \mathrm{C}$ initial temperature difference between the tank temperature and heat exchanger inlet temperature) is over $20^{\circ} \mathrm{C}$ between 13 and 37 min into the simulation. During this 24-min period the heat transfer rate ranges from 13 to $23 \mathrm{~kW}$.

\subsection{Comparison of Experimental and Numerical Results}

To use our analytical model to characterize the performance of heat exchangers not tested in the laboratory, it is important to first compare the results of the model to available experimental data. We tested four heat exchangers, smooth and finned coil, of two different sizes $\left(2.5-\mathrm{m}^{2}\left[27-\mathrm{ft}^{2}\right]\right.$ and $1.7-\mathrm{m}^{2}$ 


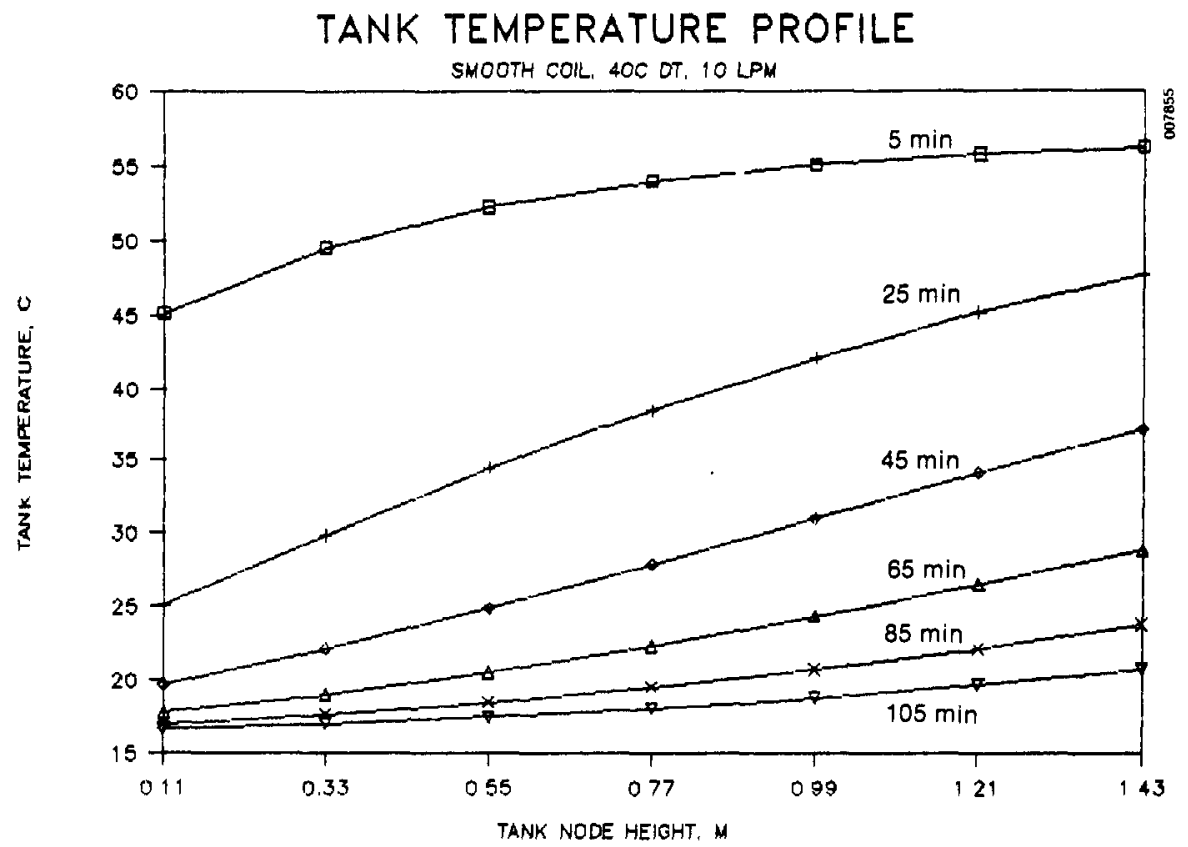

Figure 5-8. Stratified Tank Temperature Profile at Different Times during Simulation

[18-ft $\mathrm{f}^{2}$ ] outside surface area). For most of these, we tested the heat exchanger at $5,10,15$, and $20 \mathrm{~L} / \mathrm{min}(1.3,2.6,4.0$, and $5.2 \mathrm{gal} / \mathrm{min})$ and at four different initial tank temperatures, approximately $10^{\circ}, 20^{\circ}, 40^{\circ}$, and $60^{\circ} \mathrm{C}\left(18^{\circ}, 36^{\circ}, 72^{\circ}\right.$, and $\left.108^{\circ} \mathrm{F}\right)$ above the heat exchanger inlet temperature.

We attempted to verify our model by comparing the results of a baseline case $(10 \mathrm{~L} / \mathrm{min}[2.6 \mathrm{gal} / \mathrm{min}]$ heat exchanger flow rate, initially mixed tank temperature $40^{\circ} \mathrm{C}\left[72^{\circ} \mathrm{F}\right]$ above heat exchanger inlet temperature) for both the smooth and finned coils. Table 5-1 1 ists the assumptions used in the model. From these baseline cases, we will change the flow rate $(5$ and $15 \mathrm{~L} / \mathrm{min}[1.3$ and $4.0 \mathrm{gal} / \mathrm{min}])$ and then lower the initial tank temperature $\left(10^{\circ} \mathrm{C}\left[18^{\circ} \mathrm{F}\right]\right.$ above heat exchanger inlet) and compare these results to those obtained from laboratory testing. All data presented are calculated unless expressly labeled as experimental. Figure 5-9 compares the heat exchanger outlet temperature for analytical and experimental results for flow rates of 5,10 , and $15 \mathrm{~L} / \mathrm{min}$ $(1.3,2.6$, and $4.0 \mathrm{gal} / \mathrm{min})$ for the smooth-coil heat exchanger. The results agreed well within $1^{\circ} \mathrm{C}\left(2^{\circ} \mathrm{F}\right)$ for the $10-$ and $15-\mathrm{L} / \mathrm{min}(2.6-$ and $4.0-\mathrm{gal} / \mathrm{min})$ cases. The agreement was not as good for the $5-\mathrm{L} / \mathrm{min}(1.3-\mathrm{gal} / \mathrm{min})$ case, deviating $2^{\circ} \mathrm{C}\left(4^{\circ} \mathrm{F}\right)$ in some cases. However, the agreement was much better at the start of the test, when most of the heat transfer occurred. Figure 5-10 depicts the same 5,10 , and $15 \mathrm{~L} / \mathrm{min}(1.3,2.6$, and $4.0 \mathrm{gal} / \mathrm{min})$ cases for the finned-coil heat exchanger. Although the agreement was not as good as for the smooth-coil heat exchanger, it was again quite good during the first $30 \mathrm{~min}$ of the test.

The next two cases to be compared were from the same two heat exchangers, smooth and finned coil, but in a tank where the initially mixed tank temperature was only $10^{\circ} \mathrm{C}\left(18^{\circ} \mathrm{F}\right)$ above the heat exchanger inlet temperature. At this 


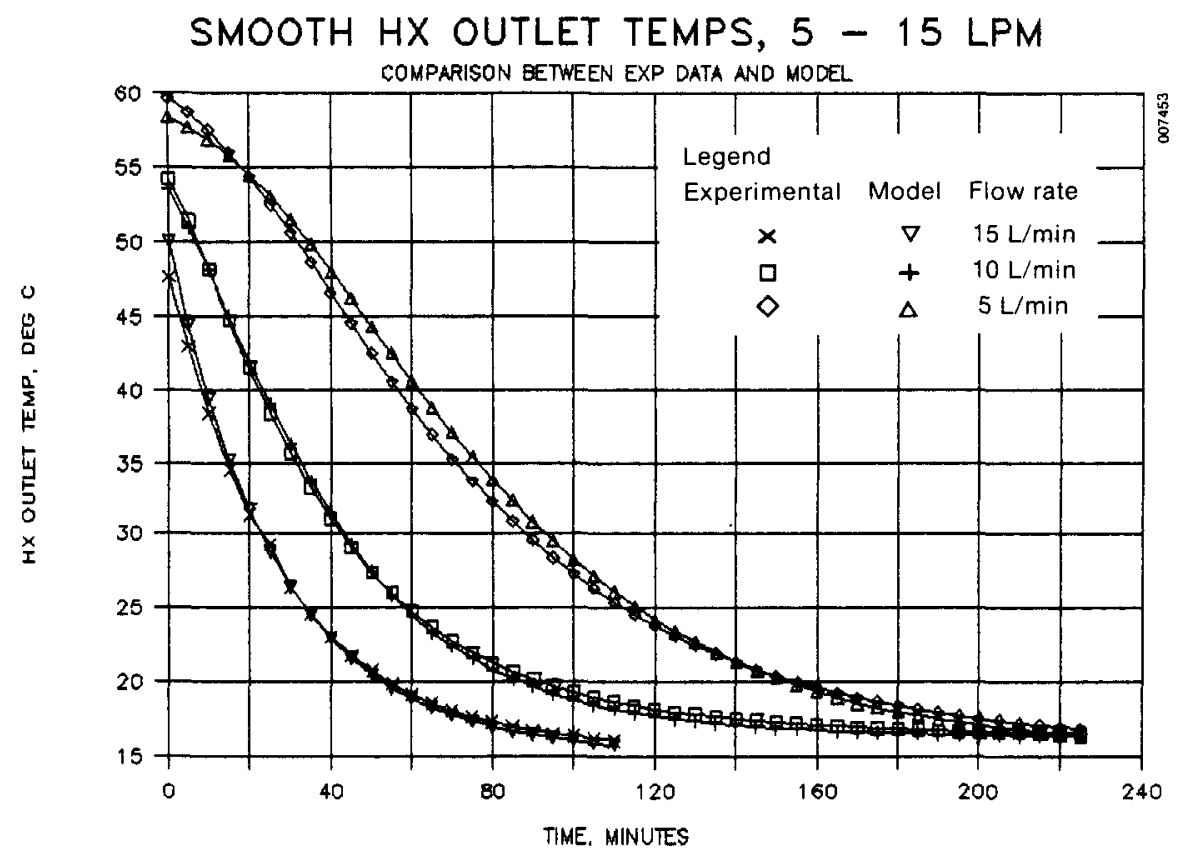

Figure 5-9. Model versus Experimental Data: Smooth Heat Exchanger Outlet Temperature versus Flow Rate

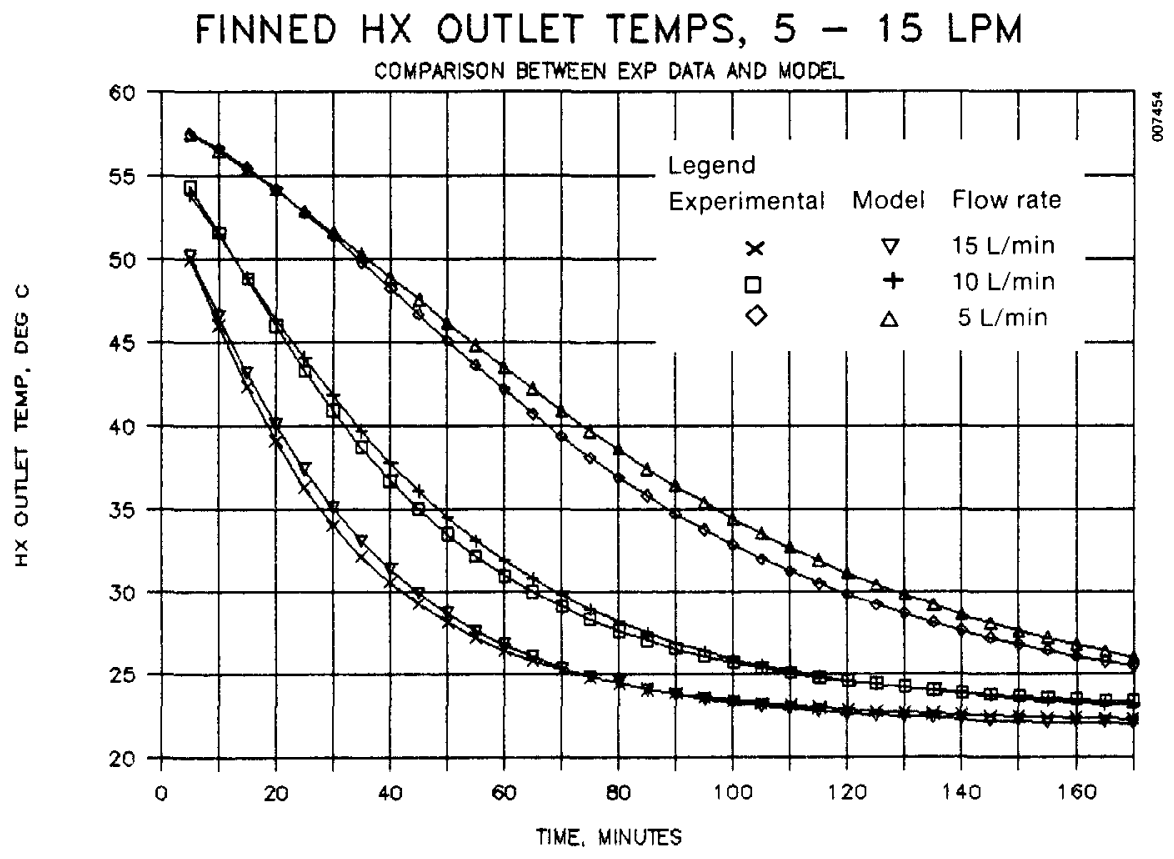

Figure 5-10. Model versus Experimental Data: Finned Heat Exchanger Outlet Temperature versus Flow Rate 
initial tank temperature there was not the driving force that there was in the case with the higher initial tank temperature. We did not change the C-value for the lower initial tank temperature. Figures 5-11 and 5-12 show the comparison of the analytical versus experimental heat exchanger outlet temperature for the lower initial tank temperature $\left(10^{\circ} \mathrm{C}\left[18^{\circ} \mathrm{F}\right]\right.$ above heat exchanger inlet at a flow rate of $10 \mathrm{~L} / \mathrm{min}[2.6 \mathrm{gal} / \mathrm{min}])$ for the smooth- and finnedcoil cases, respectively. The agreement in these two cases was within $1^{\circ} \mathrm{C}$ $\left(2^{\circ} \mathrm{F}\right)$ of the heat exchanger outlet. These figures, which show temperature versus time, show an underprediction of the heat removed from the tank as indicated by the higher heat exchanger outlet temperature early in the test.

Considering the simplifying assumptions described in section 5.1 and other differences between the model and the test heat exchanger, the agreement between the experimental and analytical results seems quite good. Such differences include (1) variation of flow rate ( $\pm 1 \%$ ) during the test versus no change in model, (2) difference in actual thermistor location and tank node location in model, (3) inlet tube to coil from top to bottom of tank modeled only as additional heat exchanger area, and (4) inherent measurement error. The model also used a constant $C$ factor to calculate the average outside heat transfer coefficient (Eq. 5-3).

The energy extracted from the tank as represented by the heat exchanger outlet temperature appeared to agree fairly well when varying the initial tank temperature and heat exchanger flow rate. Parametric analysis of heat exchanger performance can now be performed with some confidence that the general trends of heat exchanger performance determined analytically will agree with actual heat exchangers of similar configuration.

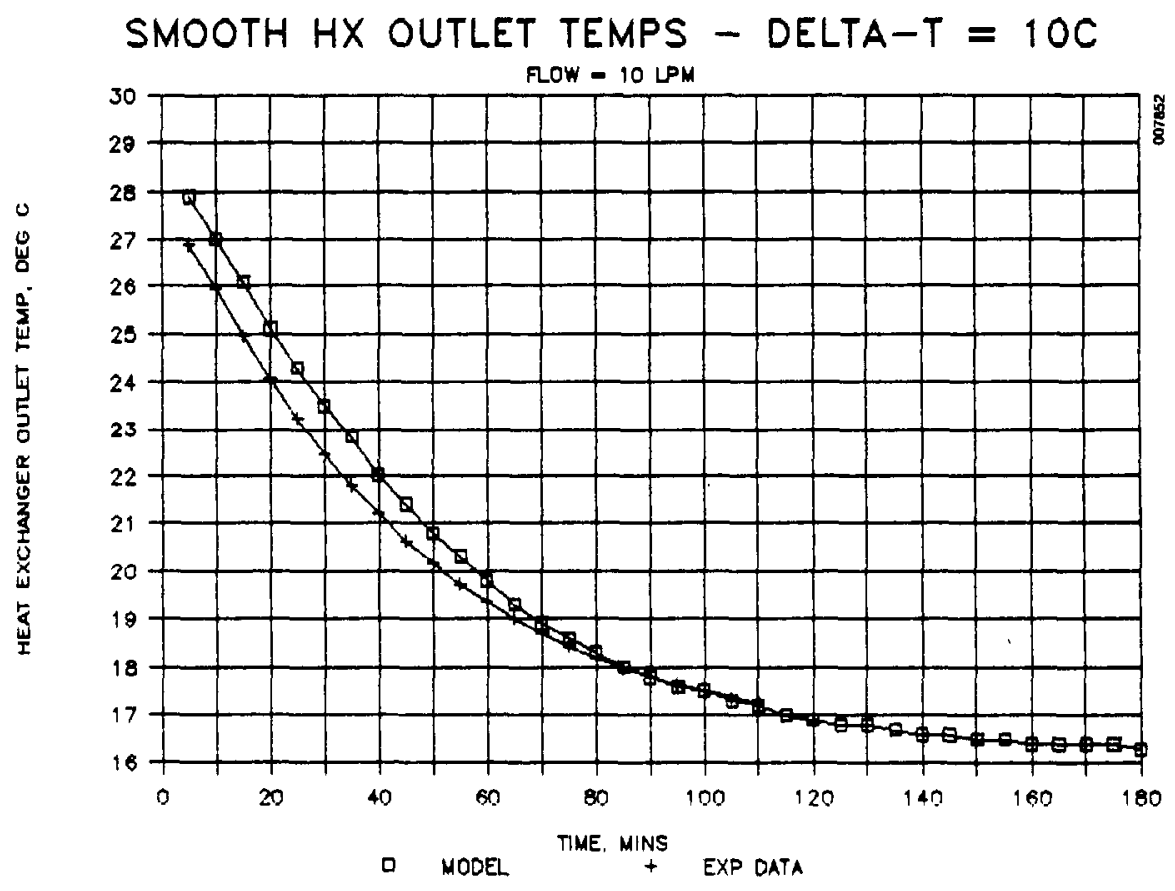

Figure 5-11. Model versus Experimental Data: Smooth Heat Exchanger Outlet Temperature with Lower Tank Temperature 


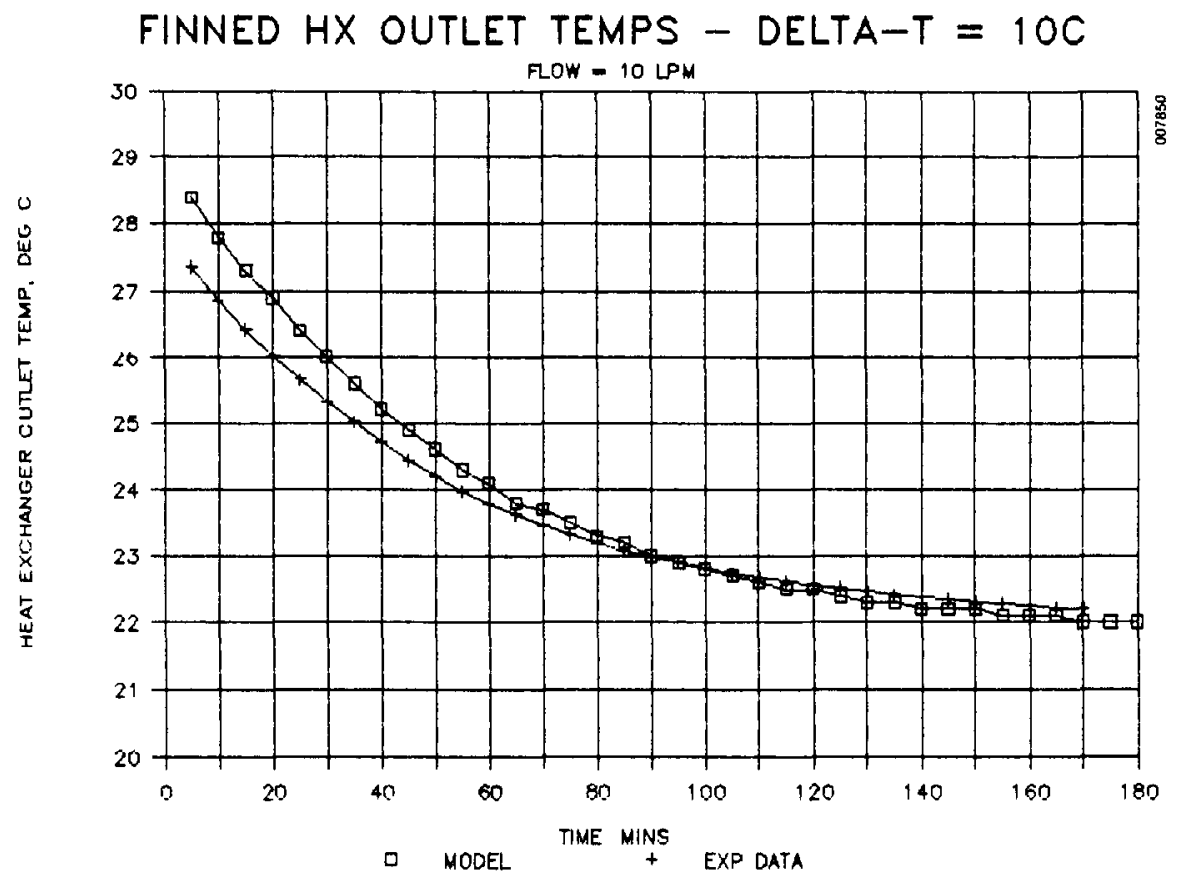

Figure 5-12. Model versus Experimental Data: Finned Heat Exchanger Outlet Temperature with Lower Tank Temperature

\subsection{Results of Parametric Analysis}

The initial case was a $2.45-\mathrm{m}^{2}\left(26-\mathrm{ft}^{2}\right)$, smooth-coil heat exchanger similar to that built for the experiment. The conditions of the base case were a flow rate of $10 \mathrm{~L} / \mathrm{min}(2.6 \mathrm{gal} / \mathrm{min})$ and a temperature difference between the initially mixed tank and the heat exchanger inlet of $40^{\circ} \mathrm{C}\left(72^{\circ} \mathrm{F}\right)$. The heat exchanger outlet temperature, an indication of the energy removed from the tank, and the vertical average tank temperature are shown in Figure 5-13. At $10 \mathrm{~L} / \mathrm{min}(2.6 \mathrm{gal} / \mathrm{min})$ the vertical average tank temperature was $2{ }^{\circ}-4^{\circ} \mathrm{C}$ $\left(4^{\circ}-7^{\circ} \mathrm{F}\right)$ below the heat exchanger outlet. Most of the energy had been removed from the tank after the first hour of the test. The heat transfer rate $q$, as a function of the LMTD, is shown in Figure 5-14. At these baseline conditions the heat transfer rate was a direct function of the LMTD, which is defined as

$$
\operatorname{LMTD}=\frac{\left(T_{S, b}-T_{H x, i}\right)-\left(T_{S, t}-T_{H x, o}\right)}{\ln \left(\frac{T_{S, b}-T_{H x, i}}{T_{S, t}-T_{H x, o}}\right)}
$$

The effect of heat exchanger flow rate on the heat exchanger outlet and average tank temperature is shown in Figures $5-15$ and 5-16, respectively. As expected, the higher the flow rate, the more quickly the energy in the tank was depleted as shown by the heat exchanger outlet temperature and storage tank temperature decreasing more rapidly. 


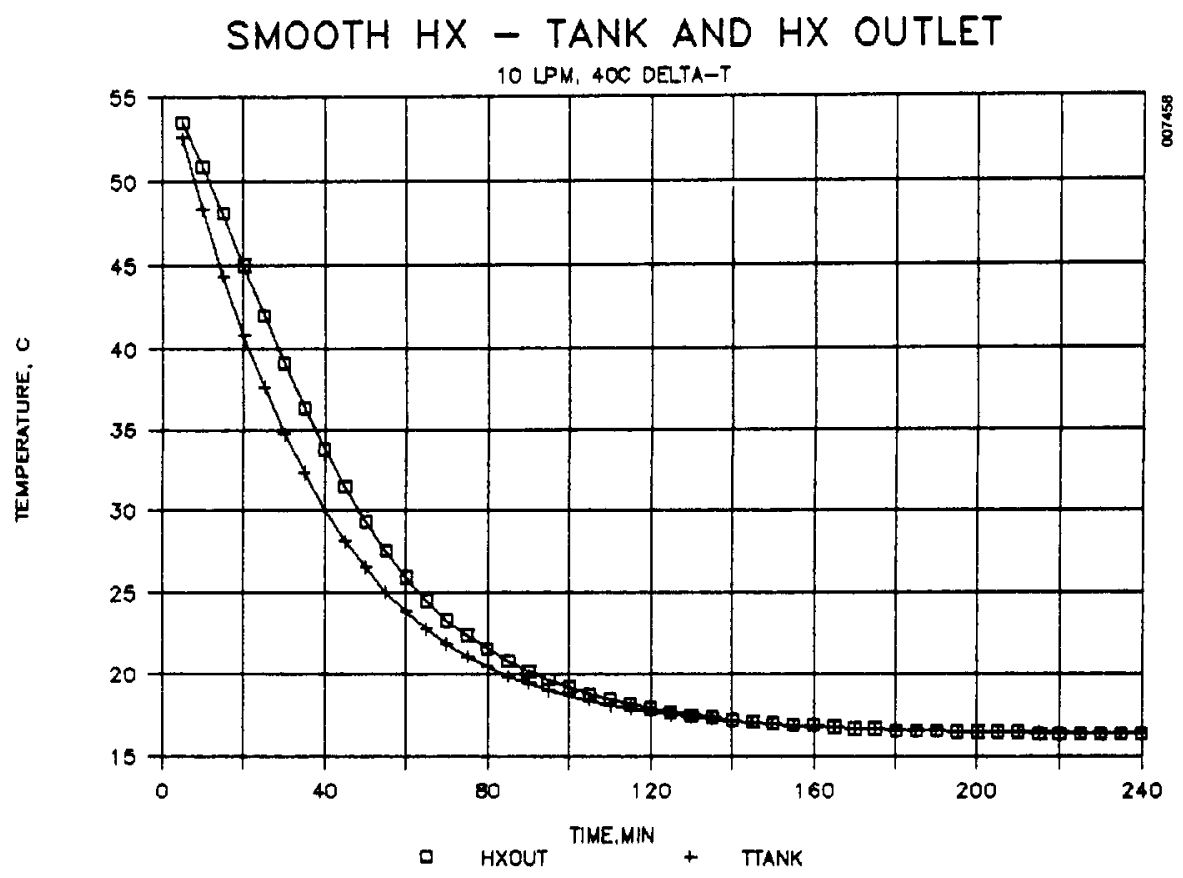

Figure 5-13. Baseline Case: Outlet Temperature and Vertical Average Tank Temperature

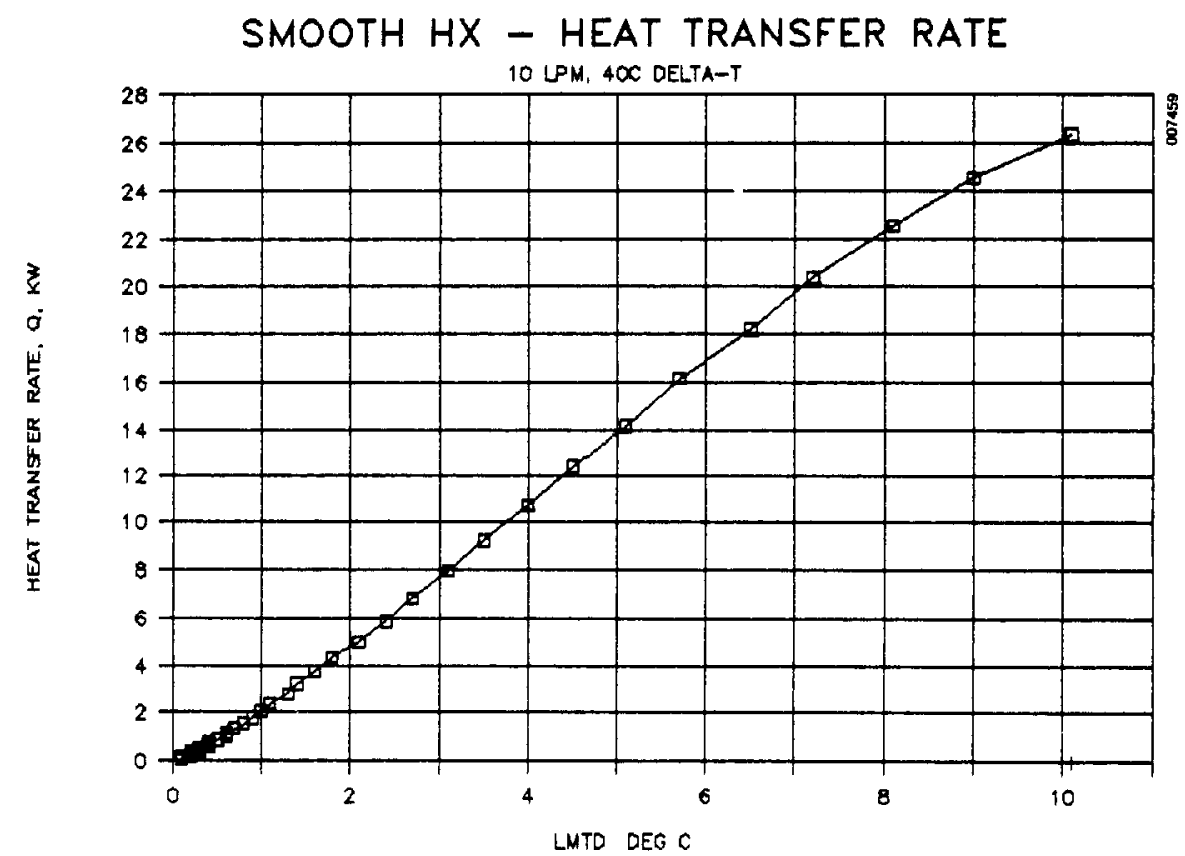

Figure 5-14. Baseline Case: Heat Transfer Rate versus LMTD 


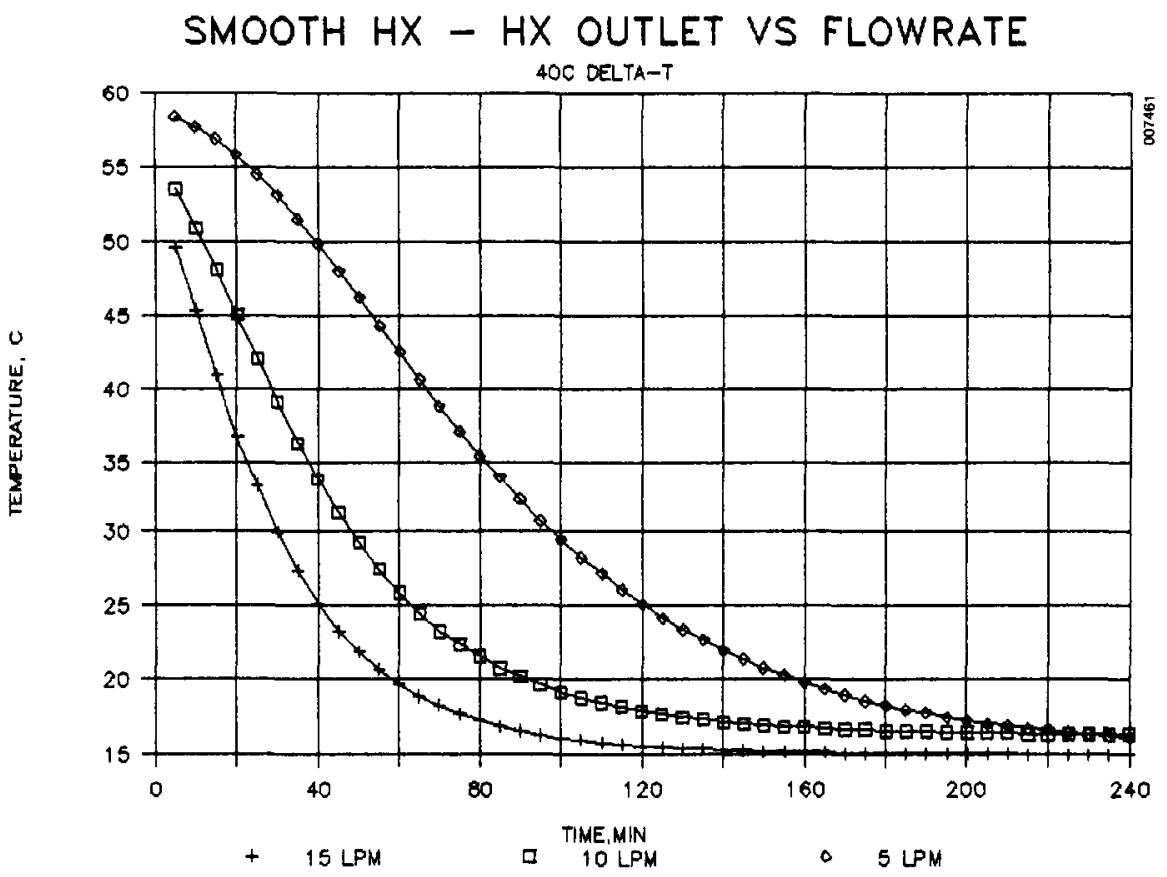

Figure 5-15. Smooth Coil Heat Exchanger Outlet Temperature versus Flow Rate

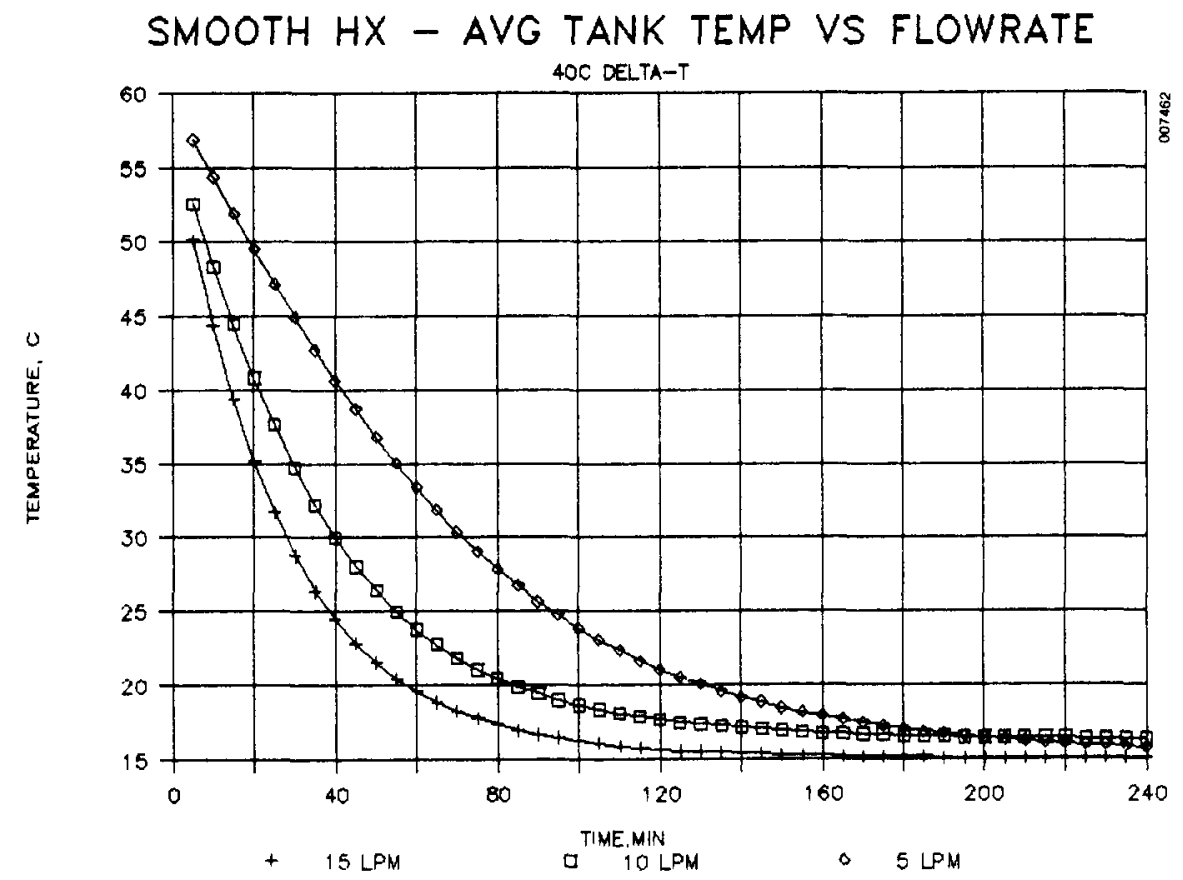

Figure 5-16. Smooth Coil Heat Exchanger Vertical Average Tank Temperature versus Flow Rate 
Figure 5-17 shows the heat transfer rate for the smooth heat exchanger at flow rates of 5,10 , and $15 \mathrm{~L} / \mathrm{min}$. At higher flow rates the heat transfer rate from the tank is dramatically increased. The heat transfer rate is simply a function of the flow rate and capacitance of the fluid and the temperature difference across the heat exchanger.

Our next model was patterned after the $2.46-\mathrm{m}^{2}\left(26-\mathrm{ft}^{2}\right)$, finned-coil heat exchanger tested in the laboratory.

The effect of flow rate on heat transfer rate for finned heat exchangers is shown in Figure 5-18. If you compare these results with those in Figure 5-17 for the smooth heat exchanger, you see a pronounced improvement in heat transfer rate for the smooth heat exchanger. The initial point reflects the heat transfer rate at $5 \mathrm{~min}$ and is $23 \%$ higher for the smooth heat exchanger with the same external surface area at each flow rate.

Figure 5-19 compares heat transfer rates of the finned and smooth heat exchangers as a function of LMTD at an initial tank temperature of $40^{\circ} \mathrm{C}$. This figure shows another view of the marked improvement of a smooth heat exchanger over a finned heat exchanger of the same external surface area. At an LMTD of $10^{\circ} \mathrm{C}$ the smooth heat exchanger has a $40 \%$ higher heat transfer rate than the finned heat exchanger. Even at lower LMTDs, the smooth heat exchanger similarly outperforms the finned heat exchanger with equal external surface area. Figure 5-20 shows the same plot with an initial tank temperature $30^{\circ} \mathrm{C}$ lower. Again the improvement in heat transfer rate of the smooth heat exchanger is apparent. At an LMTD of $3^{\circ} \mathrm{C}$ the improvement is nearly $60 \%$.

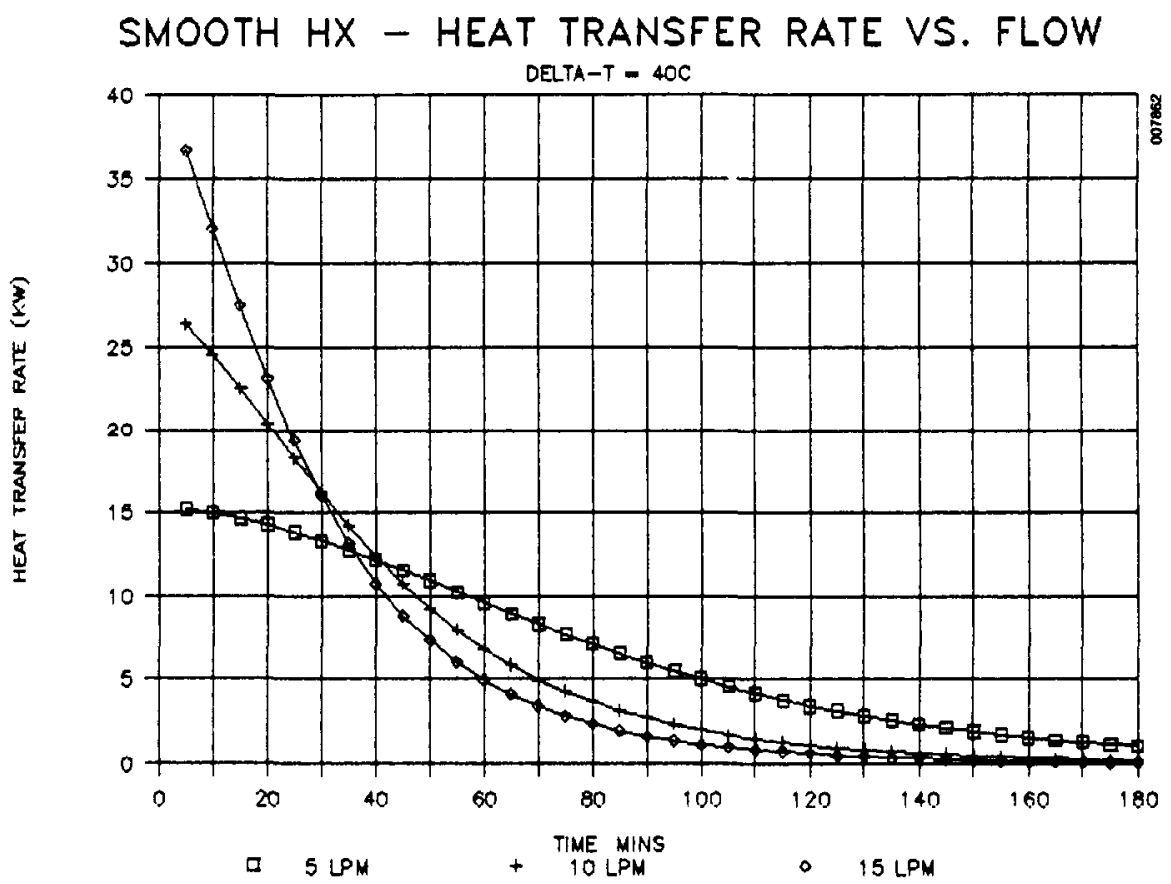

Figure 5-17. Heat Transfer Rate for Smooth Heat Exchanger versus Time for Flow Rates of 5,10 , and $15 \mathrm{~L} / \mathrm{min}$ 


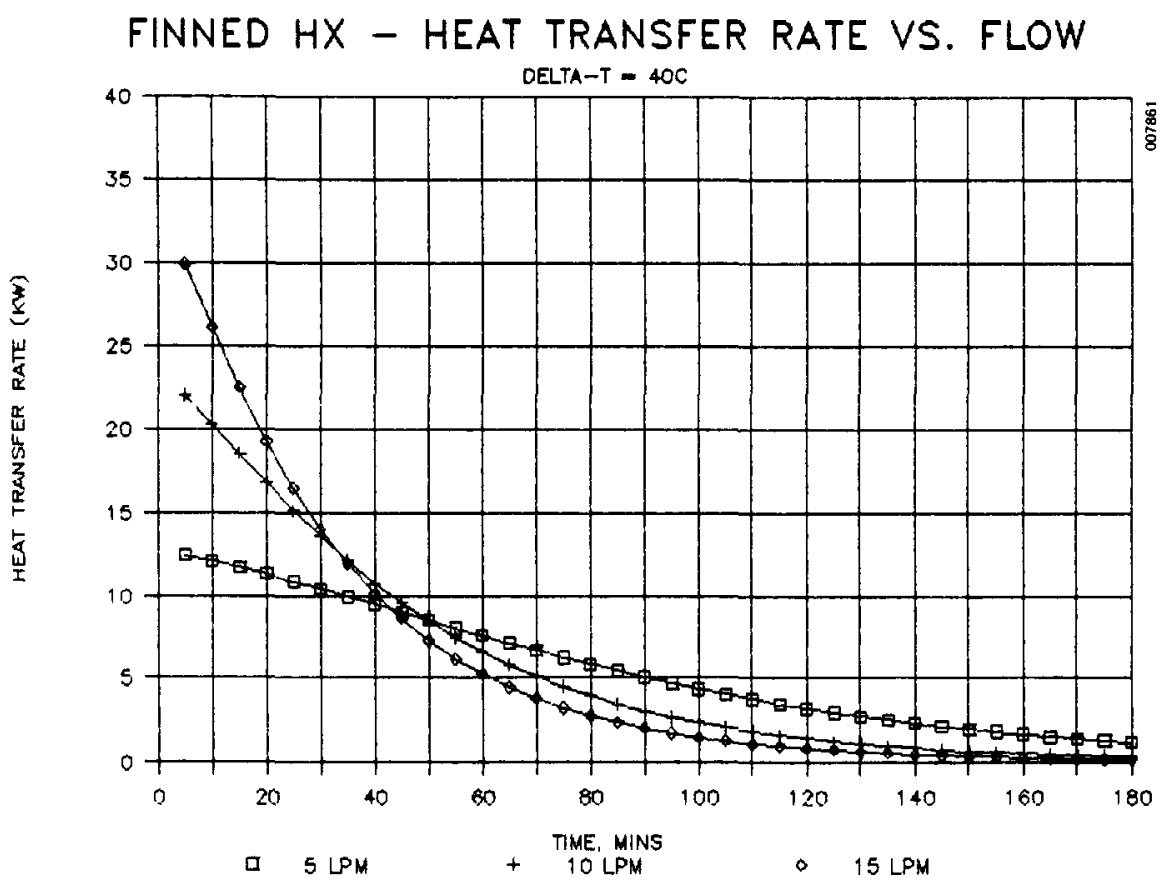

Figure 5-18. Heat Transfer Rate for Finned Heat Exchanger versus Time for Flow Rates of 5,10 , and $15 \mathrm{~L} / \mathrm{min}$

FINNED VS SMOOTH HX HEAT TRANSFER RATE

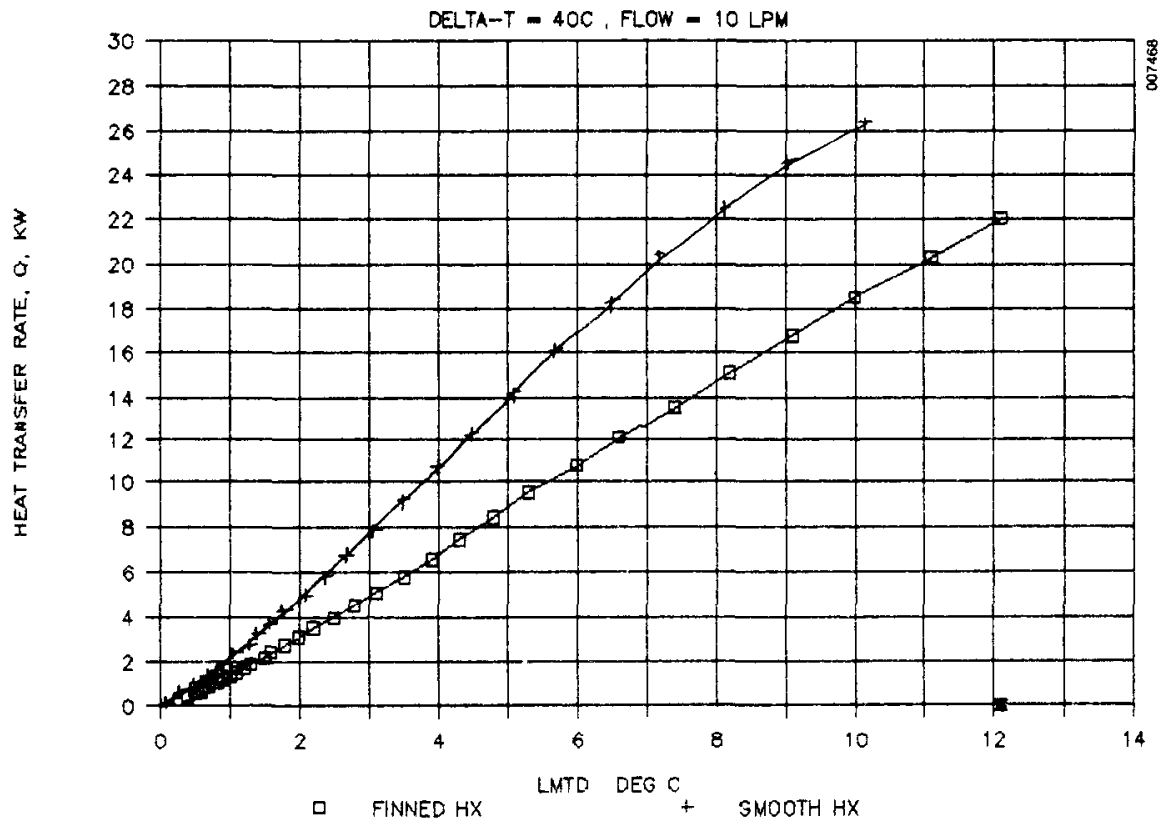

Figure 5-19. Comparison of Finned and Smooth Heat Exchangers: Heat Transfer Rates for Initial Tank Temperature of $40^{\circ} \mathrm{C}$ above Heat Exchanger Inlet 


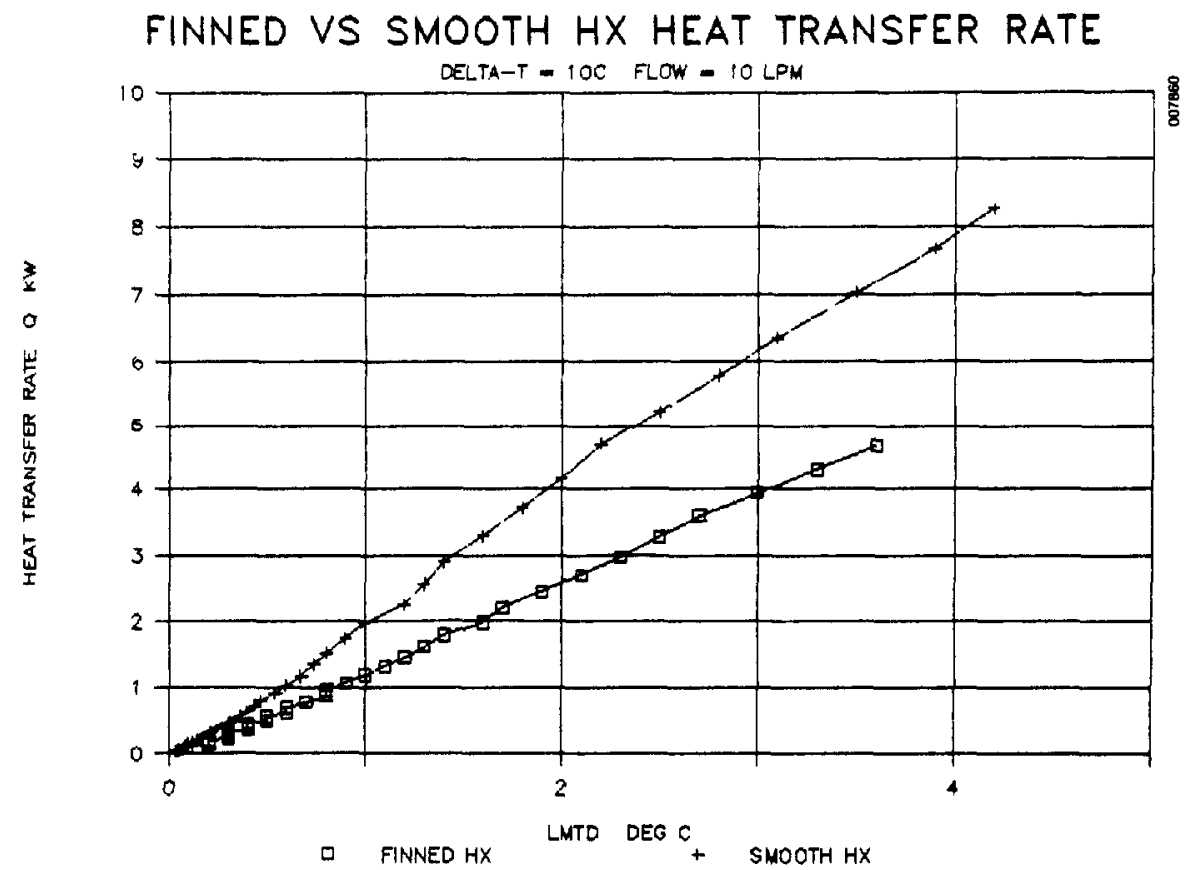

Figure 5-20. Comparison of Finned and Smooth Heat Exchangers: Heat Transfer Rates for Initial Tank Temperature of $10^{\circ} \mathrm{C}$ above Heat Exchanger Inlet

Both of these heat exchangers had approximately the same external surface area, but the smooth coil had a much higher inside surface area for heat transfer. For a given external area, the finned heat exchanger did not perform as well, but note that the internal surface area of the smooth heat exchanger is more than four times greater than the finned heat exchanger. Also, the fin efficiency reduces the performance of the finned heat exchanger.

The final parameter analyzed was the outside area of the heat exchanger. The heat transfer rates of heat exchangers with $0.25,0.5,1,2$, and 5 times the area of the baseline case are depicted in Figures 5-21 and 5-22 for the smooth- and finned-coil heat exchangers, respectively. Note that the changes in area are not linear. In both cases, the larger-area heat exchangers deplete the energy in the tank at a faster rate. The maximum LMTDs were much lower for the heat exchangers with higher areas. The largest LMTD is seen at the beginning of the test. For a given time step, the smaller-area heat exchangers will produce a larger LMTD after the initial time step, which is indicated on the graphs as the maximum LMTD. The result that is seen from these two plots is that for a given LMTD, the larger heat exchangers have a higher heat transfer rate. This is not unexpected. The difference between the finned and smooth heat exchangers is evident for each area. Comparing Figures 5-21 and 5-22 indicates improved performance of the smooth over the finned heat exchanger for a given LMTD and surface area. 
SMOOTH HX Q VS. SURFACE AREA

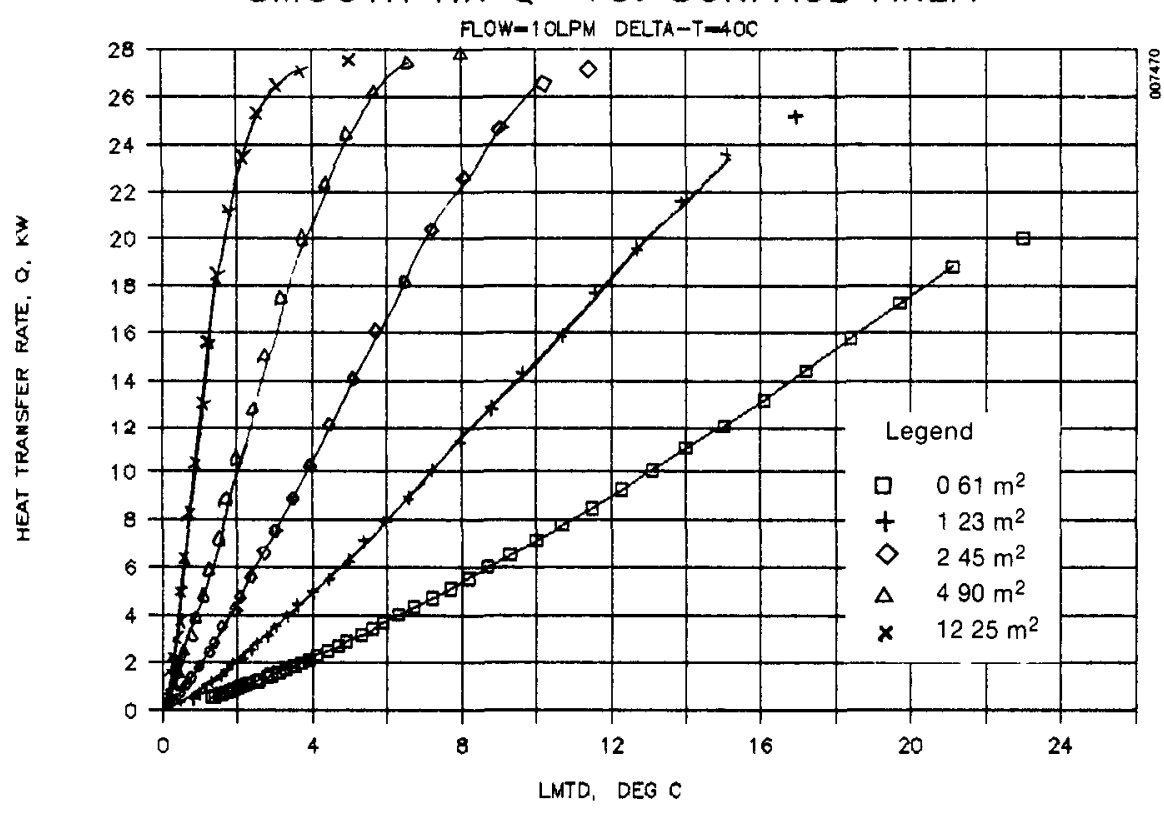

Figure 5-21. Effect of Smooth Heat Exchanger Surface Area on Heat Transfer Rate versus LMTD

FINNED HX Q VS. SURFACE AREA

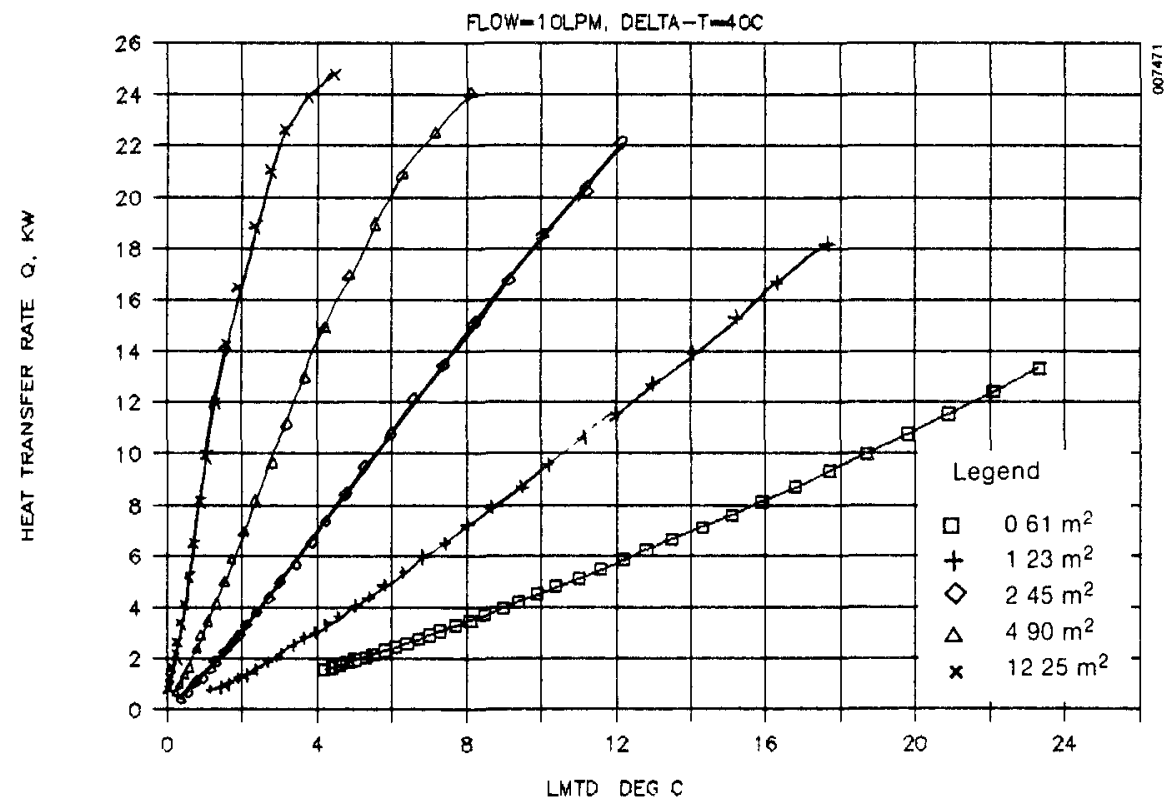

Figure 5-22. Effect of Finned Heat Exchanger Surface Area on Heat Transfer Rate versus L.MTD 


\subsection{CONCLUSIONS AND RECOMMENDATIONS}

The testing and analysis of heat exchangers that transfer heat by natural convection and are used in stratified storage tanks is very difficult. Typical engineering approaches to characterize the performance of heat exchangers use the concept of effectiveness. The heat exchanger effectiveness is a very useful concept in forced convection situations or when one source is isothermal. The effectiveness concept requires that the storage tank be represented by one temperature, which is not possible in a stratified tank.

In this report, we have discussed the various approaches to representing the storage tank by one temperature and shown the results of some of those definitions graphically. We have graphically represented the measured performance of four heat exchangers using various parameters, including the heat transfer rate, heat exchanger UA, heat exchanger $\mathrm{U}$-value, and heat exchanger $\mathrm{C}-\mathrm{factor}$, versus various definitions of temperature differences including the LMTD. We also correlated the Nusselt and Rayleigh numbers.

The results from these tests show the actual performance of various heat exchangers. Designers can use these results when they design similar heat exchangers. Our test results show that heat exchangers can be used in storage tanks without destroying the stratification in the storage tank and can even enhance stratification. Therefore, they could be used in conjunction with a low flow strategy as identified by Fanney and Klein (1986). Low collector flow rates result in storage tank stratification that leads to higher colector efficiency and improved system performance. An ideal system for this approach would be an unpressurized drainback system where the fluid in the storage tank (water) would be circulated through the collectors. Whenever the pump stops, the water "drains back" into the storage tank. Energy is removed from the storage tank by a load-side heat exchanger, such as discussed in this report. Such a system would allow the use of a low-cost unpressurized collector and storage tank, very low flow rates, and, hence, a small pump and smaller pipes and possibly simpler controls.

In addition to general information on how load-side heat exchangers perform, we presented measured heat exchanger U-values. These values ranged from under $100 \mathrm{~W} / \mathrm{m}^{2}{ }^{\circ} \mathrm{C}\left(18 \mathrm{Btu} / \mathrm{h} \mathrm{ft}{ }^{2}{ }^{\circ} \mathrm{F}\right)$ for low temperature differences to as high as $1200 \mathrm{~W} / \mathrm{m}^{2}{ }^{\circ} \mathrm{C}\left(210 \mathrm{Btu} / \mathrm{h} \mathrm{ft}{ }^{2}{ }^{\circ} \mathrm{F}\right)$ for high temperature differences. The reducedarea smooth coil (with $70 \%$ of the area of the original larger coil) had a higher U-value than the original smooth coil. This indicates that the additional heat exchanger area of the larger coil did not transfer energy as effectively as the smaller area. Reducing the heat exchanger area can lead to higher U-values because there is less area to transfer heat and the average temperature difference between coil and water remains higher, although it will also reduce the heat transfer rate since there is less area for heat transfer to occur.

As expected, heat transfer rates increase with flow rate and temperature difference between the storage tank and heat exchanger inlet. Increasing heat exchanger flow rates also decreases stratification in the tank since the fluid has less time to be heated in a certain length of the heat exchanger. This results in cooler fluid at the outlet of the heat exchanger, which subsequently cools the top of the tank. Low heat exchanger flow rates can lead to significant temperature stratification in the storage tank. 
Perhaps the best correlation we had was between the Nusselt and Rayleigh numbers. The results were very consistent for each heat exchanger type and did not deviate because of flow rate and initial temperature differences. The Nusselt numbers ranged from 1 to about 35 for corresponding Rayleigh numbers of $6.3 \times 10^{4}$ to $7.9 \times 10^{6}$. Generally, the Nusselt number did not fall below 3 .

One significant result of this work is that under the conditions we tested, the smooth coil outperformed the finned coil. In fact, for a given Rayleigh number, the reduced-smooth coil had a significantly higher Nusselt number than the larger, original finned coil. Finned coils are sometimes required because of lack of space but do not perform as well as ordinary, smooth copper pipe with the same heat transfer area. Part of the reason is because fins have an efficiency less than 1 and therefore the effective heat transfer area is less than the actual heat exchanger area. In addition, the fins may reduce the velocity past the base of the pipe. This is consistent with the results of the collector-side testing at SERI (Farrington and Bingham 1986) where the smooth also outperformed the finned heat exchangers.

We recommend, when possible, that smooth coils be used for both load-side and collector-side heat exchangers. In addition, when compatible with the overall design of a system, load-side heat exchangers should be designed vertically to enhance storage tank stratification. Placing the heat exchanger symmetrically in the tank with equal volumes of water on each side of the coil (instead of halfway between the edge and the center) should minimize cold or stagnant volumes of water, since convective heat transfer is a mass-dependent phenomenon.

The analytical model provided some interesting results. In particular, the performance of a heat exchanger in a stratified tank was considerably improved over the same heat exchanger in a mixed tank. This indicates that for loadside heat exchangers, stratification improves performance significantly. This also indicates an improvement over placing the heat exchanger in the top of the tank. The heat transfer rate of the heat exchanger was higher for a given LMTD for lower heat exchanger flow rates. The heat transfer rates of heat exchangers with larger exterior surface areas were much more sensitive to LMTD, while the difference in heat transfer rates for the smaller heat exchangers was relatively small. Comparing finned-and smooth-coil heat exchangers with similar external surface areas indicated much better performance for the smooth-coil heat exchangers, which had a much larger inside surface area for heat transfer.

The analytical model developed to analyze load-side heat exchangers did a reasonable job of simulating the performance, based on comparison with experimental results. Further development of the model to handle different heat exchanger geometries would be useful. In particular, a more detailed model coupling the natural convection to the stratifying fluid should be developed. The number of simplifying assumptions used could be reduced to produce more accurate results. The analytical model we developed cannot easily be used to size heat exchangers. The development of a closed-form solution to load-side heat exchanger performance would provide designers with a tool they could use in specifying heat exchangers for these applications. 
So far, a simple design tool has not been developed that can be used to analyze the performance of load-size heat exchangers. To effectively compare load-side heat exchangers to other types of heat exchangers, a numerical model, such as the one discussed in this report, must be used. Similarly, parametric analysis to investigate the effect of heat exchanger area, flow rate, and storage tank size must presently be accomplished with a detailed numerical model. 


\subsection{REFERENCES}

Arpaci, V., and P. Larsen, 1984, Convection Heat Transfer, NJ: Prentice-Hall, Inc.

Clark, William, 1987, Meeting at SERI, March 4, 1987.

Conner, R. J., et al., June 1981, Martin Marietta Thermal Analysis System (MITAS), MOS-SPLPD-71-FD238, Denver, CO: Martin Marietta Corp.

Fanney, A., and S. Klein, 1986, "Thermal Performance Comparisons for Solar Hot Water Systems Subjected to Various Collector and Heat Exchanger Flow Rates," ASES '86, Proceedings of the 1986 Annual Meeting, Boulder, Co: American Solar Energy Society, Inc., Pp. 256-259.

Farrington, R. B., 1986, Test Results of Immersed-Coil Heat Exchangers and Liquid Storage Tanks Used in the Packaged Systems Program, SERI/TR-254-2841, Golden, CO: Solar Energy Research Institute.

Farrington, R., and C. Bingham, 1986, Testing and Analys is of Immersed Heat Exchangers, SERI/TR-254-2866, Golden, CO: Solar Energy Research Institute.

Feiereisen, T., 1982, "An Experimental Study of Immersed Coil Heat Exchangers," Master's thesis, Madison, WI: University of Wisconsin.

Feiereisen, T., S. Klein, J. Duffie, and W. Beckman, 1982, "Heat Transfer from Immersed Coils," ASME 82-WA/So1-18, Madison, WI: University of Wisconsin.

Jones, G. F., J. D. Balcomb, and D. R. Otis, 1985, A Model for Thermally Driven Heat and Air Transport in Passive Solar Buildings, ASME 85-WA/HT-69, presented at the ASME Winter Annual Meeting, November 17-21, 1985 in Miami Beach, Fla., New York: ASME.

Klett, D., D. Goswami, and M. Saad, Apr. 1983, "Thermal Performance of Submerged Coil Heat Exchangers Used in Solar Energy Storage Tanks," presented at ASME technical conference on commercial building heating and cooling applications, held 19 Apr. in Orlando, FL.

Kreith, F., and M. Bohn, 1986, Principles of Heat Transfer, 4th edition, NY: Harper and Row.

Kutscher, C., et al., Aug. 1982, Design Approaches for Solar Industrial Process Heat Systems, SERI/TR-253-1356, Golden, CO: Solar Energy Research Institute.

Kutscher, C., et al., July 1984, Low-Cost Collectors/Systems Development Progress Report, SERI/RR-253-1750, Golden, CO: Solar Energy Research Institute.

McAdams, W., 1954, Heat Transmission, NY: McGraw-Hi11 Book Company, Inc.

Petukhov, B. S., 1970, "Heat Transfer and Friction in Turbulent Pipe Flow with Variable Physical Properties," Advances in Heat Transfer, Vo1. 6, p. 503. 


\section{APPENDIX A \\ MEASUREMENT UNCERTAINTY ANALYSIS}

\section{A.1 Sources of Heat Exchanger Test Measurement Error}

In a recent conference paper, Farrington and Wells [1] discuss the procedure used for this measurement uncertainty analysis. This method is based on ASME Performance Test Code 19.1-1985 [2]. Table A-1 lists sources of elemental error for measuring the effectiveness of an immersed heat exchanger. Within each category, the error sources are classified as to their nature, whether they cause scatter in the data (random or precision errors), or whether they cause fixed offsets in the data (systematic or bias errors).

The elemental errors were derived from various sources. When possible they were measured or derived from manufacturers' specifications. When this was not possible they were calculated or estimated using the best information available.

First, the sources of error in the calibration process were considered. These errors originated from the standards used to establish the known temperatures, the circulating liquid calibration baths in which the temperature sensors were calibrated, the instrumentation to measure the sensors during the calibration, self-heating errors in the sensors during calibration, etc. The errors that resulted from the curve-fitting process used with the calibration data to establish the polynomial expressions (used in the data acquisition computer to calculate temperatures from measuring the resistance of the sensors) are included in the data reduction category of errors.

Four-wire RTDs were used where possible to eliminate the effect of lead resistance. The RTD leads were short-circuited near the sensor to ensure that a proper four-wire measurement was being made.

Very small thermistors with a very short time constant (measured as $18 \mathrm{~ms}$ using the plunge into water technique) to avoid disturbing the convective flow and allowing detection of very rapid changes in the convective currents were used to measure the tank temperature.

The thermistors were provided with 2-m leads calibrated by the manufacturer. The tank temperature thermistor had a $2-\mathrm{m}$ lead resistance of $46.79 \Omega$ and a resistance from additional leads of $3.40 \Omega$. The lead resistance was accounted for in the data acquisition program. The change in resistance of the leads, because of varying temperature of the environment, was less than $1 \mathrm{mK}$. 
Table A-1. Elemental Errors (mK)

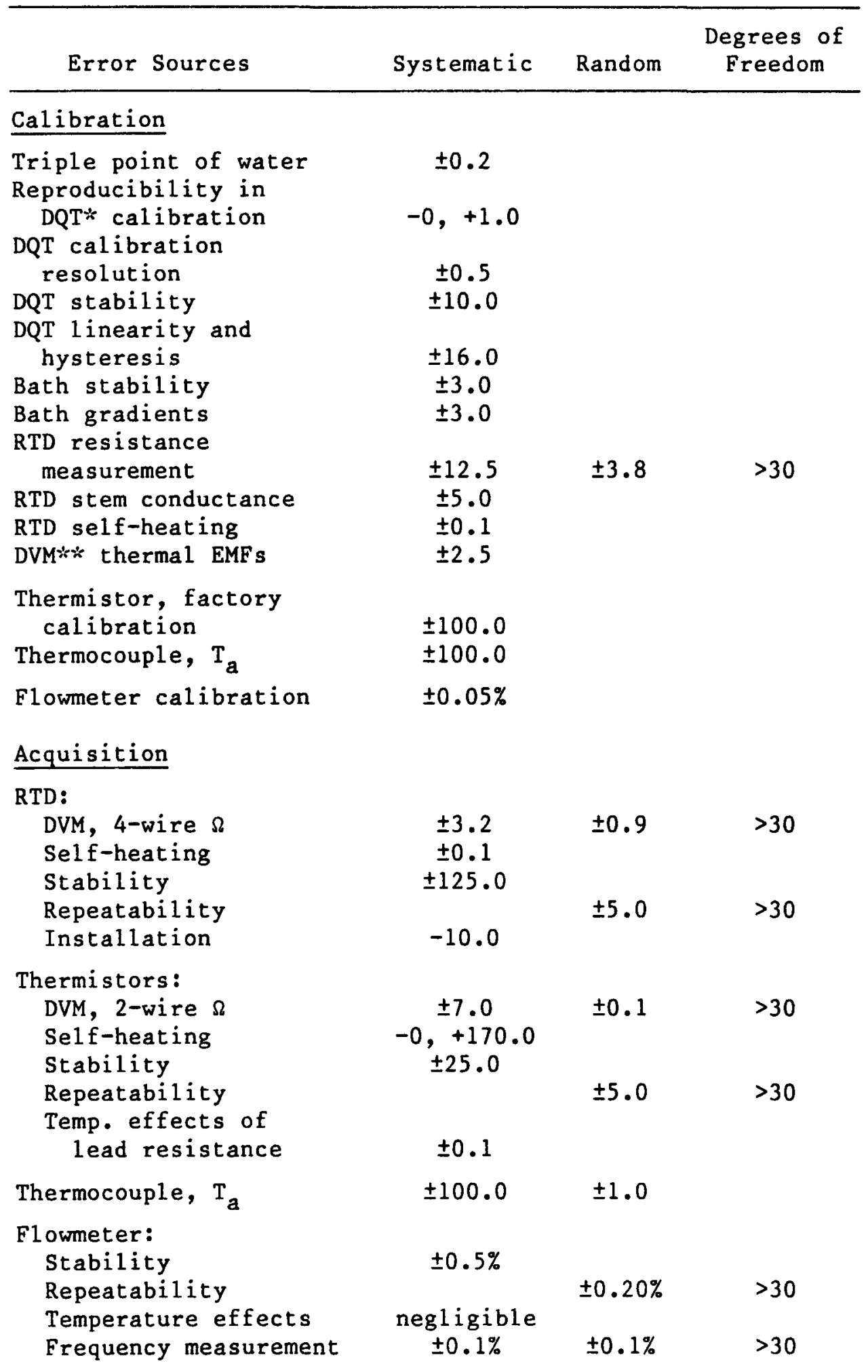


Table A-1. Elemental Errors (mK) (Concluded)

\begin{tabular}{|c|c|c|c|}
\hline Error Sources & Systematic & Random & $\begin{array}{l}\text { Degrees of } \\
\text { Ereedom }\end{array}$ \\
\hline \multicolumn{4}{|l|}{ Reduction } \\
\hline $\begin{array}{l}\text { RTD curve-fitting to } \\
\text { calibration data } \\
\text { (worst residual) }\end{array}$ & \pm 2.1 & & \\
\hline $\begin{array}{l}\text { Computation of } \\
\text { temperature } \\
\text { from polynomial }\end{array}$ & & \pm 5.0 & $>30$ \\
\hline $\begin{array}{l}\text { Curve-fitting } T_{1} \\
\text { Curve-fitting flow rate }\end{array}$ & $\begin{array}{l} \pm 50.0 \\
\pm 0.3 \%\end{array}$ & & \\
\hline
\end{tabular}

*DQT, HP 2804A digital quartz thermometer. **DVM, HP 3056A digital voltmeter.

\section{A.2 Uncertainty Calculations and Results}

Theoretically, only three sensors are required to determine the effectiveness of an immersed heat exchanger, those that measure: the temperature of the fluid entering the heat exchanger, the temperature of the fluid leaving the heat exchanger, and the temperature of the tank.

The effectiveness for an immersed heat exchanger is

$$
\varepsilon=\frac{\mathrm{T}_{\mathrm{Hx}, \mathrm{O}}-\mathrm{T}_{\mathrm{Hx}, \mathrm{i}}}{\mathrm{T}_{\mathrm{S}}-\mathrm{T}_{\mathrm{Hx}, \mathrm{i}}} \text {. }
$$

The total systematic error is

$$
\mathrm{B}_{\varepsilon}=\left[\left(\frac{\partial \varepsilon}{\partial \mathrm{T}_{\mathrm{Hx}, 0}} \mathrm{~B}_{\mathrm{Tx}, \mathrm{o}}\right)^{2}+\left(\frac{\partial \varepsilon}{\partial \mathrm{T}_{\mathrm{Hx}, \mathrm{i}}} \mathrm{B}_{\mathrm{T}_{\mathrm{Hx}, \mathrm{i}}}\right)^{2}+\left(\frac{\partial \varepsilon}{\partial \mathrm{T}_{\mathrm{S}}} \mathrm{B}_{\mathrm{T}_{\mathrm{S}}}\right)^{2}\right] 1 / 2,
$$

which equals

$$
\begin{gathered}
\mathrm{B}_{\varepsilon}=\left\{\left(\frac{1}{\mathrm{~T}_{\mathrm{S}}-\mathrm{T}_{\mathrm{Hx}, \mathrm{i}}}\right)^{2} \mathrm{~B}_{\mathrm{T}_{\mathrm{Hx}, \mathrm{o}}^{2}}^{2}+\left[\frac{\mathrm{T}_{\mathrm{S}}-\mathrm{T}_{\mathrm{Hx}, \mathrm{o}}}{\left(\mathrm{T}_{\mathrm{S}}-\mathrm{T}_{\mathrm{Hx}, \mathrm{i}}\right)^{2}}\right]^{2} \mathrm{~B}_{\mathrm{Tx}, \mathrm{i}}^{2}\right. \\
\left.+\left[\frac{\mathrm{T}_{\mathrm{Hx}, 0}-\mathrm{T}_{\mathrm{Hx}, \mathrm{i}}}{\left(\mathrm{T}_{\mathrm{S}}-\mathrm{T}_{\mathrm{Hx}, \mathrm{i}}\right)^{2}}\right]^{2} \mathrm{~B}_{\mathrm{T}_{\mathrm{S}}}^{2}\right\}^{1 / 2},
\end{gathered}
$$

where the Bs are the total systematic errors for that measurement. The same equation is used to calculate the total random error for the heat exchanger effectiveness except that the individual random measurement errors $R_{J}$ are used instead of $\mathrm{B}_{\mathrm{J}}$.

Properly combining the uncertainties (including using methods of combining large and small errors) from each elemental source of error leads to the results shown in Table A-2. 
Table A-2. Total Sensor Measurement Uncertainty (mK)

\begin{tabular}{lcc}
\hline \multicolumn{1}{c}{ Measurement } & Bias Limit & $\begin{array}{c}\text { Random } \\
\text { Uncertainty }\end{array}$ \\
\hline $\begin{array}{l}\text { Heat exchanger } \\
\text { inlet temperature }\end{array}$ & \pm 67.3 & \pm 18.8 \\
$\begin{array}{l}\text { Heat exchanger } \\
\text { outlet temperature }\end{array}$ & \pm 67.3 & \pm 18.8 \\
Tank temperature & $+295.1,-125.2$ & \pm 5.0 \\
Ambient temperature & \pm 150 & \pm 1.0 \\
Flow rate & $\pm 0.59 \%$ & $\pm 0.22 \%$ \\
\hline
\end{tabular}

The uncertainties need to be calculated for the total positive systematic error and the total negative systematic error (since these are some asymmetrical systematic errors) as well as the total random error. After that the two types of errors are combined. For a high temperature difference between the smooth-coil heat exchanger inlet and tank, the following conditions existed during the test:

$$
\begin{aligned}
\dot{\mathrm{m}} & =0.168 \mathrm{~kg} / \mathrm{s}(10.1 \mathrm{~L} / \mathrm{min}) \\
\mathrm{T}_{\mathrm{S}} & =55.47^{\circ} \mathrm{C} \\
\mathrm{T}_{\mathrm{Hx}, \mathrm{i}} & =17.50^{\circ} \mathrm{C} \\
\mathrm{T}_{\mathrm{Hx}, \mathrm{o}} & =54.27^{\circ} \mathrm{C} \\
\mathrm{UA}_{\mathrm{Hx}} & =1957 \mathrm{~W} /{ }^{\circ} \mathrm{C} \\
\mathrm{q} & =25,866 \mathrm{~W} \\
\varepsilon & =96.8 \% .
\end{aligned}
$$

These values are put into $\mathrm{Eq} . \mathrm{A}-3$, which results in

$$
\mathrm{B}_{\varepsilon}=\left(0.026 \mathrm{~B}_{\mathrm{T}_{\mathrm{Hx}, \mathrm{o}}}^{2}+0.00083 \mathrm{~B}_{\mathrm{T}_{\mathrm{Hx}, \mathrm{i}}}^{2}+0.026 \mathrm{~B}_{\mathrm{T}_{\mathrm{S}}}^{2}\right)^{1 / 2}
$$

It is clear that at these conditions the accuracy of $\mathrm{T}_{\mathrm{Hx}}$, and $\mathrm{T}_{\mathrm{S}}$ are more important than $\mathrm{T}_{\mathrm{Hx}, \mathrm{i}}$ - This basic equation is used to calculate both systematic errors (positive and negative) and the random error. The sensor uncertainties from Table $\mathrm{A}-2$ are used in $\mathrm{Eq}$. $\mathrm{A}-4$ to give

$$
\begin{aligned}
& \mathrm{B}_{\varepsilon}^{+}=0.008 \\
& \mathrm{~B}_{\varepsilon}^{-}=0.004 .
\end{aligned}
$$

The same procedure is followed for the total random error, which leads to

$$
R_{\varepsilon}= \pm 0.0005 \text {. }
$$


It is important to realize that the systematic errors are much larger than the random errors.

At this point the different types of errors are combined to get

$$
\begin{aligned}
& U_{95}^{+}=+0.008 \\
& U_{95}^{-}=-0.004
\end{aligned}
$$

for $\mathrm{U}_{95}$ and

$$
\begin{aligned}
& U_{99}^{+}=+0.009 \\
& U_{99}^{-}=-0.005
\end{aligned}
$$

for $\mathrm{U}_{99}$. For this example the overall uncertainty using $\mathrm{U}_{95}$ is

$$
\varepsilon=0.968+0.008,-0.004 \text {, }
$$

or an error range from $-0.4 \%$ to $+0.8 \%$. The error range using $U_{99}$ is $-0.5 \%$ to $+0.9 \%$.

Higher errors would be expected at smaller temperature differences. For a low temperature difference between the smooth-coil heat exchanger inlet and tank, the following conditions existed during the testing:

$$
\begin{aligned}
\dot{\mathrm{m}} & =0.168 \mathrm{~kg} / \mathrm{s}(10.09 \mathrm{~L} / \mathrm{min}) \\
\mathrm{T}_{\mathrm{S}} & =29.46^{\circ} \mathrm{C} \\
\mathrm{T}_{\mathrm{Hx}, \dot{\mathrm{i}}} & =16.25^{\circ} \mathrm{C} \\
\mathrm{T}_{\mathrm{Hx}, \mathrm{o}} & =27.71^{\circ} \mathrm{C} \\
\mathrm{UA}_{\mathrm{Hx}} & =1395 \mathrm{~W} /{ }^{\circ} \mathrm{C} \\
\mathrm{q} & =8061 \mathrm{~W} \\
\mathrm{E} & =86.8 \% .
\end{aligned}
$$

When these values are put into Eq. A-4, the result is

$$
\mathrm{B}_{\varepsilon}=\left(0.076 \mathrm{~B}_{\mathrm{T}_{\mathrm{Hx}, 0}^{2}}^{2}+0.01 \mathrm{~B}_{\mathrm{T}_{\mathrm{Hx}, \mathrm{i}}}^{2}+0.066 \mathrm{~B}_{\mathrm{T}_{\mathrm{S}}}^{2}\right)^{1 / 2} \text {. }
$$

At the low temperature differences, the accuracy of $\mathrm{T}_{\mathrm{Hx}, \mathrm{O}}$ is the most important contributor for both the systematic and random errors. Following the same procedures as before, the results are

$$
\begin{aligned}
& \mathrm{B}_{\varepsilon}^{+}=+0.02 \\
& \mathrm{~B}_{\varepsilon}^{-}=-0.01 \\
& \mathrm{R}= \pm 0.001
\end{aligned}
$$


and

$$
\begin{aligned}
& \mathrm{U}_{95}=+0.02,-0.01 \\
& \mathrm{U}_{99}=+0.023,-0.013 .
\end{aligned}
$$

This leads to the result that the overall uncertainty using $U_{95}$ ranges from $-1.2 \%$ to $+2.3 \%$ of the measured effectiveness. The uncertainty range increases using $U_{99}$, ranging from $-1.5 \%$ to $+2.6 \%$ of the measured effectiveness. This higher uncertainty is expected at the lower temperature difference since the sensor error is a larger fraction of the temperature differences.

Since the uncertainty of the effectiveness is so much greater for the smaller temperature differences, we calculated the uncertainties after each scan. A plot of the heat exchanger effectiveness plus or minus the uncertainty is shown in Figure A-1(a) for the low temperature difference case.

However, for back-to-back tests and comparisons, the systematic error cancels and the uncertainty is $t_{95} R$, which is equal to \pm 0.001 or $\pm 0.1 \%$ for the first example and \pm 0.002 or $\pm 0.2 \%$ for the second example.

The heat transfer was calculated from Eq. 2-4.

The total systematic error of the calculated heat transfer is

$$
\mathrm{B}_{\mathrm{q}}=\dot{\mathrm{m}} \mathrm{C}_{\mathrm{p}}\left\{\left[\frac{\left(\mathrm{T}_{\mathrm{Hx}, \mathrm{o}}-\mathrm{T}_{\mathrm{Hx}, \mathrm{i}}\right)}{\dot{\mathrm{m}}}\right]^{2} \underset{\mathrm{m}}{2}+\mathrm{B}_{\mathrm{T}_{\mathrm{Hx}, \mathrm{i}}}^{2}+\mathrm{B}_{\mathrm{T}_{\mathrm{Hx}, \mathrm{o}}}^{2}\right\}^{1 / 2} \text {, }
$$

which assumes negligible error in calculating the heat capacity of water, as was done for the other calculations.

The heat-exchanger UA was calculated from Eq. 2-5.

The total systematic error of the heat-exchanger UA is

where

$$
\begin{aligned}
& B(U A)_{H x}=\left\{\left(\frac{u}{T_{S, t}-T_{H x, o}}-u v y\right) 2 B_{T_{S}, t}^{2}+\left(\frac{-u}{T_{S, b}-T_{H x, i}}+u v y\right)^{2} B_{T_{S, b}}^{2}\right. \\
& +\left[\frac{\mathrm{u}}{\mathrm{T}_{\mathrm{S}, \mathrm{b}}-\mathrm{T}_{\mathrm{Hx}, \mathrm{i}}}-\mathrm{vy}\left(\mathrm{u}+\dot{\mathrm{m}} \mathrm{C}_{\mathrm{p}}\right)\right]^{2} \mathrm{~B}_{\mathrm{T}_{\mathrm{Hx}, \mathrm{i}}^{2}}^{2} \\
& +\left[\frac{-u}{\mathrm{~T}_{\mathrm{S}, \mathrm{t}}-\mathrm{T}_{\mathrm{Hx}, \mathrm{o}}}+\mathrm{vy}\left(\mathrm{u}+\dot{\mathrm{m}} \mathrm{C}_{\mathrm{p}}\right)\right] 2 \mathrm{~B}_{\mathrm{T}}^{2} \mathrm{Hx}_{\mathrm{o}}
\end{aligned}
$$

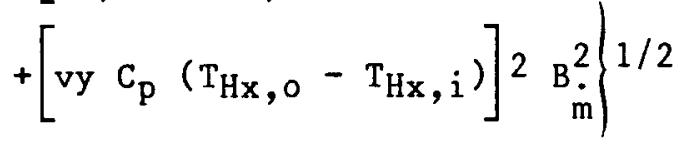

$$
u=\dot{m} c_{p} \frac{\left(T_{H x, o}-T_{H x, i}\right)}{\left(T_{S, t}-T_{H x, o}\right)-\left(T_{S, b}-T_{H x, i}\right)}
$$




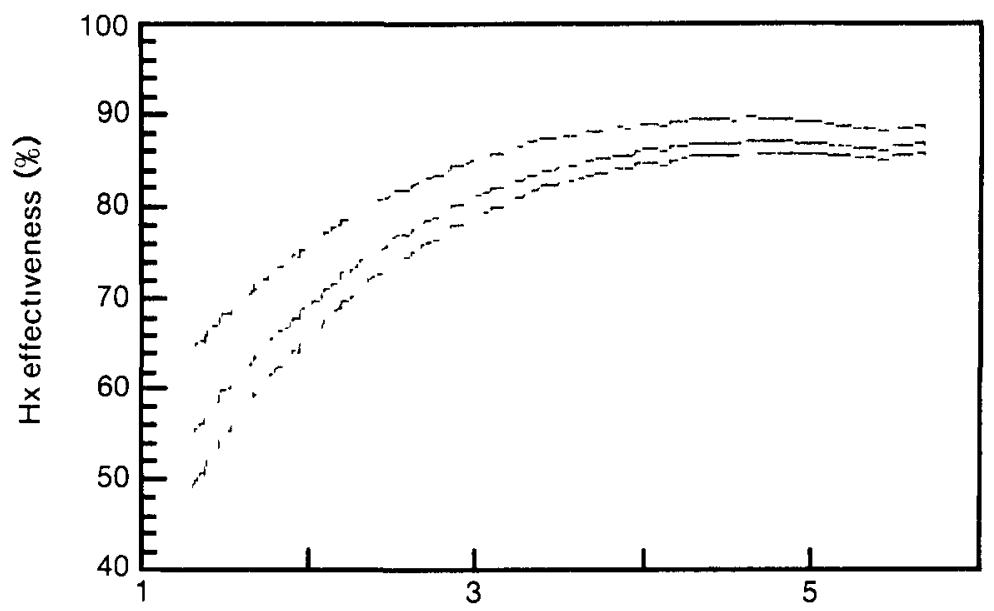

(a) Heat exchanger effectiveness plus 蓉 or minus $U$ versus LMTD

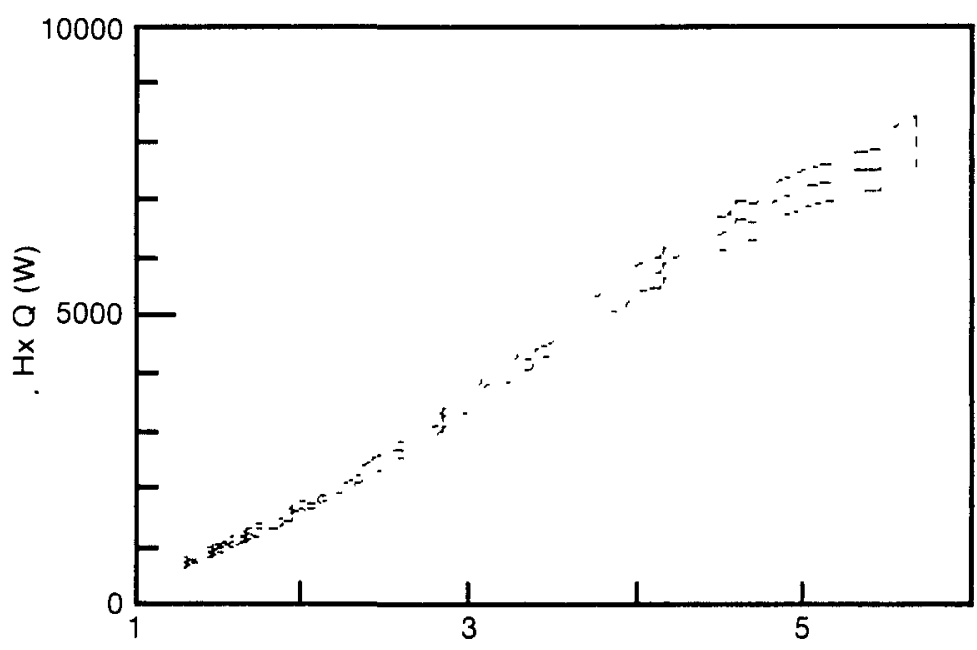

(b) Heat exchanger $Q$ plus or minus $U$ versus LMTD

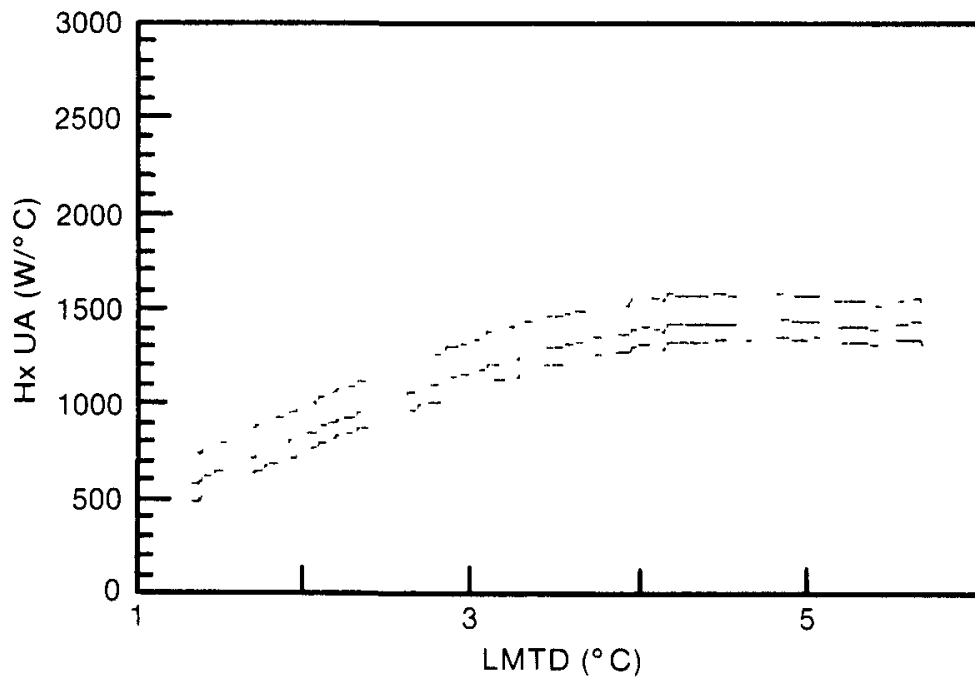

(c) Heat exchanger UA plus or minus $U$ versus LMTD

Figure A-1. Uncertainty of Effectiveness, Heat Transfer Rate, and UA for $10 \mathrm{~L} / \mathrm{min}, 10^{\circ}, \Delta \mathrm{t}$ Case 


$$
\begin{aligned}
& v=\ln \left(\frac{\mathrm{T}_{\mathrm{S}, t}-\mathrm{T}_{\mathrm{Hx}, \mathrm{o}}}{\mathrm{T}_{\mathrm{S}, \mathrm{b}}-\mathrm{T}_{\mathrm{Hx}, \mathrm{i}}}\right) \\
& \mathrm{y}=\left[\left(\mathrm{T}_{\mathrm{S}, \mathrm{t}}-\mathrm{T}_{\mathrm{Hx}, \mathrm{o}}\right)-\left(\mathrm{T}_{\mathrm{S}, \mathrm{b}}-\mathrm{T}_{\mathrm{Hx}, \mathrm{i}}\right)\right]-1 .
\end{aligned}
$$

A summary of the bias 1 imits (or systematic error) and random errors is given in Table A-3 for the effectiveness, heat transfer, and UA for both the high and low temperature difference cases. A summary of the total measurement error for both cases is given in Table A-4 for each calculated quantity.

Plots of the heat transfer rate and UA of the hejt exchanger along with their uncertainties are shown in Figures $A-1(b)$ and $A-1(c)$, respectively, for the low temperature difference case.

Since our final systematic errors were asymmetrical, we calculated positive and negative uncertainties. These results state that the actual effectiveness should rarely be beyond these uncertainty limits. It also shows to what extent the heat exchanger effectiveness can be measured confidently. Changes in heat exchanger effectiveness of $0.10 \%$ to $0.23 \%$, which is the random uncertainty component of the result, can be measured if the instrumentation is not altered (sensors untouched, digital voltmeter [DVM] left on, same environmental conditions, etc.).

An end-to-end analysis of the measurement system was conducted using two digital quartz thermometer probes as reference temperatures in a stirred ice bath. The results were checked against systematic errors determined in the pretest analysis. The measurement system showed the response of $\mathrm{T}_{\mathrm{Hx}}, \mathrm{i}$ to be $0.023 \mathrm{~K}$ below and $\mathrm{T}_{\mathrm{Hx}}$, o to be equal to the digital quartz thermometers near the ice point of water. Each sensor had 100 consecutive readings taken to determine the random error of the measurement system for that sensor. The random error was $2.3 \mathrm{mK}$ for the heat exchanger inlet RTD, $2.2 \mathrm{mK}$ for the heat exchanger outlet RTD, and $0.7 \mathrm{mK}$ for the tank thermistor. These results show that the errors are well within the expected range of errors. However, the end-to-end check includes some built-in systematic errors in the standards that could not be determined. The results of the end-to-end check are well within the detailed calculations and are a necessary and useful check to show that there were not any gross errors in the experiment or uncertainty analysis.

Sensor failure, including severe degradation or catastrophic failure, will cause the result to exceed the uncertainty limits. In addition, the measurements must be in the proper location.

Table A-3. Summary of Bias Limits and Random Errors

\begin{tabular}{lccccc}
\hline \multirow{2}{*}{ Quantity } & \multicolumn{2}{c}{ High $\Delta \mathrm{T}$} & \multicolumn{2}{c}{ Low $\Delta \mathrm{T}$} \\
\cline { 2 - 3 } & Bias Limit & Random Error & & Bias Limit & Random Error \\
\hline $\mathrm{q}(\mathrm{W})$ & $-0.004,+0.008$ & \pm 0.0005 & & $-0.01,+0.02$ & \pm 0.001 \\
$\mathrm{UA}_{\mathrm{Hx}}\left(\mathrm{W} /{ }^{\circ} \mathrm{C}\right)$ & $-73,+87$ & \pm 339 & & \pm 291 & \pm 107 \\
\hline
\end{tabular}


Table A-4. Measurement Uncertainty Summary

\begin{tabular}{|c|c|c|c|c|c|c|}
\hline \multirow{2}{*}{ Quantity } & \multicolumn{3}{|c|}{$\mathrm{High} \Delta \mathrm{T}$} & \multicolumn{3}{|c|}{ Low $\Delta \mathrm{T}$} \\
\hline & Value & $\mathrm{U}_{95}$ & $\mathrm{U}_{99}$ & Value & $\mathrm{U}_{95}$ & $\mathrm{U}_{99}$ \\
\hline \multirow[t]{2}{*}{$\varepsilon$} & 0.968 & $-0.004,+0.008$ & $-0.005,+.009$ & 0.868 & $-0.01,+0.02$ & $-0.013,+0.023$ \\
\hline & & $-0.4 \%$ to $+0.8 \%$ & $-0.5 \%$ to $+0.9 \%$ & & $-1.1 \%$ to $+2.3 \%$ & $-1.5 \%$ to $+2.6 \%$ \\
\hline \multirow[t]{2}{*}{$q(W)$} & 25,860 & \pm 1128 & \pm 1576 & 8,061 & \pm 359 & \pm 501 \\
\hline & & $\pm 4.4 \%$ & $\pm 6.1 \%$ & & $\pm 4.5 \%$ & $\pm 6.2 \%$ \\
\hline \multirow[t]{2}{*}{$(\mathrm{UA})_{\mathrm{Hx}}\left(\mathrm{W} /{ }^{\circ} \mathrm{C}\right)$} & 1,957 & $-90,+101$ & $-125,+138$ & 1,395 & $-71,+91$ & $-98,+121$ \\
\hline & & $-4.6 \%$ to $+5.2 \%$ & $-6.4 \%$ to $+7.1 \%$ & & $-5.1 \%$ to $6.5 \%$ & $-7.0 \%$ to $+8.6 \%$ \\
\hline
\end{tabular}

임 
This uncertainty analysis was useful in detecting unsteady sensors and channels, increasing confidence in the results, and permitting others to make meaningful decisions by knowing the range of possible errors in the data.

\section{A.3 References}

1. Farrington, R. B., and C. V. Wells, A Thorough Approach to Measurement Uncertainty Analysis Applied to Immersed Heat Exchanger Testing, SERI/TP-253-2862, Golden, CO: Solar Energy Research Institute, April 1986.

2. Measurement Uncertainty, ANSI/ASME PTC 19.1-1985, New York: American Society of Mechanical Engineers, 1986. 


\section{APPENDIX B \\ TYPICAL EXPERIMENTAL OUTPUT, ORIGINAL FINNED HEAT EXCHANGER, $5 \mathrm{~L} / \mathrm{min}$}

Graphs 10 to 24 of Table 4-2 are shown in Figures B-1 through B-13 for all the $5-\mathrm{L} / \mathrm{min}(1.3-\mathrm{gal} / \mathrm{min})$ tests of the original (1arger-size) finned heat exchanger. These graphs show the results of plotting various performance characteristics versus different operating conditions and are for four different initial tank temperatures. The initial temperature differences are easily identified by the right end of each curve. Several items are noteworthy. In Figures $B-1$ and $B-2$, the calculated effectiveness exceeds $100 \%$. Because of the low flow rate, the heat exchanger outlet exceeded the average storage tank temperature, which the effectiveness values of these graphs used. The peak effectiveness did not occur at the beginning of the test (at the maximum temperature difference) but midway through the test, as the tank began to cool and the denominator in the effectiveness decreased. However, when the effectiveness was based on the temperature at the top of the storage tank, the effectiveness never exceeded $100 \%$, as seen in Figures B-9, B-11, and B-12.

It is easy to see that although the curves in any one of the plots are similar, they give different effectiveness values for a given temperature difference depending on the initial tank temperature. Certainly, these results are of 1 ittle value. What is needed is one effectiveness per operating point that is independent of how that point was reached.

Similar remarks can be made for graphs 12 to 15, shown in Figures B-3 through B-6. At flow rates greater than $5 \mathrm{~L} / \mathrm{min}(1.3 \mathrm{gal} / \mathrm{min})$, the heat $t$ rangfer rate plotted as a function of the difference between the average storage tank temperature and the heat exchanger inlet temperature produced results nearly independent of the temperature difference, as shown in Figure B-5 as an example of graph 14.

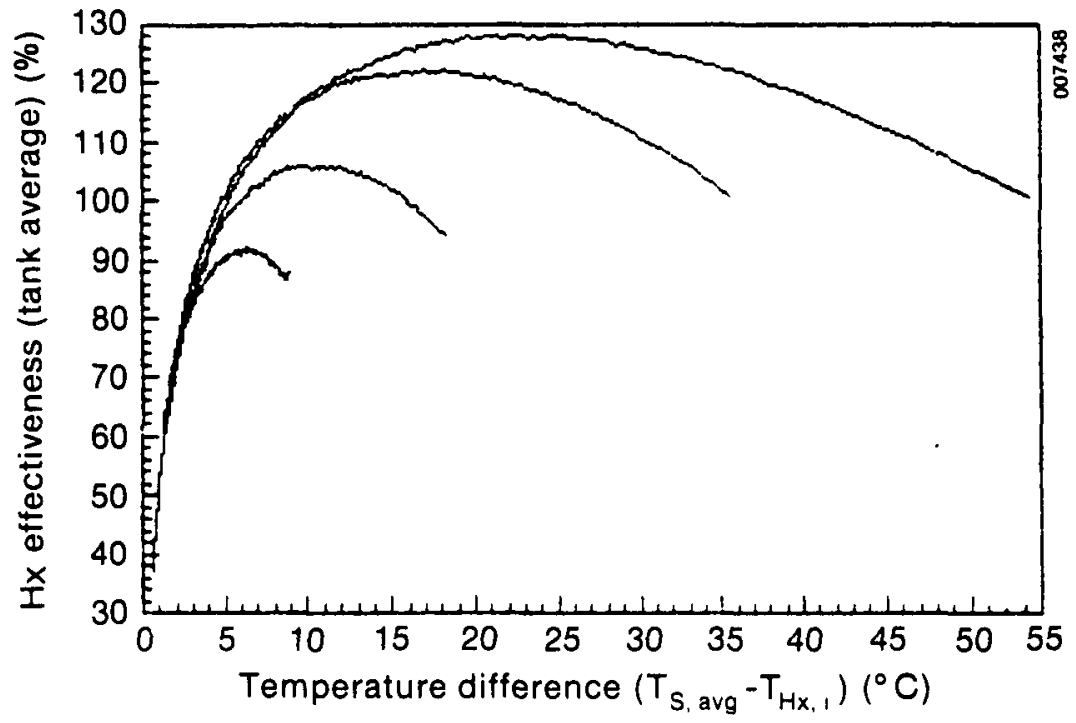

Figure B-1. Heat Exchanger Effectiveness, $\operatorname{Fn}\left(T_{S, \text { avg }}\right)$ versus $\left(T_{S, \text { avg }}-T_{H x, i}\right)$ 
Figures $B-7$ and $B-8$ are discussed as part of Figures $4-8$ and 4-9. Figure $B-13$ shows how the heat exchanger UA was a strong function of the temperature difference.

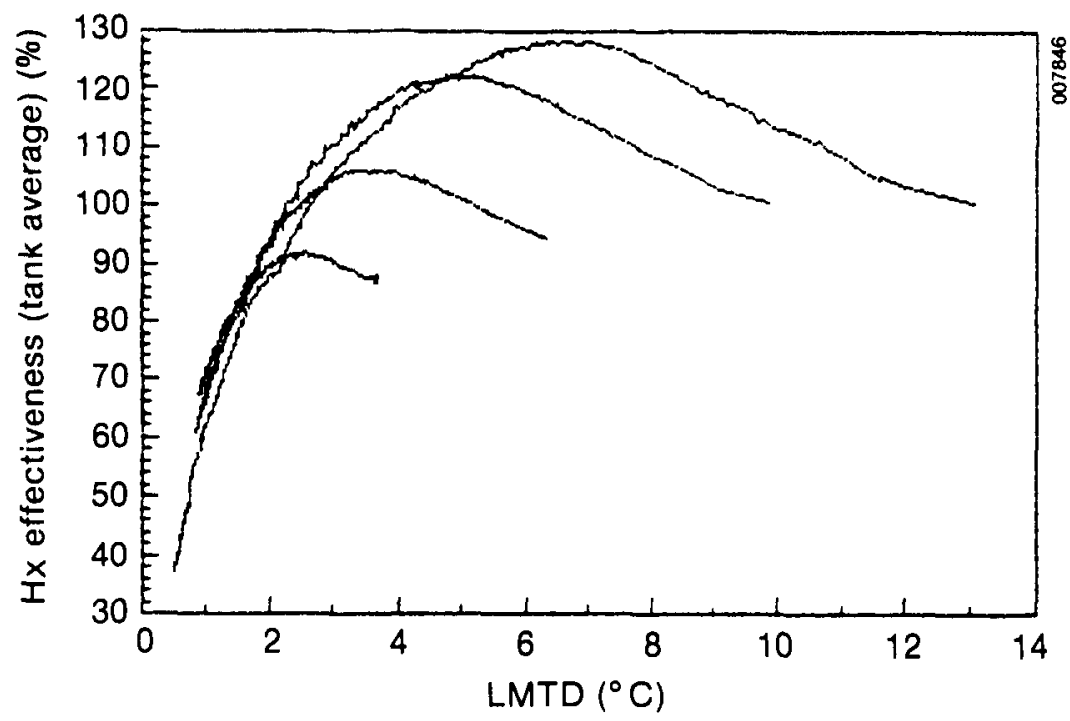

Figure B-2. Heat Exchanger Effectiveness, Fn $\left(T_{S, \text { avg }}\right)$ versus LMTD

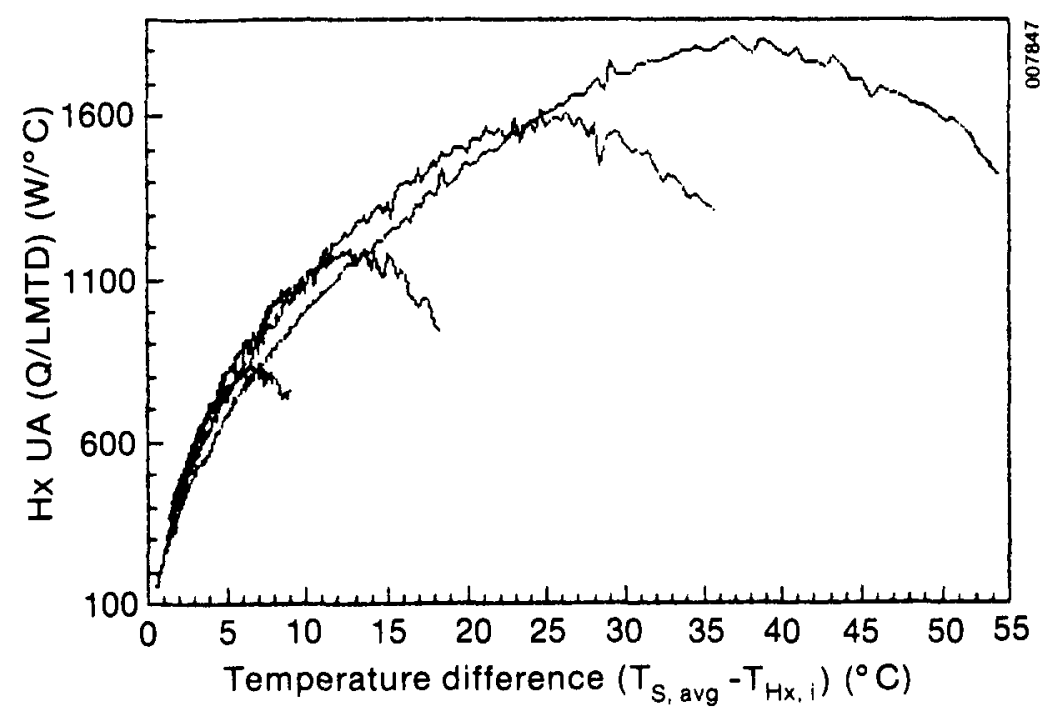

Figure B-3. Heat Exchanger UA, Fn(LMTD) versus

$$
\left(T_{S, a v g}-T_{H x, i}\right)
$$




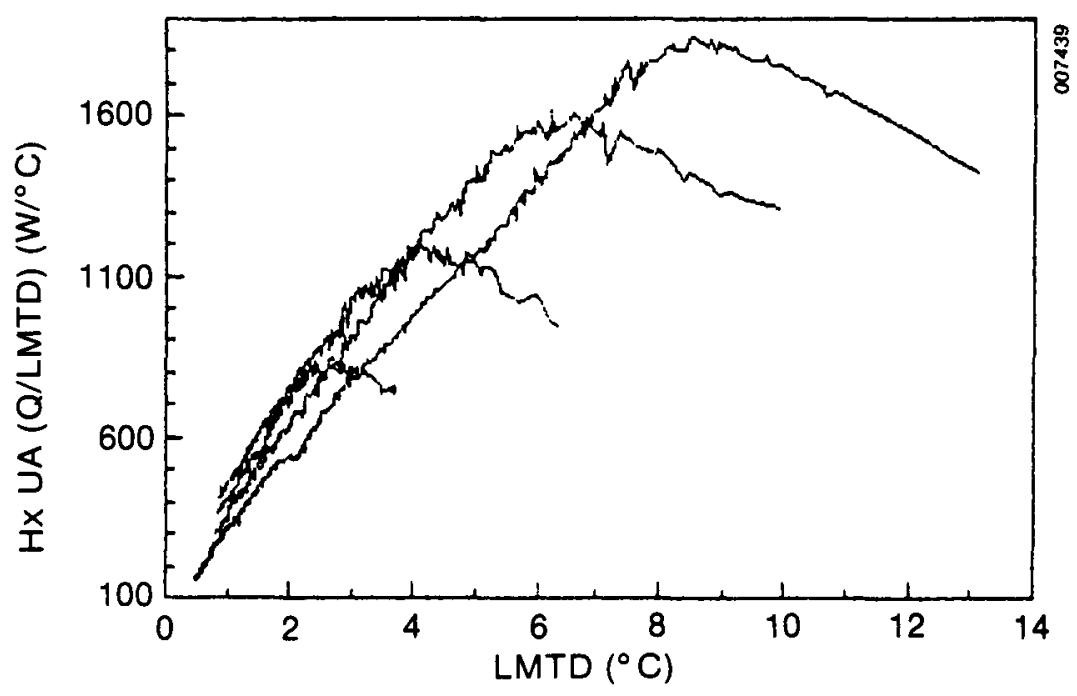

Figure B-4. Heat Exchanger UA, Fn(LMTD) versus LMTD

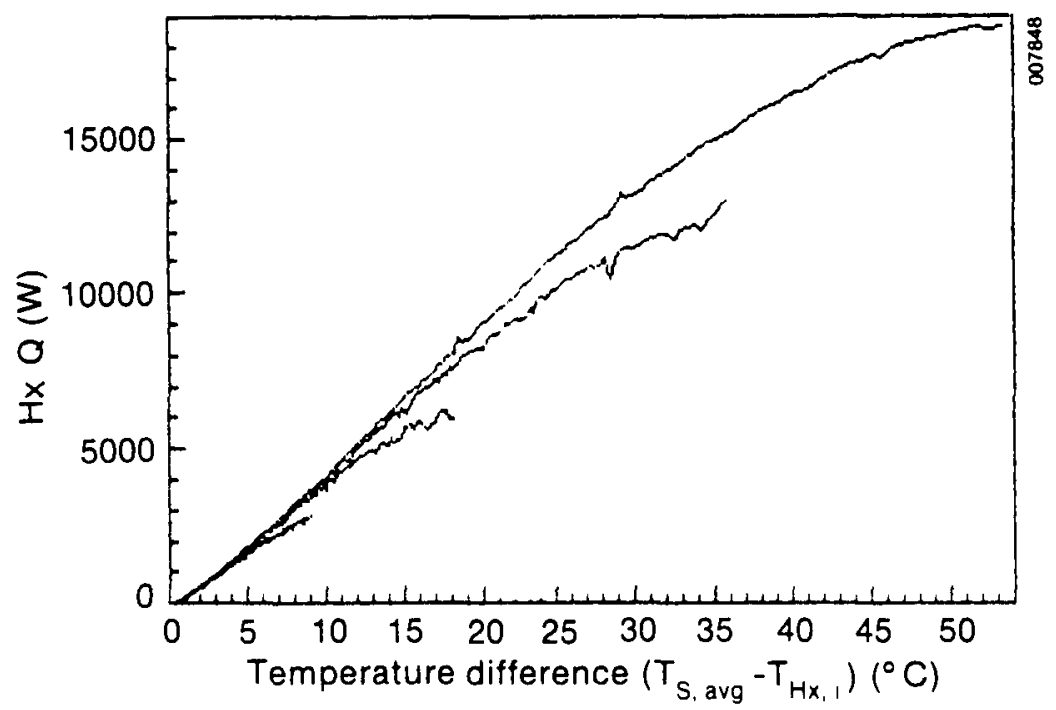

Figure B-5. Heat Exchanger Heat Transfer Rate versus $\left(T_{S, \text { avg }}-T_{H x, i}\right)$ 


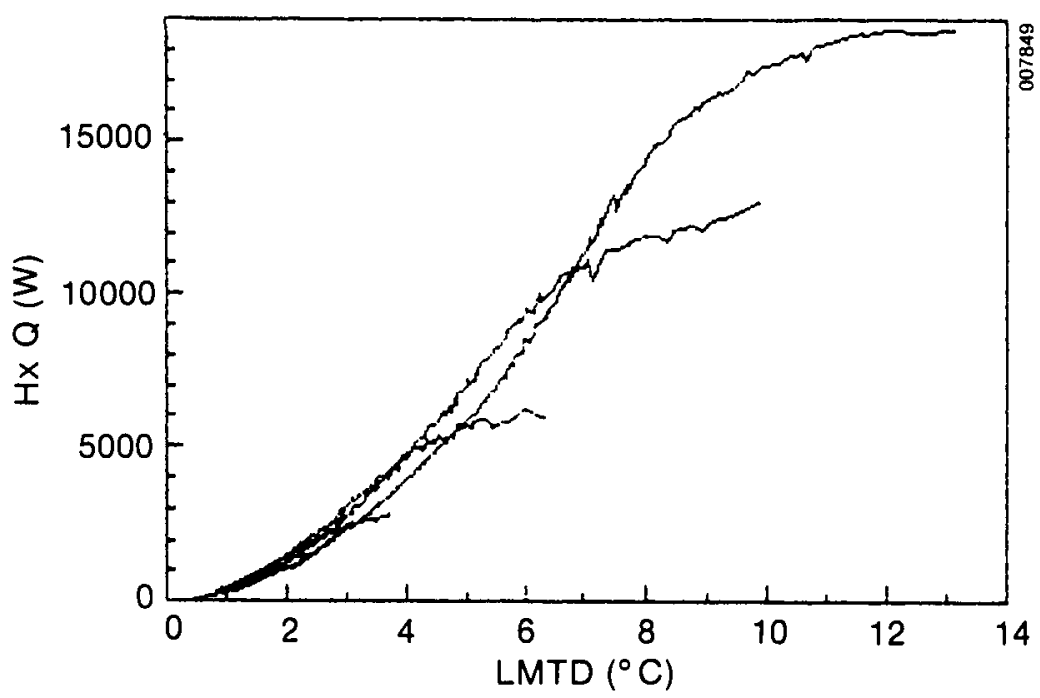

Figure B-6. Heat Exchanger Heat Transfer Rate versus LMTD

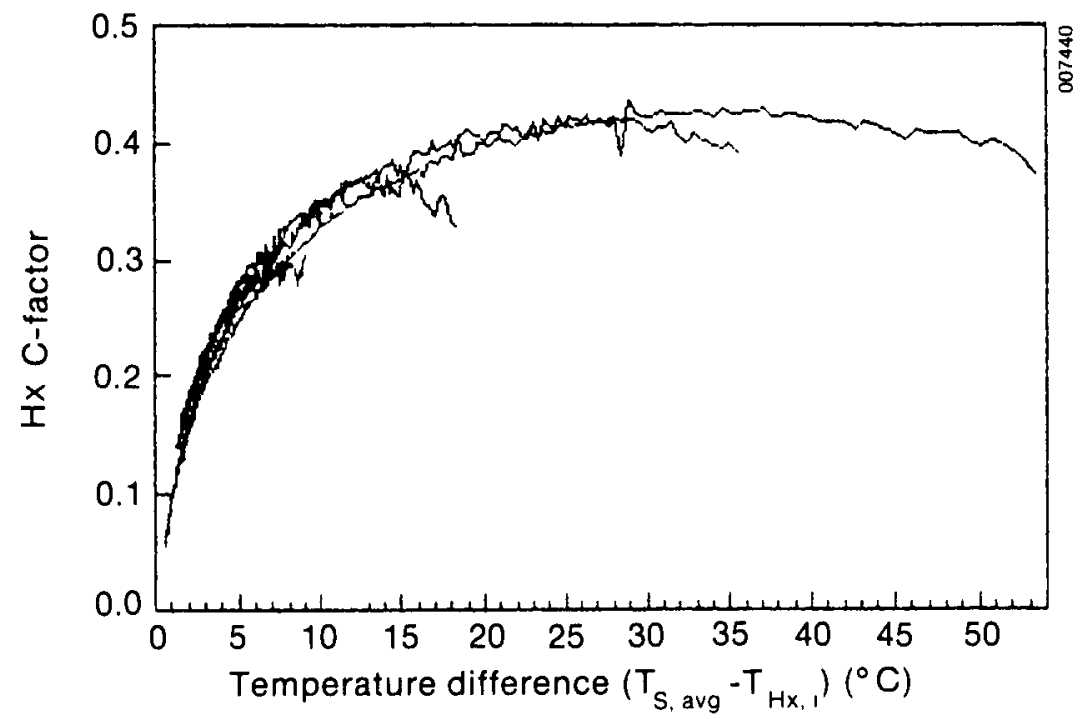

Figure B-7. Heat Exchanger C-factor versus ( $\mathrm{T}_{\mathrm{S}, \text { avg }}-\mathrm{T}_{\mathrm{Hx}, \mathrm{i}}$ ) 


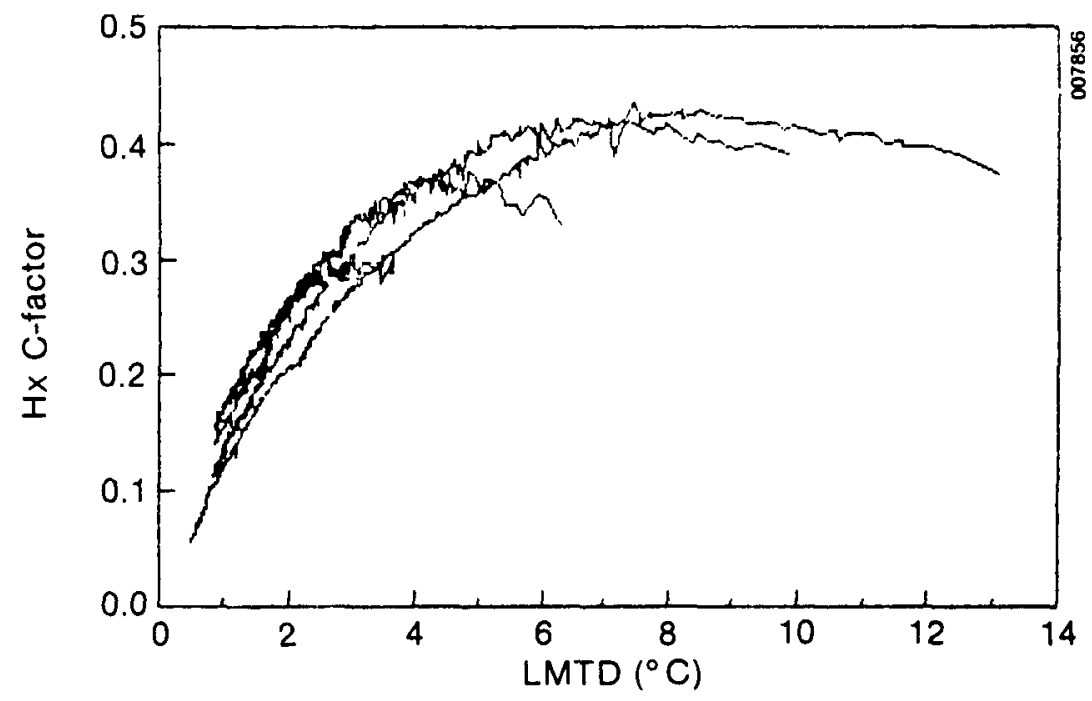

Figure B-8. Heat Exchanger C-factor versus LMTD

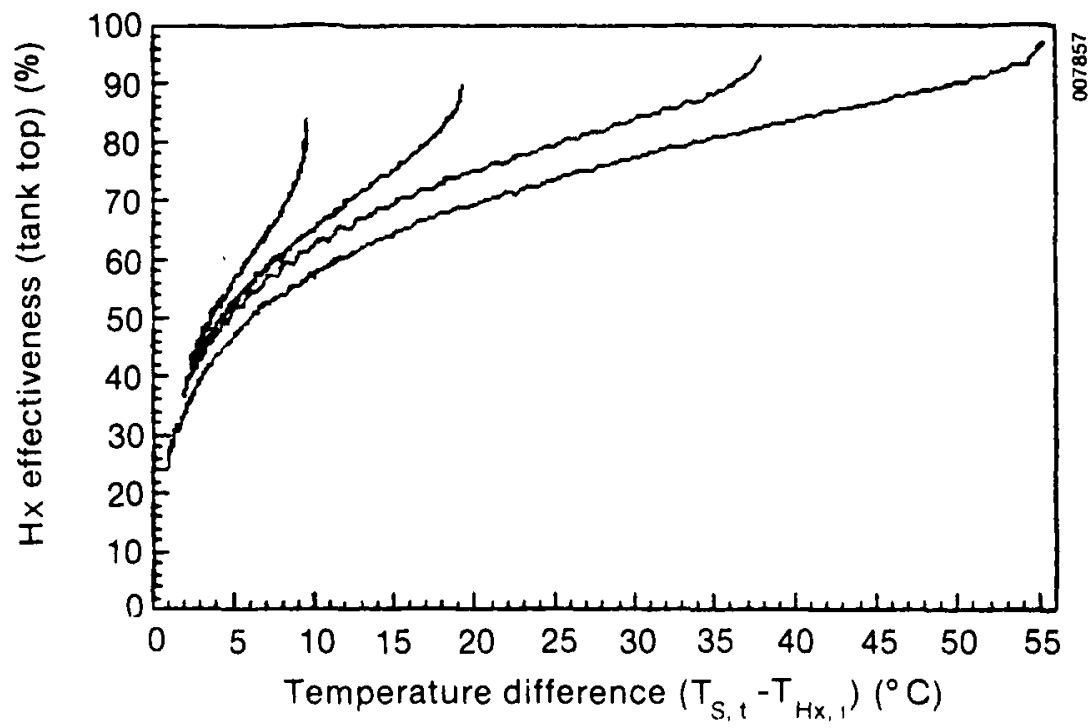

Figure B-9. Heat Exchanger Effectiveness,

$$
\operatorname{Fn}\left(T_{S, t}\right) \text { versus }\left(T_{S, t}-T_{H x, i}\right)
$$




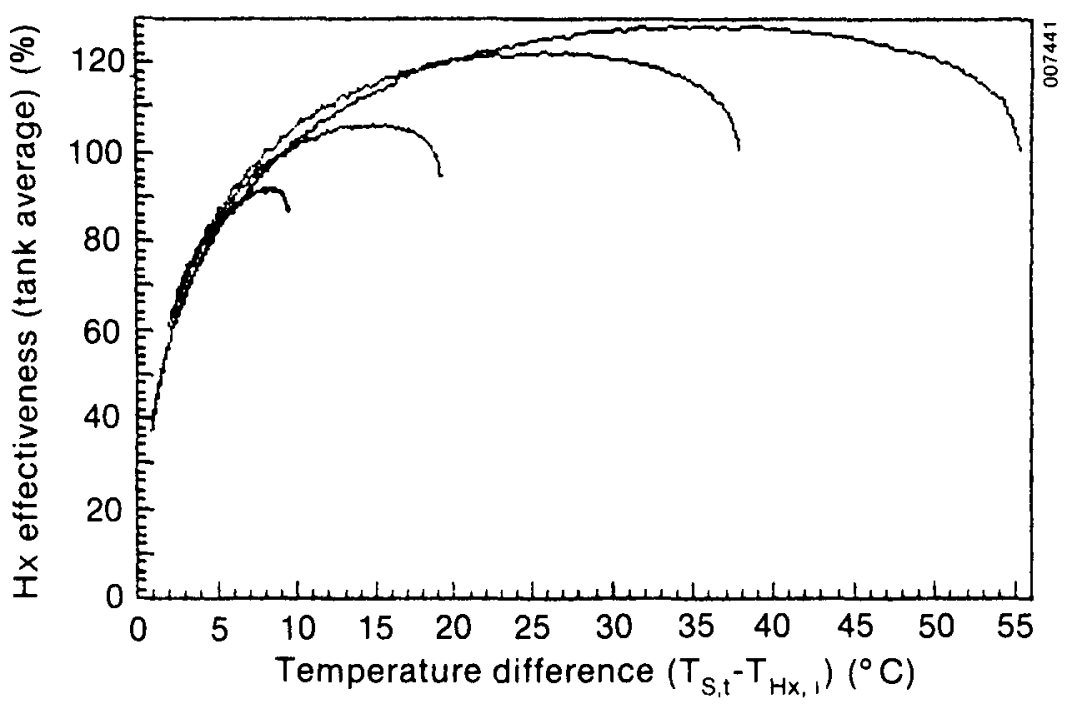

Figure B-10. Heat Exchanger Effectiveness,

$$
\operatorname{Fn}\left(T_{S, \text { avg }}\right) \text { versus }\left(T_{S, t}-T_{H x, i}\right)
$$

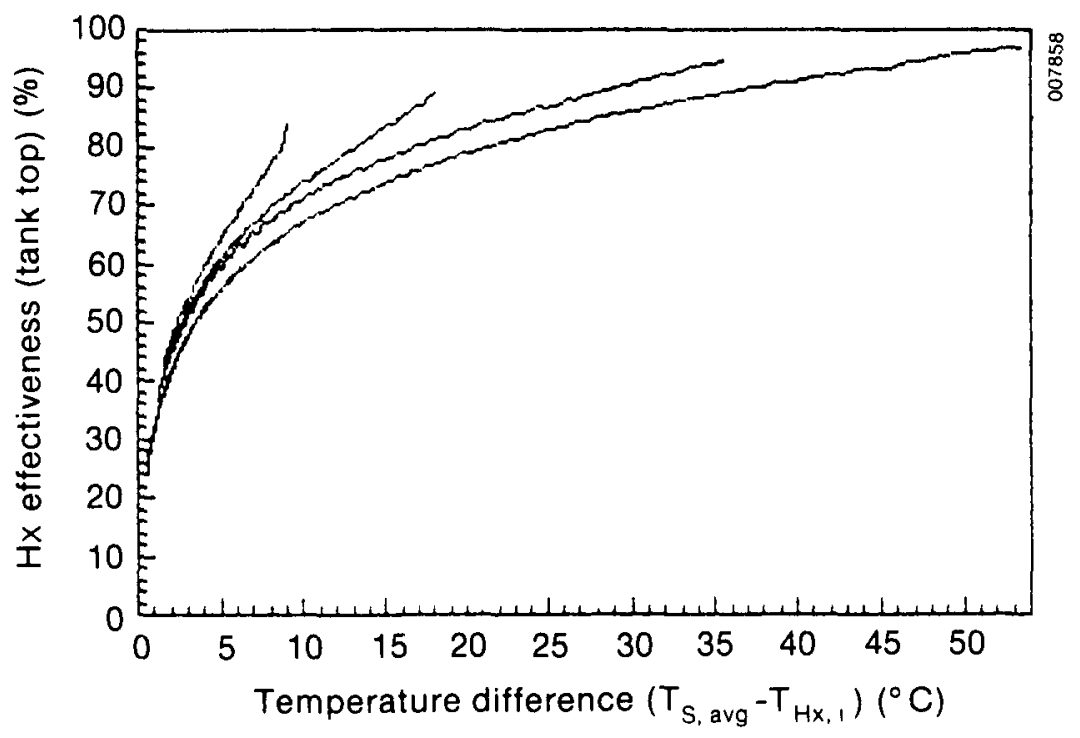

Figure B-11. Heat Exchanger Effectiveness,

$$
\operatorname{Fn}\left(T_{S, t}\right) \text { versus }\left(T_{S, a v g}-T_{H x, i}\right)
$$




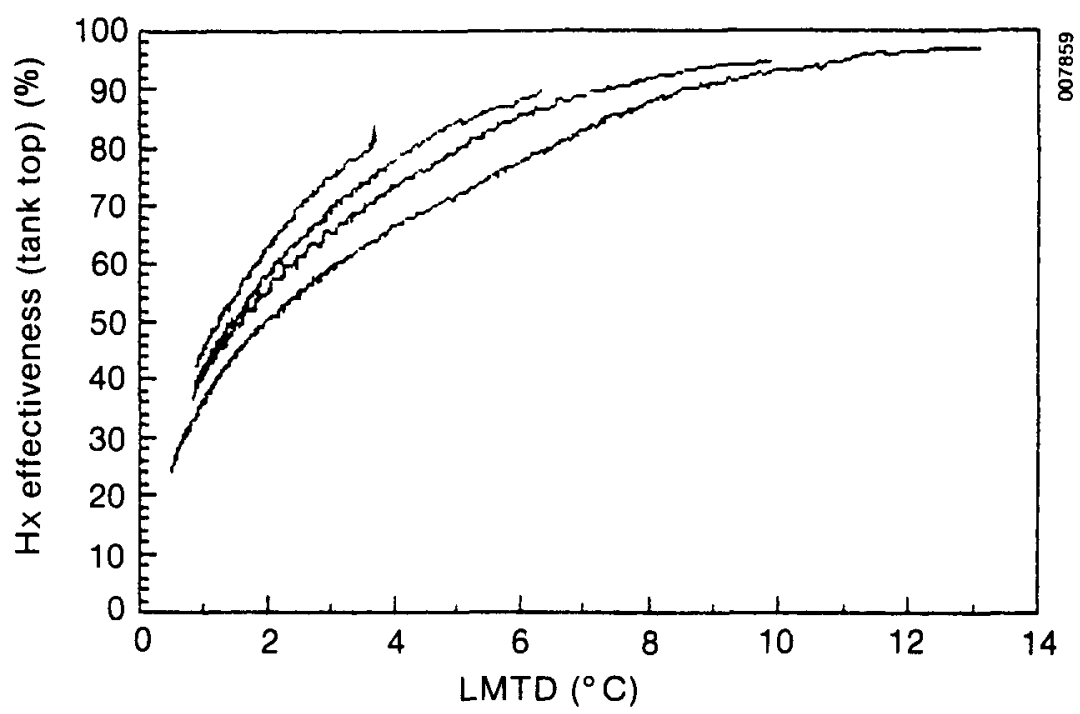

Figure B-12. Heat Exchanger Effectiveness, $\operatorname{Fn}\left(\mathrm{T}_{S, t}\right)$ versus LMTD

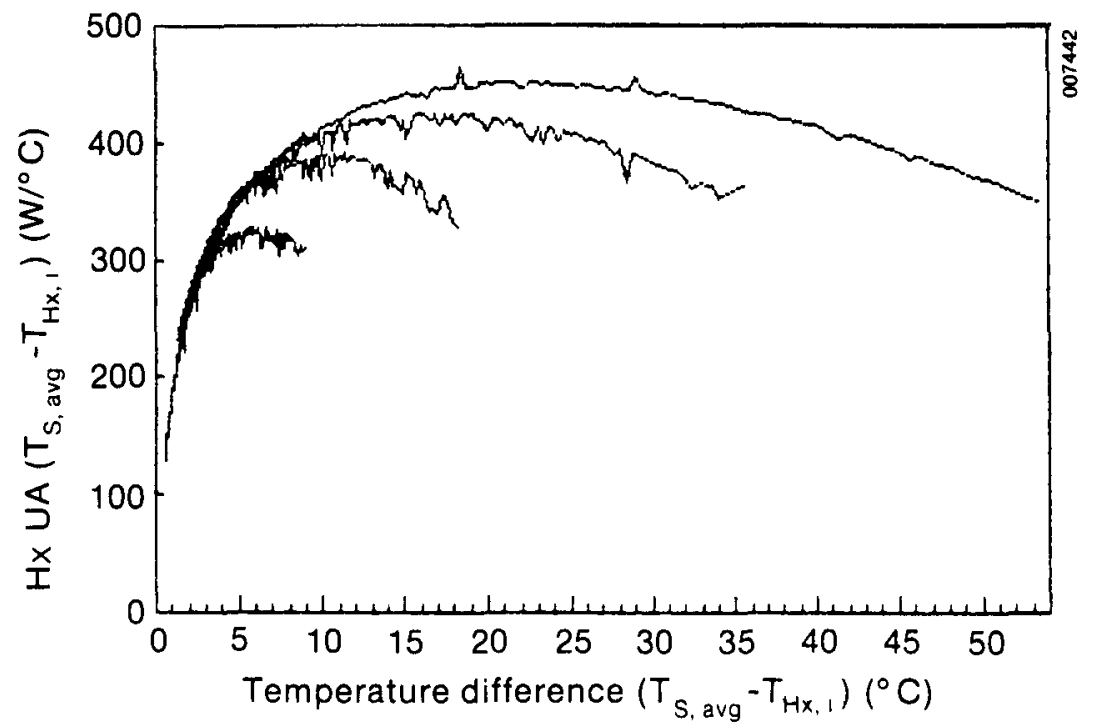

Figure B-13. Heat Exchanger $U A, \quad F n\left(T_{S}\right.$, avg
$\left.-T_{H x, i}\right)$ versus $\left(T_{S, \text { avg }}-T_{H x, i}\right.$ 


\section{SELECTED DISTRIBUTION LIST}

\author{
Alten Corp. \\ 3788 Fabian Way \\ Palo Alto, CA 94303 \\ Attn: Mr. Terry Buffum \\ American Society of \\ Mechanical Engineering \\ United Engineering Center \\ 345 East 47 th Street \\ New York, NY 10017 \\ Attn: News Editor \\ Argonne National Laboratory \\ Building 362 \\ 9700 South Cass Avenue \\ Argonne, IL 60439 \\ Attn: Mr. William Shertz \\ Mr. Peter Armstrong \\ 715 Peterson Street \\ Fort Collins, CO 80524 \\ Boulder Energy Conservation Center \\ P.O. Box 791 \\ Boulder, CO 80306 \\ Attn: Mr. Bob Westby \\ Brookhaven National Laboratory \\ Building 475 \\ Upton, NY 11973 \\ Attn: Mr. William Wilhelm \\ California Polytechnic \\ State University \\ Agr. Engineering Department \\ San Luis Obispo, CA 93407 \\ Attn: Professor Ed Carnegie \\ California State University \\ 6000 "J" Street \\ Sacramento, CA 95819 \\ Attn: Dr. Jim Berguam \\ Central Salt and Marine Chemicals \\ Research Institute \\ Solar Energy Division \\ Gi jubhai Badheka Marg. \\ Bhavnagar - 364002 \\ INDIA \\ Attn: Dr. M. R. Adiga
}

Centre of Energy Studies

Indian Institute of Technology

Hauz Khas, New Delhi-110016

INDIA

Attn: Dr. Tara Chandra Kandpal

Centre Scientifique et Technique du Batiment

24, Rue Joseph Fourier

38400 Saint Martin D'Heres, FRANCE

Attn: Mr. J. L. Chevalier

Colorado Solar Design

2951 W. Park P1ace

Denver, CO 80219

Attn: Mr. Jim Elder

Colorado State University

Department of Mechanical Engineering

Fort Collins, CO 80523

Attn: Dr. S. Karaki

Colorado State University

Department of Mechanical Engineering

Fort Collins, CO 80523

Attn: Dr. George Lof

Comtec

Box 5642

Victoria, BC

V8R $6 S 4$ CANADA

Attn: Mr. Day Chapin

Contemporary Systems, Inc.

Route 12

Walpole, NH 03608

Attn: Mr. John Christopher

Mr. Charles Dah1, P.E.

3613 Willowick Drive

Ventura, CA 93003

Davis Energy Group

2655 Portage Bay Avenue, Suite 非

Davis, CA 95616

Attn: Dr. Dick Bourne

DMNES

P.0. Box 1830

Limassol, Cyprus

Attn: Mr. Mike Merino 
DSET Laboratories

Box 1850 Black Canyon Stage I

Phoenix, AZ 85029

Attn: Mr. Matthew Rupp

EMC Engineering

P.0. Box 36009

Denver, CO 80236

Attn: Mr. Doug Dougherty

The Energy Center

2516 Park Street

Terre Haute, IN 47803

Attn: Mr. Robert Mason

Energy Engineering

4616 McLeod Rd., N.E.

Albuquerque, NM 87109

Attn: Dr. Karl Feldman, Jr.

Energy Systems Centre

Ontario Research Foundation

Mississauga, Ontario

CANADA L5K 183

Attn: Mr. Bruce E. Sibbitt

Engineering Staff College of India

Visvesvaraya Bhavan

Khairataba, Hyderabad-500 004

INDIA

Attn: Dr. M. Ramakrishna Rao

ETEC

Rockwell International Corporation P.O. Box 1449

Canoga Park, CA 91304

Attn: Mr. Oscar Hillig

ETEC

Rockwell International Corporation P.0. Box 1449

Canoga Park, CA 91304

Attn: Mr. Paul Pekrul

\section{FAFCO}

255 Constitution Ave.

Menlo Park, CA 94835

Attn: Mr. Freeman Ford

Florida Alternative Energy Corp. 2155 Jason St.

Merritt Island, FL 32952

Attn: Mr. Henry Healey

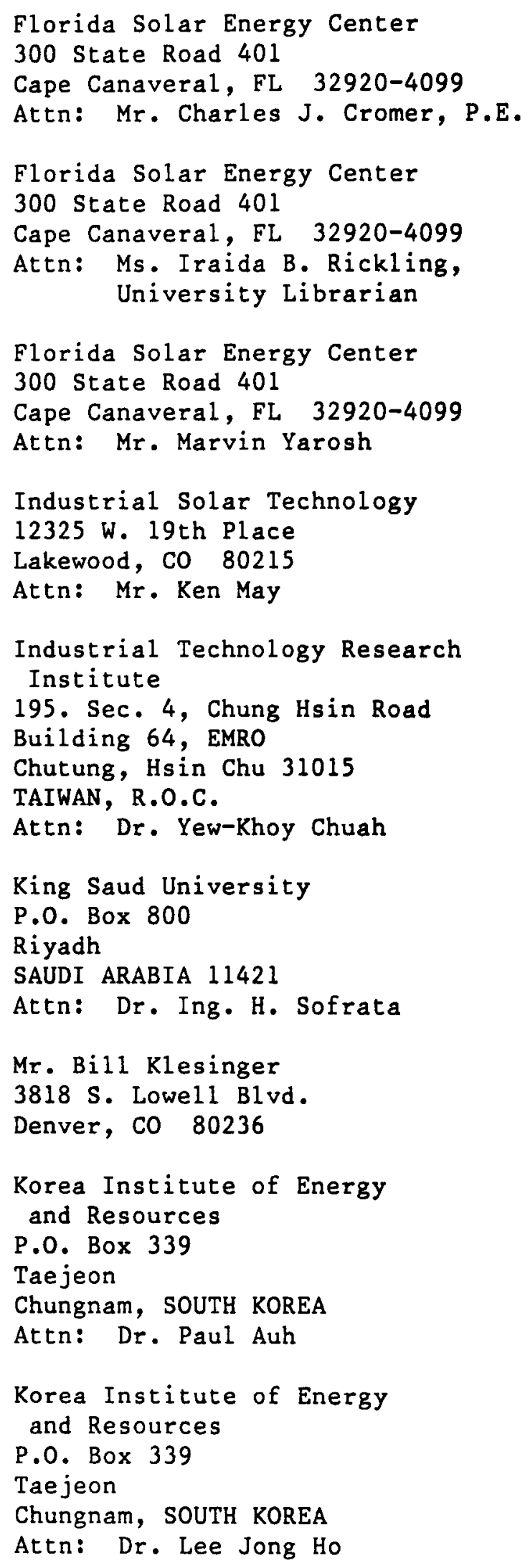


Lawrence Berkeley Laboratory

University of California

Building 90-2024

Berkeley, CA 94720

Attn: Dr. Mashuri Warren

Los Alamos National Laboratory

Mail Stop J 576

P.O. Box 1663

Los Alamos, NM 87544

Attn: Mr. John Avery

Dr. Peter Lunde

4 Daniel Lane

W. Simsbury, CT 06092

McMillan Sales

4801 E. 48th Ave.

Denver, CO 80216

Attn: Mr. Matt Carr

Mr. John Meeker

P.O. Box 261212

160 South Allison Street

Lakewood, CO 80226

Ministry of Mining,

Energy and Tourism

P.0. Box 495

2 St. Lucia Avenue

Kingston, JAMAICA

Attn: Mrs. M. Scott-Thomas

Dr. Ali M. E1 Nashar

Water and Electricity Department

P.O. Box 219

Abu Dhabi

United Arab Emirates

National Bureau of Standards

Building 226, Room B-320

Gaithersburg, MD 20899

Attn: Mr. Robert Dikkers

National Bureau of Standards

Thermal Solar Group

Building 226, Room B-322

Gaithersburg, MD 20899

Attn: Dr. Hunter Fanney
National Research Council of Canada

Low Temperature Laboratory

Division of Mechanical Engineering

Ottawa, Ontario

CANADA

Attn: Mr. Steven Beale

National Technical University

of Athens

School of Chemical Engineering

Thermodynamics and Transport

Phenomena Laboratory

Athens 147, GREECE GR-106 82

Attn: Dr. John Palyvos

Naval Civil Engineering Lab

Port Hueneme, CA 93043

Attn: Mr. Ed Durlak (Code L73)

New Mexico Energy Research and

Development Institute

Room 358, Pinon Building

1220 South St. Francis Drive

Santa Fe, NM 87501

Attn: Mr. Steve Parker,

Project Scientist

New Mexico Solar Energy Institute

Box 3SOL

Las Cruces, NM 88003

Attn: Dr. Roger Farrer

North Carolina A\&T State University

Mechanical Engineering Department

Greensboro, NC 27411

Attn: Dr. David Klett

Novan Energy, Inc.

1630 North 63rd Street

Boulder, CO 80301

Attn: Mr. Peter Jacobs

Oregon Department of Energy

Labor and Industries Building

Room 102

Salem, OR 97310-0831

Attn: Mr. David Robison

Penn State University

P.O. Box 519

Uniontown, PA 15401

Attn: Prof. David B. Meredith 
Pioneer Solar 2905 Xenon St.

Lakewood, CO 80215

Attn: Mr. Tim Connolly

Ramada Energy Systems 1421 South McClintock

Tempe, AZ 85281

Attn: Mr. R. Bingmann

Ramada Energy Systems

1421 South $\mathrm{McCl}$ intock

Tempe, AZ 85281

Attn: Mr.W. Clark

Red Rocks Community College

12600 West 6th Avenue

Golden, CO 80401

Attn: Mr. Jon Klima

Reynolds Metals Company

P.0. Box 27003

Richmond, VA 23261

Attn: R. Spears

Royal Scientific Society

P.O. Box 5211

Amman, JORDAN

Attn: Mr. Malek Kabariti

Science Applications

International Corp.

5113 Leesburg Pike

Suite 710

Falls Church, VA 22041

Attn: Mr. William Scholten

SEP Inc.

372 E. 16th St.

Greeley, Co 80631

Attn: Mr. Larry Finn

Solar Development, Inc.

3630 Reese Ave.

Riviera Beach, FL 33404

Attn: Mr. O. Kazimir

Solaron Corporation

1885 West Dartmouth Avenue

Englewood, CO 80110

Attn: Mr. M. Faybik
Solaron Corporation

1885 West Dartmouth Avenue

Englewood, CO 80110

Attn: Dr. George Lof

Sunbelt Energy Corporation

2686 South Tejon

Engl ewood, CO 80110

Attn: Mr. Mike Davis

Sunmaster Corporation

35 West William Street

P.0. Box 1077

Corning, NY 14830

Attn: Mr. Michael Platt, P.E.

Sunsearch Inc.

P.0. Box T

Guilford, CT 06437

Swedish Council for

Building Research

Sankt Goransgatan 66

S-11233

Stockholm, SWEDEN

Attn: Mr. Hans E. B. Andersson

Tata Energy Research Institute

7 Jorbagh

New Delhi - 110003

INDIA

Attn: Dr. Veena Joshi

Tennessee Valley Authority

MR 3S-43E

1101 Market Street

Chat anooga, TN 37402-2801

Attn: Mr. Dale Depew

Trident Energy Systems

1355 Willow Way, Suite 216

Concord, CA 94520

Attn: Mr. David Horne

Unique Supply

P.O. Box 11165

Englewood, CO 80151

Attn: Mr. J. Stein

Universidad Politecnica

Department: Termodinamica

P.0. Box 22012

Valencia, SPAIN 46071

Attn: Prof. J. Canada Ribera 
University of California

Department of Mechanical Engineering

Irvine, CA 92717

Attn: Dr. M. Young

University of Colorado

Civil, Environmental and

Architectural Engineering

Campus Box 428

Boulder, CO 80309-0428

Attn: Dr. Jan Kreider

University of Colorado

Mechanical Engineering Dept.

Campus Box 427

Boulder, CO 80309-0427

Attn: Dr. D. Kassoy

University of Houston

Department of Mechanical Engineering

University Park

Houston, TX 77004

Attn: Dr. Rick Bannerot

University of Nebraska

4911 Davenport

Omaha, NE 68132

Attn: Dr. Bing Chen

University of Wisconsin

1343 Engineering Research Building

Madison, WI 53706

Attn: Dr. W. Beckman

University of Wisconsin

1343 Engineering Research Building

Madison, WI 53706

Attn: Dr. J. Mitchell

U.S. Department of Energy

Forrestal Building

1000 Independence Avenue, S.W.

Washington, D.C. 20585

Attn: Mr. Robert Hassett

$\mathrm{CE}-311,5 \mathrm{H}-065$

U.S. Department of Energy

Forrestal Building

1000 Independence Avenue, S.W.

Washington, D.C. 20585

Attn: Dr. Fred Morse

$\mathrm{CE}-31,5 \mathrm{H}-095$
U.S. Department of Energy

Forrestal Building

1000 Independence Avenue, S.W.

Washington, D.C. 20585

Attn: Mr. Dave Pellish

$\mathrm{CE}-312,5 \mathrm{H}-047$

U.S. Solar

P.O. Drawer $K$

Hampton, FL 32044

Attn: Mr. S. Gorman

Mr. Mark Verbeck

P.0. Box 18460

Denver, CO 80218

Vitro Laboratories

14000 Georgia Avenue

Silver Spring, MD 20910

Attn: Mr. Ed Pollock

\section{SERI Staff:}

Frank Kreith

Chuck Kutscher

A1 Lewandowski

Paul Notari

Ken 01 sen

Doug Powell

Steve Rubin

Chet Wells 


\begin{tabular}{|c|c|c|c|}
\hline $\begin{array}{l}\text { Document Control } \\
\text { Page }\end{array}$ & $\begin{array}{l}1 \text { SERI Report No } \\
\text { SERI/TR-3094 }\end{array}$ & 2 NTIS Accession No & 3 Recipient's Accession No \\
\hline \multirow{2}{*}{\multicolumn{3}{|c|}{$\begin{array}{l}4 \text { Title and Subtitle } \\
\text { Testing and Analysis of Load-Side Immersed Heat } \\
\text { Exchangers for Solar Domestic Hot Water Systems }\end{array}$}} & $\begin{array}{l}5 \text { Publication Date } \\
\text { October } 1987 \\
\end{array}$ \\
\hline & & & 6 \\
\hline \multicolumn{3}{|c|}{$\begin{array}{l}7 \text { Author(s) } \\
\text { Robert B. Farrington, Carl E. Bingham }\end{array}$} & 8 Performing Organization Rept No \\
\hline \multicolumn{3}{|c|}{9 Performing Organization Name and Address } & $\begin{array}{l}10 \text { Project/Task/Work Unit No } \\
3062.410\end{array}$ \\
\hline \multicolumn{3}{|c|}{$\begin{array}{l}\text { Solar Energy Research Institute } \\
\text { A Division of Midwest Research } \\
1617 \text { Cole Boulevard } \\
\text { Golden, Colorado } 80401-3393\end{array}$} & $\begin{array}{l}11 \text { Contract (C) or Grant (G) No } \\
\text { (C) } \\
\text { (G) }\end{array}$ \\
\hline \multirow{2}{*}{\multicolumn{3}{|c|}{12 Sponsoring Organization Name and Address }} & $\begin{array}{l}13 \text { Type of Report \& Period Covered } \\
\text { Technical Report }\end{array}$ \\
\hline & & & 14 \\
\hline
\end{tabular}

15 Supplementary Notes

16 Abstract (Limit 200 words)

This report describes work to determine the performance of load-side heat exchangers for use in residential solar domestic hot water systems. We measured the performance of four heat exchangers: a smooth coil and a finnęd coil having heat transfer areas of $2.5 \mathrm{~m}^{2}\left(26 \mathrm{ft}^{2}\right)$ and those having areas of $1.7 \mathrm{~m}^{2}\left(19 \mathrm{ft}^{2}\right)$. A numerical modet using the thermal network program MITAS was constructed, and results were compared to the experimental results.

Research showed a smooth coil with only $70 \%$ of the surface area of a finned coil performed better than the finned coil. Also, load-side heat exchangers can maintain and enhance stratification in storage tanks, perititing the use of control strategies that take advantage of stratified storage tanks to increase system performance. The analytical model, which agreed reasonably well with the experimental results, was used to vary heat exchanger flow rate and area and initial tank temperature for both a smoothand a finned-coil heat exchanger. Increasing the heat exchanger flow rate and area results in higher heat transfer rates but not necessarily optimal performance. Lower initial tank temperatures resulted in reduced tank stratification. The smooth heat exchanger outperformed the finned heat exchanger with the same outside surface area.

17 Document Analysis

a Descriptors

Heat Exchangers; Hot-Water Systems; Solar Energy; Stratification

b Identifiers/Open-Ended Terms

c UC Categories

62

18 Avallability Statement 19 No of Pages

National Technical Information Service U.S. Department of Commerce 5285 Port Royal Road Springfield, Virginia 22161 